\title{
Discussion Paper No. 18-032 \\ Unemployment Effects of the German Minimum Wage in an Equilibrium Job Search Model
}

Maximilian J. Blömer, Nicole Guertzgen, Laura Pohlan, Holger Stichnoth, and Gerard J. van den Berg

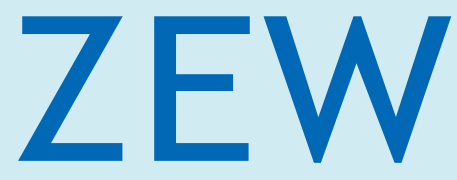

Zentrum für Europäische Wirtschaftsforschung $\mathrm{GmbH}$

Centre for European

Economic Research 
Discussion Paper No. 18-032

\title{
Unemployment Effects of the German Minimum Wage in an Equilibrium Job Search Model
}

\author{
Maximilian J. Blömer, Nicole Guertzgen, \\ Laura Pohlan, Holger Stichnoth, \\ and Gerard J. van den Berg
}

Download this ZEW Discussion Paper from our ftp server:

http://ftp.zew.de/pub/zew-docs/dp/dp18032.pdf

Die Discussion Papers dienen einer möglichst schnellen Verbreitung von neueren Forschungsarbeiten des ZEW. Die Beiträge liegen in alleiniger Verantwortung der Autoren und stellen nicht notwendigerweise die Meinung des ZEW dar.

Discussion Papers are intended to make results of ZEW research promptly available to other economists in order to encourage discussion and suggestions for revisions. The authors are solely responsible for the contents which do not necessarily represent the opinion of the ZEW. 


\title{
Unemployment Effects of the German Minimum Wage in an Equilibrium Job Search Model
}

\author{
Maximilian J. Blömer ${ }^{1}$, Nicole Guertzgen*2, Laura Pohlan ${ }^{3}$, \\ Holger Stichnoth ${ }^{4}$, and Gerard J. van den Berg ${ }^{5}$ \\ ${ }^{1}$ ifo Institute, $\mathrm{HU}$ Berlin \\ ${ }^{2}$ University of Regensburg, IAB Nuremberg, ZEW Mannheim \\ ${ }^{3} Z E W$ Mannheim, IAB Nuremberg \\ ${ }^{4} Z E W$ Mannheim \\ ${ }^{5}$ University of Bristol, IFAU, IZA, CEPR, ZEW Mannheim, CESifo
}

20th July 2018

\begin{abstract}
We structurally estimate an equilibrium search model using German administrative data and use this for counterfactual analyses of a uniform minimum wage. The model with worker and firm heterogeneity does not restrict the sign of employment effects a priori and allows for different job offer arrival rates for the employed and the unemployed. We find that unemployment is a non-monotonic function of the minimum wage level. Effects differ strongly by labour market segment. Cross-segment variation of the estimated effects is mostly driven by firm productivity levels rather than by search frictions or the opportunity cost of employment.
\end{abstract}

Keywords: wages, job durations, work, employment, productivity, structural estimation. JEL-Code: J31; J51; J64

\footnotetext{
${ }^{*}$ Corresponding author: Nicole Guertzgen, IAB, Regensburger Strasse 104, D-90478 Nuremberg. nicole.guertzgen@iab.de. We are grateful to Richard Blundell, Philipp Dörrenberg, Bernd Fitzenberger, Clemens Fuest, Mario Meier, Fabien Postel-Vinay, Jean-Marc Robin, Jan Tilly, Carsten Trenkler as well as participants of a ZEW Workshop on Labour Market Policy Evaluations, a ZEW Summer Workshop on Structural Models for Policy Evaluation, the ESPE, EEA, SaM, VfS, and EALE conferences, a Workshop of the German Minimum Wage Commission and various seminars for helpful comments. We thank Andrew Shephard for kindly having shared programming routines with us. Financial support by the State of Baden-Württemberg and access to administrative data provided by the IAB are also gratefully acknowledged. Paul König, Julius Koll and Pierre Poulon provided excellent research assistance.
} 


\section{Introduction}

Equilibrium job search models have long been used to study labour markets with informational frictions or search frictions. These frictions create market power for employers and may allow them to set wages below the marginal productivity of labour. From a policy perspective, frictions are of key importance, as the consequences of certain economic policies, notably a mandatory minimum wage, may differ substantially from those in the neoclassical competitive case; see e.g. Manning (2003).

In this paper, we structurally estimate an equilibrium job search model for the German labour market to assess minimum wage effects. Before the introduction of a statutory uniform minimum wage of 8.50 euros per hour in $2015,{ }^{1}$ minimum wages had been implemented only at the sectoral level in a small number of industrial sectors. We estimate the wage-posting model by Bontemps et al. (1999), extended along the lines of Shephard (2017) to allow for different job offer arrival rates for the employed and the unemployed. The model is well-suited for our purposes. As acknowledged in the literature, accounting for heterogeneity in both firms' productivity and unemployed workers' reservation wages does not restrict the sign of unemployment effects of minimum wages a priori. ${ }^{2}$

The shapes of the heterogeneity distributions are important determinants of the magnitude of minimum wage effects. However, data from a market with a minimum wage are not very informative on the shapes of the left-hand tails of these distributions, as the minimum wage effectively left-truncates wage outcomes (see e.g. Bontemps et al., 1999). To study counterfactual minimum wage effects, it is useful to have data from periods without minimum wages, as the latter data enable identification of the heterogeneity distributions across agents on larger parts of their support. In particular, in the German context, data from before 2015 allow for identification of the effects of minimum wages below the minimum wage that was imposed in 2015, whereas data from after 2015 do not allow for that. In the paper we return to the policy change in 2015 at various instances.

Our empirical analysis relies on a large administrative data set, the IAB Sample of Integrated Employment Biographies (SIAB). This is a two per cent random sample of individuals subject to social security contributions during the time period 1975 to 2010 . We focus on data from the period 2007-2010. The SIAB data provide an ideal basis for estimating a structural equilibrium search model for several reasons. First and most importantly, the data allow us to precisely measure the duration of different labour market states and transitions between them, notably job-to-job as well as employment-to-unemployment transitions. These

\footnotetext{
${ }^{1}$ While a number of transitional measures respected existing collective agreements and those signed in the meantime, the uniform minimum wage applied to all industries by 2017 at the latest. A further transitory exemption was given to those industries where industry-specific minimum wages had already been introduced prior to 2015 via the Posting of Workers Act (Arbeitnehmerentsendegesetz). The bargaining parties in an industry subject to this legislation may request that the Federal Ministry of Labour declares its (minimum wage) agreement to be generally binding for the entire industry.

${ }^{2}$ Engbom and Moser (2017) use a similar wage-posting model, extended for heterogeneity in workers' ability, to study the role of the minimum wage in the decline of earnings inequality in Brazil. A closely related literature assumes wage bargaining instead of wage posting; Flinn (2006) provides a path-breaking application of these models to analyse minimum wage effects; see also Breda et al. (2016).
} 
transitions are crucial to the identification of the model's central parameters, such as job arrival and destruction rates. Second, as the data are based on employers' notifications to the social security authorities, they are less prone to measurement error than comparable information from survey data. Additional advantages over survey data include the larger sample size and absence of panel attrition. We focus on low- and medium-skilled individuals, as we use wage-posting models, and for these groups the assumption of wage posting is more convincing than for high-skilled individuals.

Our study contributes to the empirical literature on minimum wages in Germany. Most existing studies evaluate pre-2015 industry-specific minimum wages, typically using differencein-differences designs with industries without minimum wage as control groups. In what is probably the first quasi-experimental study for Germany, König and Möller (2009) analyse the introduction of a minimum wage in the construction industry. The authors find no significant employment effects in West Germany and small negative effects in the East. In 2011, the German Federal Ministry of Labour commissioned an evaluation of minimum wages in several industries. In general, these studies also tend to find limited employment effects (e.g. Boockmann et al., 2013; Frings, 2013), with the exception of the roofing industry (Aretz et al., 2013).

The few available ex-post analyses of the uniform minimum wage imposed in 2015 are provided by Bossler and Gerner (2016), Garloff (2016) and Caliendo et al. (2017). These studies also rely on a difference-in-differences design and, in general, exploit variation in the minimum-wage bite at the regional or establishment-level for treatment assignment. A key challenge of ex-post evaluation studies that aim to evaluate the effects of the statutory uniform minimum wage in 2015 is to find suitable control groups. Especially with a uniform minimum wage that applies to all industries and regions, a major concern is that the Stable Unit Treatment Value Assumption (SUTVA) underlying the difference-in-difference approach may be violated. The uniform minimum wage may be expected to indirectly affect high-productivity firms or workers, who are not directly subject to the minimum wage, via spillover effects. Several empirical studies document spillover effects of minimum wages for instance on wages in the upper part of the wage distribution (e.g., Autor et al., 2016 or Gregory, 2014 for German roofers).

A critical assumption in this literature is the common trend assumption both prior to and after the policy intervention. Of course, this also affects an extrapolation of our own estimation results into 2015. In this context, it is important to note that the large inflow of refugees and other migrants has led to a disproportionately large employment growth in specific sectors, such as construction, security, education and training as well as public administration (Weber, 2016). Compared with ex-post approaches, our study design has the advantages of being informative about the underlying transmission mechanisms and of being able to assess counterfactual policies and macroeconomic conditions when evaluating minimum wages. A few existing structural studies for Germany use models without search frictions but with labour demand functions derived under the assumption of perfect competition (Ragnitz and Thum, 2008; Bauer et al., 2009; Knabe and Schöb, 2009). 
In this framework, the effects of a minimum wage can by construction only be zero (if the minimum wage is not binding) or negative.

Our own analyses show that unemployment is a non-monotonic function of the minimum wage level. A minimum wage level that is equivalent in real terms to the one introduced in 2015 raises the aggregate unemployment rate by around 1.4 percentage points, a sizeable increase of $13 \%$ compared to the old steady-state value. ${ }^{3}$ We show how the minimum wage affects the wage setting of more productive firms. Moreover, we document large heterogeneity in firm productivities, search frictions and in reservation wages across labour markets differentiated by region and type of occupation. As it turns out, differences across labour market segments in the firm heterogeneity distribution are the main driver of the large variation in minimum wage effects across segments.

The remainder of the paper is structured as follows: Section 2 starts by giving a brief overview of the model. Section 3 provides a description of the data set and the construction of our main variables of interest, and Section 4 presents descriptive statistics. Section 5 outlines the estimation procedure. Section 6 presents the estimation results and graphical representations of the key steady-state relationships. Section 7 shows simulation results for the counterfactual introduction of different minimum wage levels. Section 8 concludes.

\section{Theoretical Model}

\subsection{Literature Overview}

Equilibrium job search models provide a framework in which the wage offer distribution that workers face in their search emerges as the equilibrium of a non-cooperative wage search and wage posting game between workers and employers. A minimum wage policy alters the wage offer distribution, thereby affecting the number of firms that continue to operate in the market and increasing the average wage offer that an unemployed person can expect to receive. A number of studies have estimated different variants of equilibrium job search models building on the Burdett-Mortensen framework with within-market homogeneous workers and firms and on-the-job search, to analyse minimum wage effects (notably van den Berg and Ridder, 1998).

Within-market firm heterogeneity has been shown to improve the fit of the wage distribution and has been modelled in different ways in the literature. Bontemps et al. (2000) allow for a continuous distribution but estimate it non-parametrically. In the context of a minimum wage policy, heterogeneity in firm productivity is of key importance, as in the case of homogeneous firms a minimum wage would create a "knife-edge" impact on employment, with all firms either leaving or staying in the relevant sub-market. In addition to incorporating heterogeneity in firm productivity, the model by Bontemps et al. (1999) also allows for

\footnotetext{
${ }^{3}$ These numbers cannot be straightforwardly compared to differences between outcomes in say 2016 and 2014 . First, our results refer to equilibrium changes whereas the data from 2015 and 2016 reflect short-term adjustments and the data from 2014 may reflect anticipation effects. Secondly, as discussed above, the German labour market witnessed major concurrent shocks in 2015, notably due to the so-called refugee crisis.
} 
heterogeneity in workers' reservation wages. This creates more flexibility in terms of the predicted employment effects. In particular, it implies that the minimum wage can have a positive effect on employment. Because the minimum wage precludes low wage offers, it draws more unemployed workers with high reservation wages into the market. In the absence of a minimum wage, these workers have to wait longer for a wage offer that is acceptable to them.

\subsection{Model Description}

In this section, we provide a brief description of the model by Bontemps et al. (1999), which we will extend by allowing the job offer arrival rate to differ across employed and unemployed individuals, as in Shephard (2017) and Engbom and Moser (2017). We start by describing firms' and individuals' strategies. Individuals maximise their expected steady-state discounted future income. They are characterised by heterogeneous opportunity costs of employment denoted by $b$, which may include search costs and unemployment benefits. The distribution of $b$ is denoted by $H$, assumed to be continuous over its support $[\underline{b}, \bar{b}]$. Job offers arrive at constant rate $\lambda_{0}>0\left(\lambda_{1}>0\right)$ for the unemployed (employed) and are characterised by a draw from a wage offer distribution $F$ with support $[\underline{w}, \bar{w}]$. Layoffs arrive at constant rate $\delta$. Unemployed individuals searching for a job face an optimal stopping problem, the solution to which consists in accepting any wage offer $w$ such that $w>\phi$. Employed individuals, in contrast, accept any wage offers strictly greater than their present wage contract. As in Bontemps et al. (2000), the reservation wage is implicitly defined as

$$
\phi=b+\left(\kappa_{0}-\kappa_{1}\right) \int_{\phi}^{\bar{w}} \frac{\bar{F}(x)}{1+\frac{\rho}{\delta}+\kappa_{1} \bar{F}(x)} d x,
$$

where $\rho$ denotes individuals' discount rate, $\bar{F}(x)=1-F(x)$, and $\kappa_{i}=\frac{\lambda_{i}}{\delta}, i=0,1$. The distribution of reservation wages, $A$, is then given by

$$
A(\phi)=H\left(\phi-\left(\kappa_{0}-\kappa_{1}\right) \int_{\phi}^{\bar{w}} \frac{\bar{F}(x)}{1+\frac{\rho}{\delta}+\kappa_{1} \bar{F}(x)} d x\right) .
$$

Equating equilibrium flows into and out of unemployment, the fraction of unemployed with a reservation wage no larger than $\phi$ for $\phi \leq \underline{w}$ is represented by

$$
u A_{u}(\phi)=\frac{1}{1+\kappa_{0}} A(\underline{w}) .
$$

For $\phi>\underline{w}$, the fraction is given by

$$
u A_{u}(\phi)=\frac{1}{1+\kappa_{0}} A(\underline{w})+\int_{\underline{w}}^{\phi} \frac{d A(x)}{\left(1+\kappa_{0} \bar{F}(x)\right)} .
$$


From this, one can derive the steady-state equilibrium unemployment rate as

$$
u=\underbrace{\frac{1}{1+\kappa_{0}} A(\underline{w})}_{\text {(1) UE who accept any job offer }}+\underbrace{\int_{\text {w }}^{\bar{w}} \frac{d A(b)}{\left(1+\kappa_{0} \bar{F}(b)\right)}}_{(2) \text { UE who accept/reject offers }}+\underbrace{(1-A(\bar{w}))}_{\text {(3) UE who accept no offer }}
$$

Moreover, similar to Bontemps et al. (1999) one can show that in steady-state there exists a unique relationship between the unobserved offer and the observed earnings distribution functions. Equating the flow of layoffs and upgraded wages of those with a wage lower than or equal to $w$ and the flow of unemployed individuals accepting $w$, the distribution of earnings $G(w)$ is derived as

$$
G(w)=\frac{A(w)-\left[1+\kappa_{0} \bar{F}(w)\right]\left[\frac{1}{1+\kappa_{0}} A(\underline{w})+\int_{\underline{w}}^{w} \frac{1}{1+\kappa_{0} \bar{F}(x)} d A(x)\right]}{\left[1+\kappa_{1} \bar{F}(w)\right](1-u)} .
$$

Each firm offers only one wage and incurs a flow $p$ of marginal revenue per worker. A firm seeks to maximise its steady-state profit flow, $\pi(p, w)=(p-w) \cdot l(w)$, with $l(w)$ denoting the size of a firm's labour force. The number of workers, $l$, attracted by a firm that offers wage $w$ solves

$$
l(w)=\frac{d(1-u) G(w)}{d F(w)},
$$

and therefore

$$
l(w)=\frac{\kappa_{1} A(w)}{\left(1+\kappa_{1} \bar{F}(w)\right)^{2}}+\frac{\kappa_{0}-\kappa_{1}}{\left(1+\kappa_{1} \bar{F}(w)\right)^{2}}\left[\frac{1}{1+\kappa_{0}} A(\underline{w})+\int_{\underline{w}}^{w} \frac{1}{1+\kappa_{0} \bar{F}(x)} d A(x)\right] .
$$

It can be shown that $l(w)$ is an increasing function of the offered wage. Note that the last term distinguishes $l(w)$ from the original model by Bontemps et al. (1999), where $\lambda_{0}=\lambda_{1}$. The term reflects that if $\lambda_{0} \neq \lambda_{1}$, the number of employed and unemployed individuals that are attracted by the firm at a wage $w$ may differ from each other.

Firms are heterogeneous in their productivity $p$. The distribution of $p$ across active firms is denoted by $\Gamma(p)$, and is assumed to be continuous over its support $[p, \bar{p}]$. With $w=K(p)$ denoting the function that maps the support of the productivity distribution $\Gamma$ into the support of the wage offer distribution $F$, we have $F(w)=\Gamma\left(K^{-1}(w)\right)$. The solution to the optimal wage setting problem of a $p$-type firm is represented by

$$
K(p)=p-\left\{\frac{\kappa_{0}(\underline{p}-\underline{w})}{\left(1+\kappa_{0}\right)\left(1+\kappa_{1}\right)} A(\underline{w})+\int_{\underline{p}}^{p} l(K(x)) d x\right\} \frac{1}{l(K(p))},
$$

which completes the steady-state solution of the model. 


\section{Data}

Our empirical analysis uses German register data, the IAB Sample of Integrated Employment Biographies (SIAB). This administrative data set, which is described in more detail by vom Berge et al. (2013), is a two per cent random sample of all individuals who have at least one entry in their social security records between 1975 and 2010 in West Germany and between 1992 and 2010 in East Germany, respectively. The SIAB data cover approximately 80 per cent of the German workforce, providing longitudinal information on the employment biographies of 1,594,466 individuals. Self-employed workers, civil servants, and individuals doing military service are not included in the SIAB.

The data provide an ideal basis for estimating a structural equilibrium search model for several reasons. First and most importantly, the data contain daily information on employment records subject to social security contributions, unemployment records of benefit recipients as well as of registered job seekers. This permits us to precisely measure the duration of different labour market states and the transitions between them, notably jobto-job transitions as well as transitions between employment and unemployment (while receiving or not receiving benefits). Second, due to their administrative nature the data are less prone to measurement error than comparable information from survey data. Additional advantages over survey data include the larger sample size and a much more limited degree of panel attrition.

Sample selection proceeds in several steps. Before restricting the sample to a specific time span and population, we fill in missing values using all the information available in the full dataset (see Appendix A.1). We then disregard employment spells where individuals receive Hartz IV benefits while working, because for this group the wage alone is not a useful metric for work incentives.

We construct a stock sample by keeping only those employment and unemployment spells including the set date 1 January 2007. Restricting the sample to the period 2007 to 2010 has the advantage that it permits us to include unemployment spells for individuals receiving means-tested welfare benefits, which were not recorded in the data prior to 2007. While this comes at the cost of including left-censored unemployment spells, it enables us to adopt a consistent definition of unemployment throughout the sample period. ${ }^{4}$ This leads to a sample of 682,581 individuals.

From this sample we select only individuals who are part of the workforce. The data do not make it possible to distinguish between involuntarily unemployed individuals not receiving benefits and individuals who voluntarily left the labour force or who became self-employed or civil servants. To distinguish more precisely between voluntary and involuntary unemployment, we follow the assumptions proposed by Lee and Wilke (2009) (see Appendix A.2).

To focus on individuals in the workforce, we restrict the sample to individuals who are at least 20 years old and younger than 63 years. The sample is further restricted to low-

\footnotetext{
${ }^{4}$ Details on the definition of the different labour market states are given in Appendix A.2.
} 
and medium-skilled individuals. We exclude highly skilled individuals because this group is less likely to be in a labour market that is characterised by a wage-posting mechanism. We then drop individuals who still have missing values in the relevant observables, such as daily wages, the educational and occupational status as well as the regional affiliation. This leads to a new sample size of 370,104 individuals.

The SIAB data do not include information on hours worked. We therefore focus on full-time employment spells and disregard individuals who are employed part-time during the time period under consideration.

To calculate hourly wages for full-time employment spells, we impute the number of hours worked based on information from the German Microcensus. The imputation is done separately by region, sex, sector, job classification, and educational degree. For details, see Appendix A.3.

In the model, each job is characterised by a single, time-invariant wage. For individuals who were employed on 1 January 2007, we compute this wage as the weighted average of the wages earned over the past year in the same job, where the weights are given by the length of time over which a particular wage was received. Likewise, the wage after an unemployment-to-employment spell is based on the weighted average over the first year after the transition. ${ }^{5}$ To reduce the influence of outliers, we discount observations with implausibly low hourly wages (wages below 3 euros or below the existing sectoral minimum wages). The resulting final sample contains information on 235,706 individuals.

The wage information in the IAB data is censored since there is an upper contribution limit in the social security system. We do not inlude observations with censored wages. ${ }^{6}$

The model assumes that worker productivity is homogeneous. Following Bontemps et al. (1999), we therefore estimate the model separately for different labour market segments. We assume that both the employed and the unemployed receive job offers only within their segment. We define the segments based on six job classifications (occupation types, see Appendix A.6) and two regions (East Germany and West Germany including Berlin). These two dimensions allow us to define fairly well (though not perfectly) segmented labour markets. As Table 2 shows, $95.9 \%$ of employment-to-employment transitions remain in the same region, $83.4 \%$ remain in the same job classification, and $80.1 \%$ remain in the same region and job classification, i.e. the same labour market according to our definition. As for unemployment-to-employment transitions, $95.3 \%$ occur within the same region, $73.7 \%$ within the same job classification, and $70.7 \%$ within both the same region and the same job classification (see Table 3).

\footnotetext{
${ }^{5}$ For details, see Appendix A.4.

${ }^{6}$ For details, see Appendix A.5. In a robustness check, we address this issue by replacing censored observations with imputed wages, following Gartner (2005).
} 


\section{Descriptives}

\subsection{Transitions}

Tables 4 and 5 in Appendix A.7 report the type, number, and share of transitions for our stock sample of individuals who were either unemployed $(7.6 \%)$ or employed $(92.4 \%)$ on 1 January 2007. Of the 217,733 individuals who were employed on this date, $68 \%$ stayed in their job for the next four years while $20 \%$ moved to another job and $13 \%$ became unemployed. Transitions in the other direction are much more frequent in relative terms: $45 \%$ of the 17,973 unemployment spells ended with a transition into regular employment during the four-year period after 1 January 2007. At the same time, $55 \%$ of individuals who were unemployed on this date remained without a job over the entire period. Left-censoring is relatively frequent for the unemployment spells (22\%) because in some of the data sources for unemployment benefit histories, recording starts at a fixed date which does not necessarily coincide with the beginning of the unemployment spell (see Appendix A.2).

The table also breaks down these statistics by labour market, as defined by region and job classification. About $84 \%$ of the individuals in the sample worked or searched for a job in West Germany (including Berlin), the remaining 16\% in East Germany. On 1 January 2007, the unemployment rate was higher in East Germany (11\%) than in West Germany $(7 \%)$. However, the fraction of unemployed individuals finding a new job over the four-year observation window was almost identical in East and West Germany (44\%). Looking at transitions of employed individuals, we find that most individuals stayed at their current employer, while around $20 \%$ of the employed individuals in West Germany and $19 \%$ in East Germany changed their employer within the four years. The relative frequency of transitions into unemployment was higher in East Germany (17\%) than in West Germany (12\%).

As for the six job classifications, note the large number of observations for "production, craft" occupations which are still fairly important in Germany and especially in our sample of low- and medium-skilled individuals. The unemployment rate on 1 January 2007 varied between $5 \%$ in white-collar jobs and $20 \%$ in agriculture, partially reflecting the varying importance of seasonal unemployment. Consistent with this seasonal influence, the share of unemployment-to-employment transitions was particularly high in agriculture (65\%). At the other end of the spectrum, only $31 \%$ of the unemployed individuals in sales found work within the next four years.

In our administrative data set, the number of observations is large even when interacting job classifications with regions; sample sizes range from 1,225 (agriculture, East Germany) to 76,723 (production/craft, West Germany). Both the unemployment rates and the transitions reflect the differences already discussed; i.e., unemployment rates are lower in the West for all job classifications, and the differences across classifications also hold within the two regions. 


\subsection{Durations}

Figure 5 in Appendix A.7 shows non-parametric Kaplan-Meier estimates of the survival function for remaining in the initial state (employment or unemployment) for the whole sample. The survival functions are also shown for the twelve different sub-samples defined by region and job classification (Figures 6 to 11 in Appendix A.7). In our data, the maximum duration of an unemployment spell is six years. ${ }^{7}$ Employment spells can in principle last over the whole observation period: 35 years in West Germany (1975-2010) and 19 years in East Germany (1991-2010). ${ }^{8}$

Transitions out of Unemployment The chance of transitioning into employment is particularly high within the first year - only about $60 \%$ of the unemployed were still without a job after twelve months (cf. panel (a) in Figure 5). By the third year, about $40 \%$ of the unemployed had not found employment, and after the third year the survival function flattens out. As can be seen in panel (a) of Figures 6 to 11, the pattern is very similar for East and West Germany, but there is substantial variation across job classifications. Most notably, jobs in agriculture (Figure 6) as well as production/craft jobs (Figure 7) are characterised by short unemployment durations. Around $75 \%$ of the unemployment spells in agriculture were shorter than one year (the share is even higher in West Germany and lower in East Germany). In production/craft jobs (the largest group), more than half of the unemployment spells were shorter than one year. At the other end of the spectrum, unemployed individuals who formerly had sales and service jobs tend to have long unemployment durations (Figures 9 and 11).

Transitions out of Employment For individuals who were initially employed, transitions can be either into another job (panel(b) in Figures 5 to 11) or into unemployment (panel (c)). The durations of employment spells that end because of unemployment are in general longer than employment spells that end in a job-to-job transition. With regard to employmentto-employment transitions, the probability of still being employed at the current employer is typically around $75 \%$ after fifteen years. This holds for both East and West Germany. However, employment spells that end into unemployment tend to be longer in the West than in the East.

Regarding job classifications, sales jobs stand out both for transitions into other jobs and for transitions into unemployment; at each point in time, the share of the employed who have left

\footnotetext{
7 "Unemployment benefit I" (ALG I), a non means-tested transfer which is part of the unemployment insurance system, is typically paid for only one year (two years for older workers). Once ALG I runs out, the unemployed are entitled to the much lower and means-tested "unemployment benefit II" (ALG II), which was introduced on 1 January 2005. Before 2005, ALG I was followed by "Arbeitslosenhilfe" instead of ALG II. This means that individuals receiving "Arbeitslosenhilfe" before 2005 were entitled to ALG II afterwards. However, spells of receiving ALG II are only recorded in the data from 1 January 2007 onwards. This makes 1 January 2005 the earliest starting point for unemployment spells in our data. These spells refer to those individuals who received ALG I benefits during 2005 and 2006 and who were entitled to ALG II afterwards (starting from 2007). As our sample covers the period 2007-2010, the maximum duration of an unemployment spell is six years.

${ }^{8} 1.29 \%$ of the employment spells are left-censored which means employment without interruption at the same firm since 1 January 1975 in West Germany or since 1991 in East Germany.
} 
their initial job for one of these destinations is particularly high. Agriculture is inconspicuous for employment-to-employment transitions, but features a high share of transitions into short durations of unemployment especially in East Germany. White-collar employees tend to have the longest employment durations, with a large fraction of employment spells being right-censored.

\subsection{Wage Distributions}

Figure 12 in Appendix A.7 shows the distribution of wages before and after a labour market transition for the whole sample. As part of the descriptives, we include all three types of transitions $(\mathrm{e} \rightarrow \mathrm{e}, \mathrm{e} \rightarrow \mathrm{u}, \mathrm{u} \rightarrow \mathrm{e}$ ) and also document the wage distributions for right- and left-censored spells. In the estimation, only the wages in the initial employment spell or after a transition from unemployment to employment will be used.

As expected, wages of individuals who change their job tend to be higher than wages before a transition into unemployment. Comparing wages before and after a job-to-job transition, we find that wages earned in the new job are on average slightly higher than the wages earned in the old position. Also in line with expectations, wages after an unemployment-toemployment transition tend to be relatively low. A sizeable fraction of the unemployed move to jobs paying less than 8.50 euros an hour, the statutory minimum wage introduced in 2015, i.e. after our sampling period 2007-2010. This also holds within the different labour market segments defined by region and job classification (see Figures 13 to 18 in Appendix A.7).

These figures confirm the well-known fact that wages tend to be lower in East Germany and also document variation in hourly wages across job classifications.

In both East and West Germany, we find that on average wages are higher for white-collar employees (Figure 15) as well as for office workers (Figure 17) while wages are lower in agricultural professions (Figure 13), among service workers (Figure 18), and for individuals working in sales (Figure 16).

\section{Estimation}

We begin this section by deriving the likelihood contributions of unemployed and employed workers, taking into account stock sampling as well as left- and right-censoring. We then outline the estimation procedure, which combines the likelihood function with a non-parametric estimate of the wage distribution.

Likelihood - Unemployed Workers As seen in Equation (5), the steady-state unemployment rate has three components. For individuals with low enough opportunity costs of employment, unemployment is purely frictional. In a second group, unemployment is driven by both search frictions and the opportunity cost of employment; these individuals will accept some job offers, but reject others. Finally, there is a third group for whom unemployment is permanent given the wage offer distribution $F$, as any wage offer is below their reservation wage. As a result, the likelihood contribution of an individual who is initially unemployed is 
a mixture distribution:

$$
\begin{aligned}
& \lambda_{0}^{2-d_{b}-d_{f}} \cdot e^{-\lambda_{0}\left(t_{0 b}+t_{0 f}\right)} \cdot \frac{A(\underline{w})}{1+\kappa_{0}} \cdot f\left(w_{0}\right)^{1-d_{f}} \\
& +\int_{\underline{w}}^{d_{f} \bar{w}+\left(1-d_{f}\right) w_{0}}\left(\lambda_{0} \bar{F}(x)\right)^{2-d_{b}-d_{f}} \cdot e^{-\lambda_{0} \cdot \bar{F}(x) \cdot\left(t_{0 b}+t_{0 f}\right)} \cdot \frac{f\left(w_{0}\right)^{1-d_{f}}}{\bar{F}(x)} \cdot \frac{d A(x)}{1+\kappa_{0} \bar{F}(x)} \\
& +[1-A(\bar{w})]^{d_{b} \cdot d_{f}} .
\end{aligned}
$$

The first term of the sum corresponds to purely frictional unemployment. As job offers arrive with Poisson rate $\lambda_{0}$, unemployment durations are exponentially distributed. In a flow sample, where the elapsed ("backward") duration $t_{0 b}$ is zero by definition, the density of the residual ("forward") duration $t_{0 f}$ is given as $h\left(t_{0 f}\right)=\lambda_{0} \exp \left(-\lambda_{0} t_{0 f}\right)$. In a stock sample, we need to consider the total duration $t_{0 b}+t_{0 f}$, conditional on the elapsed duration $t_{0 b}$. The latter has the density $h\left(t_{0 b}\right)=\lambda_{0} \exp \left(-\lambda_{0} t_{0 b}\right)$. It can be shown (e.g., Lancaster, 1990) that the conditional density $h\left(t_{0 f} \mid t_{0 b}\right)$ is given as $\lambda_{0} \exp \left(-\lambda_{0} t_{0 f}\right)$. For the joint density we then obtain $h\left(t_{0 b}, t_{0 f}\right)=h\left(t_{0 f} \mid t_{0 b}\right) h\left(t_{0 b}\right)=\lambda_{0}^{2} \exp \left(-\lambda_{0}\left(t_{0 b}+t_{0 f}\right)\right)$, which is the term that figures in the likelihood expression above. The term in front of the exponential function is adjusted if either the elapsed or the residual duration is censored $\left(d_{b}=1\right.$ or $\left.d_{f}=1\right)$. $f\left(w_{0}\right)$ is the density function of wage offers evaluated at the offer that we observe as the initially unobserved person transits into employment. If the unemployment duration is right-censored $\left(d_{0 f}=1\right)$, this term drops out of the likelihood function.

The second term of the sum has the same basic structure, but with some adjustments for the fact that individuals in this group are sometimes faced with wage offers that are below their reservation wage. The unemployment spell hazard rate is therefore given not by $\lambda_{0}$, but by the product $\lambda_{0} \bar{F}(b)$. The second adjustment concerns the wage offer density, which is now truncated at $b$, so we have $f\left(w_{0}\right) / \bar{F}(b) .^{9}$

Finally, the third term applied to individuals who, given $F$, are permanently unemployed. This implies that the observed unemployment spell must be both left- and right-censored, hence the $d_{b} \cdot d_{f}$ in the exponent.

Likelihood - Employed Workers For individuals who are initially employed, the likelihood contribution is

$$
\frac{\kappa_{0}}{1+\kappa_{0}} \cdot g\left(w_{1}\right) \cdot\left[\delta+\lambda_{1} \bar{F}\left(w_{1}\right)\right]^{1-d_{1 b}} \cdot e^{-\left[\delta+\lambda_{1} \bar{F}\left(w_{1}\right)\right]\left(t_{1 b}+t_{1 f}\right)}\left[\delta^{v}\left(\lambda_{1} \bar{F}\left(w_{1}\right)\right)^{1-v}\right]^{1-d_{1 f}} .
$$

In steady state, a fraction $\kappa_{0} /\left(1+\kappa_{0}\right)$ of all individuals is employed. $g$ is the density of wages in the initial job. Unlike for the unemployed, the reservation wage of a worker is observed and equals his or her current wage, so there is no mixing distribution for the durations. However, there are now two competing reasons for why a spell may end: layoff (at rate $\delta$ ) or

\footnotetext{
${ }^{9}$ Note that as $\bar{F}(b)=1$ for $b<\underline{w}$, the first term of the sum could be integrated into the second term. We choose to present them separately here to better reflect the conceptual difference between the three components behind the unemployment rate.
} 
a better job offer (at rate $\lambda_{1} \bar{F}(w)$ ). The indicator $v$ equals 1 in the first case and 0 in the second. $t_{1 b}$ denotes the elapsed duration, and $t_{1 f}$ the residual duration of the current job. $d_{1 b}$ equals 1 if the elapsed duration is left-censored, while $d_{1 f}=1$ means that the residual duration is right-censored, i.e. the individual does not change his or her job during the observation period.

Estimation Procedure Maximum likelihood estimation of the model requires functional form assumptions for $H$ and $\Gamma$. The estimation is numerically cumbersome as $f, g$, and $\bar{F}$ are highly non-linear functions of $\Gamma$. In particular, optimisation involves the numerical computation of the inverse $K^{-1}$, further complicated by the fact that $K$ contains an integral that has to be evaluated numerically as well. Beyond these numerical concerns, there is the issue that most distributions for $\Gamma$ imply wage distributions that do not fit the data well.

As an alternative, Bontemps et al. (2000) therefore propose a three-step procedure in which the wage distribution is estimated non-parametrically:

1. In a first step, we estimate $G$ and $g$ (the cdf and pdf of the wage distribution) using a kernel density estimator, and estimate $\underline{w}$ and $\bar{w}$ as the sample minimum and maximum of the wages of workers who are employed on 1 January 2007. Based on these nonparametric estimates and a parametric assumption for the opportunity cost distribution, namely $H \sim \mathcal{N}\left(\mu_{b}, \sigma_{b}^{2}\right)$, we obtain consistent estimates for $\bar{F}$ and $f$ (conditional on $\mu_{b}, \sigma_{b}, \lambda_{0}, \lambda_{1}, \delta$ and the assumption that $\rho=0.004$ ) by numerically solving the following expressions (recall that $u$ is a function of $\bar{F}$ ):

$$
\widehat{\bar{F}}(w)=\frac{A(w)-u A_{u}(w)-(1-u) \widehat{G}(w)}{\kappa_{1} \cdot \widehat{G}(w) \cdot(1-u)+\kappa_{0} \cdot u \cdot A_{u}(w)}
$$

and

$$
\widehat{f}(w)=\frac{(1-u) \cdot \widehat{g}(w) \cdot\left(1+\kappa_{1} \hat{\bar{F}}(w)\right)}{\kappa_{0} \cdot u \cdot A_{u}(w)+\kappa_{1} \cdot(1-u) \cdot \widehat{G}(w)} .
$$

2. The estimates from Step 1 are plugged into the likelihood function, which is then maximised with respect to $\mu_{b}, \sigma_{b}, \lambda_{0}, \lambda_{1}$, and $\delta$.

3. Once these parameters are known, the productivity of a firm can be inferred from the wage that it offers:

$$
\begin{aligned}
p & =K^{-1}(w) \\
& =w+\left(\frac{\kappa_{0} \cdot A^{\prime}(w) \cdot\left(1+\kappa_{1} \cdot \widehat{\bar{F}}(w)\right)}{\left(1+\kappa_{0} \cdot \widehat{\bar{F}}(w)\right) \cdot\left(\kappa_{1} A(w)+\left(\kappa_{0}-\kappa_{1}\right)\right) \cdot u \cdot A_{u}(w)}+\frac{2 \cdot \kappa_{1} \cdot \widehat{f}(w)}{\left.1+\kappa_{1} \cdot \widehat{\bar{F}}(w)\right)}\right)^{-1}
\end{aligned}
$$

Standard errors are obtained by bootstrapping the three-step procedure. 


\section{Estimation Results}

\subsection{Parameter Estimates}

Table 1 reports the estimated parameters and the associated bootstrap standard errors. ${ }^{10}$ The large sample size of almost a quarter of a million observations allows for fairly precise estimates.

For the whole sample, we estimate a monthly job destruction rate $\delta$ of 0.0063 . Looking at twelve sub-samples defined by region and job classification, we find that job destruction rates are higher in East Germany than in the West, and higher for agricultural and sales jobs than for white-collar employees or office workers. Our estimates range from 0.0054 (white-collar, West) to 0.0118 (agriculture, East). These orders of magnitude are similar to existing studies. For France in the 1990s, Bontemps et al. (1999) find a $\delta$ between 0.0032 and 0.0069, depending on the sector. Using SIAB data for an earlier period (1995-2000), Nanos and Schluter (2014) estimate the monthly layoff rate to be between 0.0032 and 0.0243 in Germany. Holzner and Launov (2010), who use data from the German Socio-Economic Panel 1984-2001, estimate a $\delta$ of 0.0047 .

The estimated $\kappa$, i.e., the ratio of the job arrival over the job destruction rate, is greater for the unemployed than for the employed. We find $\kappa_{0}$ to be 13.72 and $\kappa_{1}$ to be 8.18. Holzner and Launov find a $\kappa_{1}$ of 2.2 , while their three values of $\kappa$ for the unemployed (they assume that individuals search on skill-specific labour markets) range between 5.6 and 17.1. In their study for France, Bontemps et al. (2000) also estimate a much higher job arrival rate for the unemployed than for the employed. In all cases, this reflects that continental European labour markets are characterised by relatively little job-to-job mobility compared with the United States.

The differences between regions and job classifications are potentially relevant for the design of the new statutory minimum wage in Germany. After a transition period, the minimum wage became uniform for all workers by 2017 at the latest. Our results suggest that the uniform rate applies to labour market segments that differ in the extent of search frictions and thus in firms' monopsony power on the labour market. ${ }^{11}$

According to our estimates, the distribution of the opportunity costs of employment has a mean $\mu_{b}$ close to 0 euros per hour, both in the whole sample and for the different sub-samples. The standard deviation $\sigma_{b}$ is estimated to be 1.85 for the whole sample.

However, unlike in the model of Bontemps et al. (1999), the reservation wages are not identical to the opportunity costs of employment. This is because job offer arrival rates are

\footnotetext{
${ }^{10}$ While multiple equilibria cannot be ruled out (see van den Berg, 2003), we have not found evidence of this for any of our estimated or simulated equilibria.

${ }^{11}$ Bachmann and Frings (2017) adopt a different approach to quantify labour market frictions in Germany and estimate labour supply elasticities specific to the individual firm. Using linked Employer-Employee Data from the IAB (LIAB), the authors document great differences in employers' market power across industries. Their findings indicate that retailing, hotels and restaurants and agriculture feature a larger degree of monopsonistic power than other services and manufacturing of food products. Note that even though their estimates are based on different sub-samples and time periods, they are well in line with our results, pointing to larger frictions in agriculture, sales and service jobs than in production and white-collar jobs.
} 
Table 1: Estimation results

\begin{tabular}{|c|c|c|c|c|c|c|c|c|c|}
\hline & $\mathrm{N}$ & $\delta$ & $\kappa_{1}$ & $\kappa_{0}$ & $\mu_{\phi}$ & $\mu_{b}$ & $\sigma_{b}$ & $\beta$ & $u$ \\
\hline Whole sample & 235706 & $\begin{array}{c}0.0063 \\
(0.0000)\end{array}$ & $\begin{array}{c}8.18 \\
(0.09)\end{array}$ & $\begin{array}{l}13.72 \\
(0.17)\end{array}$ & $\begin{array}{c}4.74 \\
(0.03)\end{array}$ & $\begin{array}{c}0.00 \\
(0.00)\end{array}$ & $\begin{array}{c}1.85 \\
(0.02)\end{array}$ & $\begin{array}{c}0.63 \\
(0.00)\end{array}$ & $\begin{array}{c}0.1081 \\
(0.0004)\end{array}$ \\
\hline \multicolumn{10}{|l|}{ West Germany } \\
\hline Agriculture & 2685 & $\begin{array}{c}0.0087 \\
(0.0002)\end{array}$ & $\begin{array}{c}7.50 \\
(0.58)\end{array}$ & $\begin{array}{l}14.48 \\
(1.23)\end{array}$ & $\begin{array}{c}4.69 \\
(0.19)\end{array}$ & $\begin{array}{c}0.00 \\
(0.00)\end{array}$ & $\begin{array}{c}2.34 \\
(0.20)\end{array}$ & $\begin{array}{c}0.46 \\
(0.01)\end{array}$ & $\begin{array}{c}0.1303 \\
(0.0040)\end{array}$ \\
\hline Production, Craft & 76723 & $\begin{array}{c}0.0058 \\
(0.0000)\end{array}$ & $\begin{array}{l}12.06 \\
(0.39)\end{array}$ & $\begin{array}{l}22.71 \\
(0.83)\end{array}$ & $\begin{array}{c}6.17 \\
(0.06)\end{array}$ & $\begin{array}{c}0.00 \\
(0.00)\end{array}$ & $\begin{array}{c}3.11 \\
(0.07)\end{array}$ & $\begin{array}{c}0.68 \\
(0.00)\end{array}$ & $\begin{array}{c}0.0856 \\
(0.0007)\end{array}$ \\
\hline White-collar & 16943 & $\begin{array}{c}0.0054 \\
(0.0000)\end{array}$ & $\begin{array}{l}10.77 \\
(0.56)\end{array}$ & $\begin{array}{l}17.84 \\
(1.05)\end{array}$ & $\begin{array}{c}5.91 \\
(0.12)\end{array}$ & $\begin{array}{c}0.00 \\
(0.00)\end{array}$ & $\begin{array}{c}2.97 \\
(0.10)\end{array}$ & $\begin{array}{c}0.74 \\
(0.01)\end{array}$ & $\begin{array}{c}0.0964 \\
(0.0014)\end{array}$ \\
\hline Sales & 10080 & $\begin{array}{c}0.0079 \\
(0.0001)\end{array}$ & $\begin{array}{c}4.79 \\
(0.22)\end{array}$ & $\begin{array}{c}8.47 \\
(0.42)\end{array}$ & $\begin{array}{c}4.15 \\
(0.09)\end{array}$ & $\begin{array}{c}0.00 \\
(0.00)\end{array}$ & $\begin{array}{c}1.52 \\
(0.07)\end{array}$ & $\begin{array}{c}0.50 \\
(0.01)\end{array}$ & $\begin{array}{c}0.1557 \\
(0.0021)\end{array}$ \\
\hline Office & 46978 & $\begin{array}{c}0.0057 \\
(0.0000)\end{array}$ & $\begin{array}{c}8.04 \\
(0.13)\end{array}$ & $\begin{array}{l}12.54 \\
(0.24)\end{array}$ & $\begin{array}{c}4.68 \\
(0.06)\end{array}$ & $\begin{array}{c}0.00 \\
(0.00)\end{array}$ & $\begin{array}{c}2.06 \\
(0.05)\end{array}$ & $\begin{array}{c}0.70 \\
(0.00)\end{array}$ & $\begin{array}{c}0.1101 \\
(0.0009)\end{array}$ \\
\hline Service & 45250 & $\begin{array}{c}0.0069 \\
(0.0000)\end{array}$ & $\begin{array}{c}7.36 \\
(0.15)\end{array}$ & $\begin{array}{l}12.56 \\
(0.36)\end{array}$ & $\begin{array}{c}4.28 \\
(0.09)\end{array}$ & $\begin{array}{c}0.00 \\
(0.02)\end{array}$ & $\begin{array}{c}1.56 \\
(0.11)\end{array}$ & $\begin{array}{c}0.58 \\
(0.00)\end{array}$ & $\begin{array}{c}0.1104 \\
(0.0010)\end{array}$ \\
\hline \multicolumn{10}{|l|}{ East Germany } \\
\hline Agriculture & 1225 & $\begin{array}{c}0.0118 \\
(0.0005)\end{array}$ & $\begin{array}{c}3.55 \\
(0.35)\end{array}$ & $\begin{array}{l}14.05 \\
(1.72)\end{array}$ & $\begin{array}{c}5.32 \\
(0.16)\end{array}$ & $\begin{array}{c}0.00 \\
(0.00)\end{array}$ & $\begin{array}{c}3.13 \\
(0.21)\end{array}$ & $\begin{array}{c}0.34 \\
(0.01)\end{array}$ & $\begin{array}{c}0.1892 \\
(0.0076)\end{array}$ \\
\hline Production, Craft & 15099 & $\begin{array}{c}0.0090 \\
(0.0001)\end{array}$ & $\begin{array}{c}7.16 \\
(0.53)\end{array}$ & $\begin{array}{l}18.74 \\
(1.52)\end{array}$ & $\begin{array}{c}5.73 \\
(0.07)\end{array}$ & $\begin{array}{c}0.00 \\
(0.00)\end{array}$ & $\begin{array}{c}2.67 \\
(0.07)\end{array}$ & $\begin{array}{c}0.45 \\
(0.00)\end{array}$ & $\begin{array}{c}0.1256 \\
(0.0016)\end{array}$ \\
\hline White-collar & 3081 & $\begin{array}{c}0.0063 \\
(0.0001)\end{array}$ & $\begin{array}{l}10.57 \\
(3.60)\end{array}$ & $\begin{array}{l}19.74 \\
(7.29)\end{array}$ & $\begin{array}{c}5.32 \\
(0.19)\end{array}$ & $\begin{array}{c}0.00 \\
(0.00)\end{array}$ & $\begin{array}{c}2.18 \\
(0.18)\end{array}$ & $\begin{array}{c}0.63 \\
(0.01)\end{array}$ & $\begin{array}{c}0.1002 \\
(0.0033)\end{array}$ \\
\hline Sales & 1932 & $\begin{array}{c}0.0091 \\
(0.0002)\end{array}$ & $\begin{array}{c}4.90 \\
(0.64)\end{array}$ & $\begin{array}{l}10.70 \\
(1.64)\end{array}$ & $\begin{array}{c}3.85 \\
(0.14)\end{array}$ & $\begin{array}{c}0.00 \\
(0.08)\end{array}$ & $\begin{array}{c}1.09 \\
(0.26)\end{array}$ & $\begin{array}{c}0.44 \\
(0.01)\end{array}$ & $\begin{array}{c}0.1704 \\
(0.0148)\end{array}$ \\
\hline Office & 6655 & $\begin{array}{c}0.0061 \\
(0.0001)\end{array}$ & $\begin{array}{c}7.89 \\
(0.70)\end{array}$ & $\begin{array}{l}13.67 \\
(1.19)\end{array}$ & $\begin{array}{c}4.47 \\
(0.12)\end{array}$ & $\begin{array}{c}0.00 \\
(0.01)\end{array}$ & $\begin{array}{c}1.42 \\
(0.10)\end{array}$ & $\begin{array}{c}0.66 \\
(0.01)\end{array}$ & $\begin{array}{c}0.1103 \\
(0.0023)\end{array}$ \\
\hline Service & 9055 & $\begin{array}{c}0.0075 \\
(0.0001)\end{array}$ & $\begin{array}{c}6.20 \\
(1.44)\end{array}$ & $\begin{array}{l}12.03 \\
(2.45)\end{array}$ & $\begin{array}{c}3.95 \\
(0.09)\end{array}$ & $\begin{array}{c}0.00 \\
(0.01)\end{array}$ & $\begin{array}{c}1.29 \\
(0.15)\end{array}$ & $\begin{array}{c}0.54 \\
(0.01)\end{array}$ & $\begin{array}{c}0.1263 \\
(0.0122)\end{array}$ \\
\hline
\end{tabular}

Note: Calibrated parameters: $\rho=0.004$. Bootstrapped standard errors in parentheses (100 runs). 
higher when unemployed, so it is optimal for the unemployed to reject certain wage offers in the hope of getting a higher offer in the future (cf. Equation (1)). Based on the estimated parameters, we find that the distribution of reservation wages is centred around a value of about 4.74 euros per hour. The reservation wages tend to be higher and more widely dispersed in the West, with the sole exception of agricultural jobs. Among job classifications, sales jobs stand out for having both the smallest mean (3.85 euros in East Germany and 4.15 euros in West Germany) and the smallest standard deviation of the reservation wage. White-collar workers and workers in production and craft have the highest reservation wages when unemployed.

The differences in $\mu_{\phi}$ between the sub-samples are almost exclusively driven not by inherent differences in opportunity costs (recall that $\mu_{b}$ is close to zero everywhere), but by differences in the frictional parameters. For instance, the difference between $\kappa_{0}$ and $\kappa_{1}$ is particularly large for production/craft jobs in the West and particularly small for sales jobs in the East, which is reflected in a much higher $\mu_{\phi}$ in the first case. Note that differences in $\kappa_{0}$ and $\kappa_{1}$ also reflect differences in layoff rates. The higher the layoff rate, the smaller the expression $\beta \equiv \rho / \delta$ in Equation (1), and thus the smaller the incentive for the unemployed to be picky when accepting a wage offer - after all, accepting a job already means giving up a higher job arrival rate. If the job has a higher probability of ending, the costs of accepting it in terms of foregone employment opportunities become smaller.

Finally, based on Equation (5) we can compute the steady-state unemployed rate $u$ implied by our estimates. For the entire sample, we find a rate of $10.81 \%$, which is higher than the rate of $7.6 \%$ observed in our stock sample. The variation across regions and job classifications is in line with the patterns documented for the sample, i.e. steady-state unemployment is higher in the East and in agricultural and sales jobs.

\subsection{Distribution of Wages, Opportunity Costs, Markups, Productivity}

Figure 1 shows key plots for the whole sample summarising the steady-state equilibrium. Panel (a) depicts our non-parametric estimate for $G$, the cdf of the wage distribution. The pdf $g$, which is not shown here, is similarly estimated using a kernel density estimator.

To find the wage offer distribution $F$ (panel (b)), the estimate for $G$ is combined with the maximum likelihood estimates for the frictional parameters and the opportunity cost distribution, as outlined in Section 5 above. Note that the location and the shape of the wage offer distributions differ from the wage distribution. For instance, more than $70 \%$ of the wage offers but only $20 \%$ of observed wages are below 10 euros.

Panel (c) shows the estimated distribution of reservation wages. This is a normal distribution centred around $\mu_{\phi}=4.74$ euros and truncated at 3 euros, the lowest admissible hourly wage. Note that there is hardly any mass left beyond 10 euros. This means that the positive effect of higher minimum wages operating through a lower rate of job offer rejections will be mostly limited to minimum wage levels below 10 euros.

Panel (d) presents the optimal wage offer as a function of firm productivity $p$. For example, a firm with a value product of 20 euros per hour will optimally set a wage of about 15 euros 


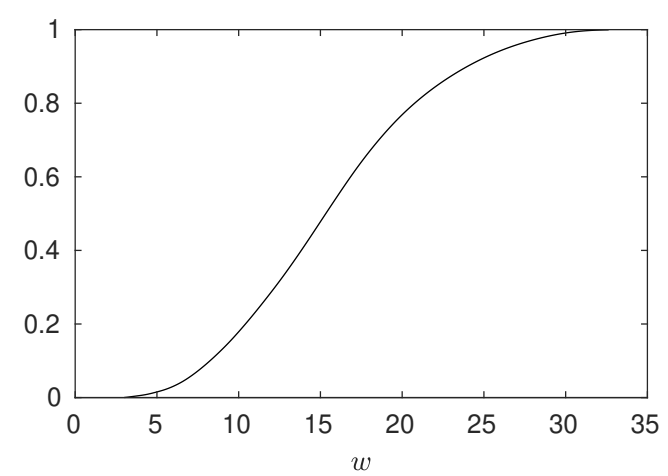

(a) Wage distribution $G(w)$

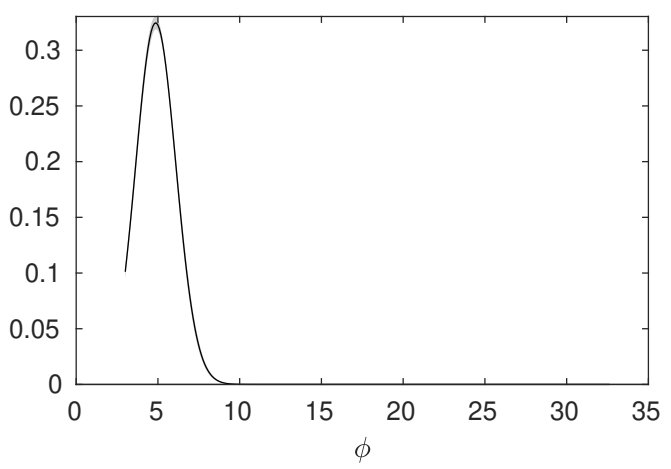

(c) Reservation wage density $A(w)$

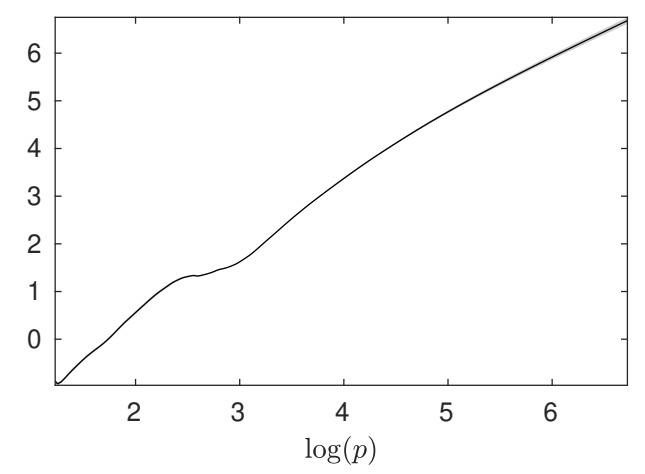

(e) Log absolute markup

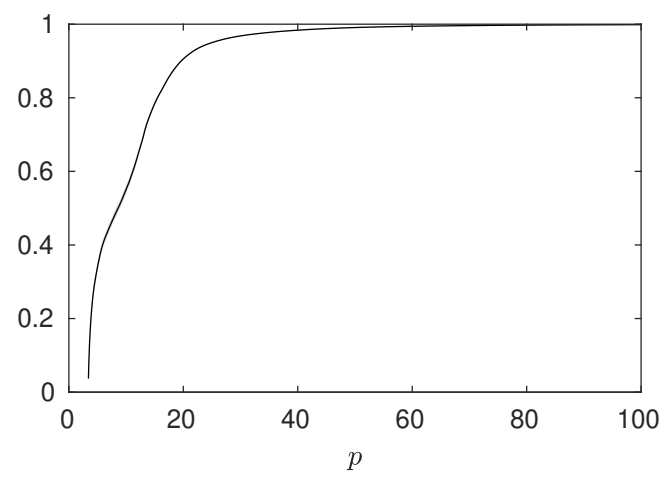

(g) Productivity distribution $\Gamma(p)$

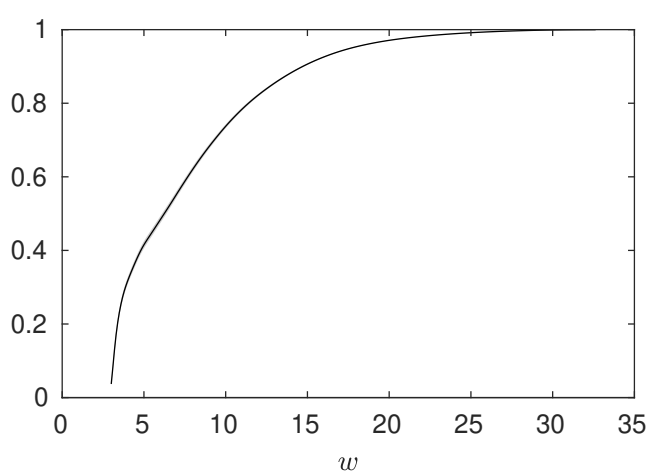

(b) Wage offer distribution $F(w)$

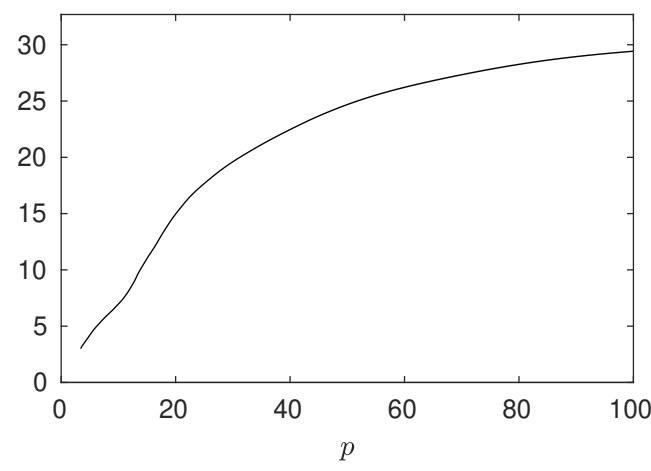

(d) Wage function $K(p)$

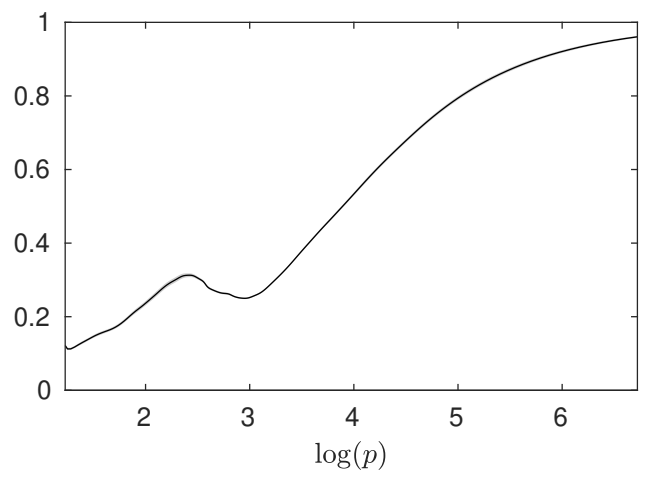

(f) Monopsony power $[p-K(p)] / p$

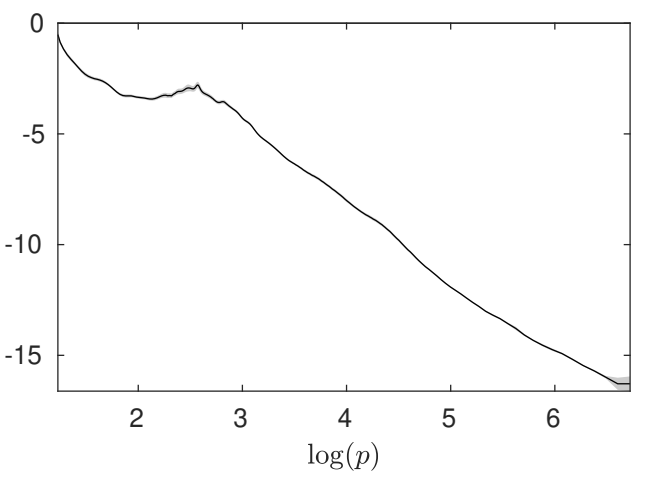

(h) Productivity log density $\log (\gamma(p))$

Key: Grey area indicates $95 \%$ confidence bands.

Figure 1: Main Equilibrium Functions (Whole Sample) 
per hour. The absolute markup, which is shown in a log-log-scale in panel (e), grows monotonically and at a roughly constant rate with a firm's productivity. Expressed as a percentage of productivity (panel (f)), the relationship becomes non-monotonic, although the pattern of a general increase is preserved; while the lowest-productivity firm has a markup of about $15 \%$, the markup is over $80 \%$ for the firm with the highest productivity. Put differently, workers obtain less than $20 \%$ of the value product in these high-productivity firms. However, as the estimate of the productivity distribution $\Gamma$ in panel $(\mathrm{g})$ makes clear, such cases are fairly rare, with the bulk of firms having a value product of less than 20 euros per hour. Finally, panel (h) shows that our three-stage estimate of firm productivity results in a (non-parametric) distribution that is not too dissimilar from a Pareto distribution in that the density $\gamma$ is a straight line in log-log-coordinates over a wide range of $p$.

The main equilibrium functions for the twelve different labour markets defined by region and job classification can be found in Appendix A.8.

\subsection{Robustness Checks}

Table 6 in Appendix A.8 reports results from a number of robustness checks for the whole sample. First, instead of disregarding individuals with wages right-censored at the upper limit for social security contributions (SSC), we use a Tobit regression to impute wages above this limit. Second, we replace the imputation of working hours with the assumption that all full-time employees work 40 hours per week. Third, we experimented with different ways of assigning a single wage to employment spells that last over several years, during which time individuals typically experience wage increases. In the theoretical model, this cannot happen as each job is characterised by a single, time-invariant wage. In our main specification, we use the average wage in the same job over the past year. In a robustness check, we use the last observed wage only. The two measures differ to the extent that individuals experience wage changes within the last year. Fourth, we truncated the wage distribution at different levels. In our main specification, wages below 3.00 euros per hour are discounted. We changed this threshold to 2.00 euros and 4.00 euros, respectively. Moreover, when replacing the right-censoring at the upper limit for SSC with an imputation procedure, we tried two variants in which we truncated the imputed wages at the 95th or 99th percentile. Finally, we set $\rho$, which is assumed to be 0.004 in our main specification, to alternative values $(0.002$ or 0.006). We also combined the robustness checks along the different dimensions.

The estimation results are fairly unaffected by these variations. The same is true for the comparative statics results (not shown here for the robustness checks). Only for the different truncation levels (2 euros/4 euros instead of 3 euros) is there a slightly stronger reaction of some of the parameters, though the comparative statics results remain qualitatively very similar. 


\section{Unemployment Effects of Different Minimum Wage Levels}

\subsection{Pathways}

Due to the heterogeneity in both the opportunity cost of employment and firms' productivity, the unemployment rate is a non-monotonic function of the minimum wage level. We will now look into the underlying mechanisms at different minimum wage levels and for different labour market segments.

Decomposition of the Unemployment Rate Unemployment can be of three types, as shown by the decomposition in Equation (5). Group (1) consists of individuals whose reservation wage is below $\underline{w}$, i.e., who will accept any job offer. This purely frictional unemployment decreases in $\kappa_{0}$, the ratio of the job arrival rate of the unemployed over the job destruction rate. For Group (2), unemployment is partly frictional (through $\kappa_{0}$ ) and partly driven by the interplay between the reservation wage and the wage offer distribution. Unemployed individuals in this group accept some job offers but reject others, depending on the wage offer. Finally, individuals in Group (3) are permanently unemployed because their reservation wage is higher than the highest wage offer $\bar{w}$.

Effects through the Wage Offer Distribution For minimum wage levels below the lowest productivity level $\underline{p}$, the model predicts that a minimum wage reduces unemployment, as long as the minimum wage shifts up firms' optimal wage offers. The reason is that in this case unemployed individuals are now more likely to receive acceptable wage offers. With $\underline{w}=3.00$ euros and our estimate for the wage offer function, this cutoff level is $\underline{\hat{p}}=\hat{K}^{-1}(3.00)=3.42$ euros for the whole sample. The introduction of a minimum wage of, say, 3.10 euros limits firms' power to set wages below productivity. The lowest wage is now 3.10 euros instead of 3.00 euros and, via Equation (8), this increase has repercussions throughout the entire wage offer distribution. This is illustrated in Panel (a) of Figure 2 for the whole sample: the higher the minimum wage level, the smaller the workforce $l$ that a firm attracts for a given wage offer $w$. Moreover, the relationship between $l$ and $w$ becomes less steep for higher minimum wages.

As a result of these interactions operating through $l(w)$, different minimum wage levels lead to different optimal wage offer functions $\hat{K}^{M W}$, and therefore to different wage offer distributions $\hat{F}^{M W}$. Increasing the minimum wage generally shifts $\hat{K}^{M W}$ upwards and $\hat{F}^{M W}$ to the right (cf. panels (b) and (c)). While the biggest changes occur for low wages and productivities, even high-productivity firms adjust their wage offer slightly in response to an increase in the minimum wage.

These changes in the wage offer distribution affect the steady-state unemployment rate. A minimum wage below $\underline{p}$ leads to an increase in $\underline{w}$, which in turn means that some individuals shift from Group (2) to Group (1) in Equation (5). As $1+\kappa_{0}>1+\kappa_{0} \bar{F}(b)$ for all $\left.\left.b \in\right] \underline{w}, \bar{w}\right]$, this leads to a reduction in the unemployment rate. For individuals staying in Group (2), unemployment goes down as $\bar{F}(w)$ decreases for all $w$. Moreover, the highest wage offer $\bar{w}$ 


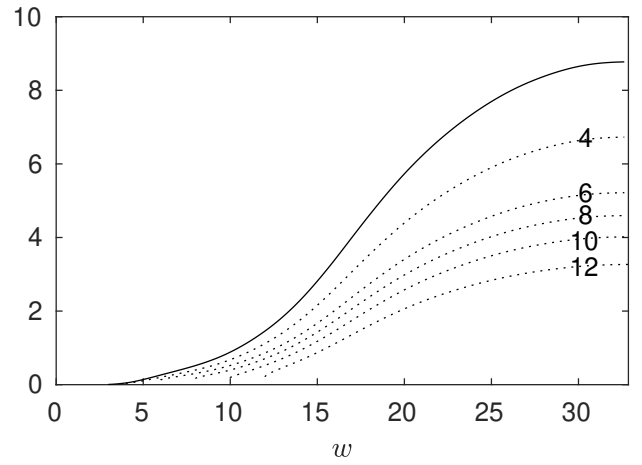

(a) Labour force size $l(w)$

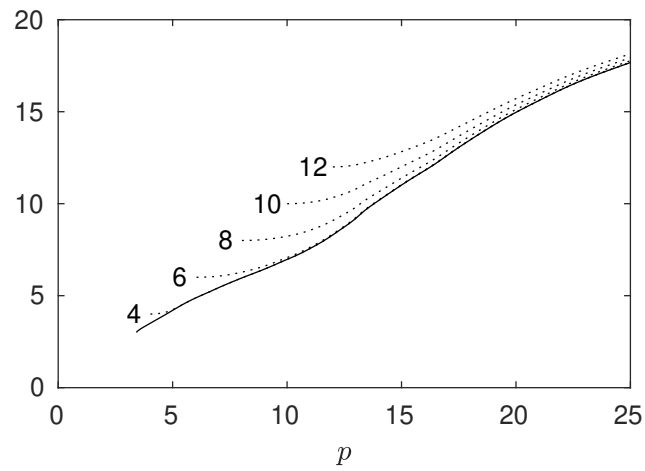

(b) Wage function $K(p)$

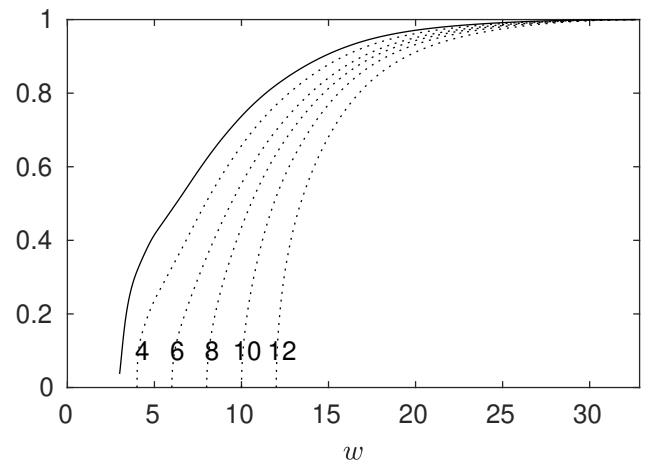

(c) Wage offer distribution $F(w)$

Key: No minimum wage (-); different minimum wage levels are 4, 6, 8, 10, and 12 euro (……...).

Figure 2: Equilibrium Functions for Different Minimum Wage Levels (Whole Sample) 
increases, which reduces the number of individuals who reject all job offers (Group 3).

Effects through the Job Arrival Rates For minimum wage levels above the lowest productivity level $\underline{p}$, the sign of the minimum wage effect on unemployment becomes ambiguous a priori. The minimum wage now affects the lowest productivity level $\underline{p}^{M W}$ that guarantees non-negative profits. As a result, the fraction of operating firms $\bar{\Gamma}\left(\underline{p}^{M W}\right)$ decreases. Following Bontemps et al. (1999, 2000), we assume that $\kappa_{0}$ and $\kappa_{1}$ are proportional to this fraction. This means that a minimum wage above $\underline{p}$ reduces the ratio of the job arrival rate over the job destruction rate. The unemployment effect of a minimum wage is now the result of two countervailing forces: the reduction in unemployment as higher wage offers lead to less frequent rejections of job offers, and the negative effect arising from the fact that job offers now arrive at a slower rate. Formally, the second effect reduces the denominators in Equation (5), thereby increasing the frictional component of unemployment in Groups 1 and 2.

Effects through Reservation Wages So far, we have discussed the channels operating through the wage offer distribution and the job offer arrival rates. Both channels are already present in the Bontemps et al. (1999) model with homogenous $\lambda$. In our extension of the model with $\lambda_{0} \neq \lambda_{1}$, there is an additional channel operating through $A$, the distribution of reservation wages $\phi$. This channel is present regardless of whether the minimum wage is below or above $\underline{p}$. As shown in Equation (1), the reservation wage $\phi$ depends on $\kappa_{0}, \kappa_{1}$, $F$ and $\bar{w}$, all of which are functions of the minimum wage. While an increase in $\bar{w}$ raises the reservation wage, a proportional reduction in $\kappa_{0}$ and $\kappa_{1}$ lowers it. $F$ has a double effect on $\phi$, operating both through the numerator and the denominator of the second term in Equation (1). Empirically, the resulting net influence on $A$ turns out to be relatively small in our application. In fact, the different density plots of $A$ are identical to the status-quo plot for the range of minimum wage levels considered here, and are therefore not shown. As a result, the minimum wage effects in the richer model with $\lambda_{0} \neq \lambda_{1}$ prove to be very close to the ones in the model with homogeneous $\lambda$.

Total Effect on Unemployment Figure 3 shows the effect of different minimum wage levels on the unemployment rate and the average unemployment duration, based on the estimation results for the whole sample. The solid line in the upper panel is the effect that is actually predicted by the model. The dotted line allows for heterogeneity in $b$, but switches off the channel operating through the reduction in job offer arrival rates; these are held constant at their estimated status-quo levels. The dashed line shows the ratio $1 /\left(1+\hat{\kappa}_{0}\right)$. In this case, the positive effect working through the wage offer distribution is switched off. All unemployment is purely frictional from the start, and higher minimum wages increase search frictions and thereby unemployment through the reduction in $\kappa_{0}$ and $\kappa_{1}$.

In our actual model (solid line), the relationship between $u$ and the minimum wage level is non-monotonic; from a status-quo level (with no minimum wage) of about $11 \%$, unemployment falls for very low levels of $w^{M W}$ and reaches its minimum at $w^{M W}=3.45$ euros. 


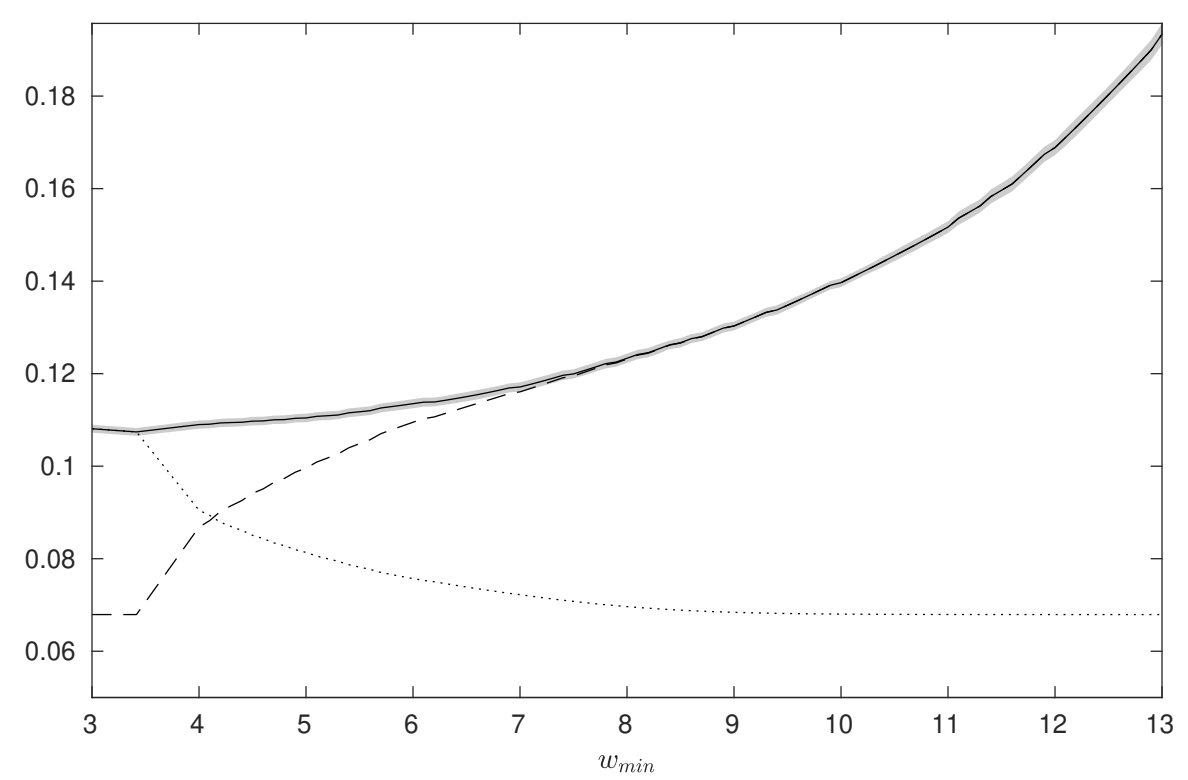

(a) Unemployment rate $u$

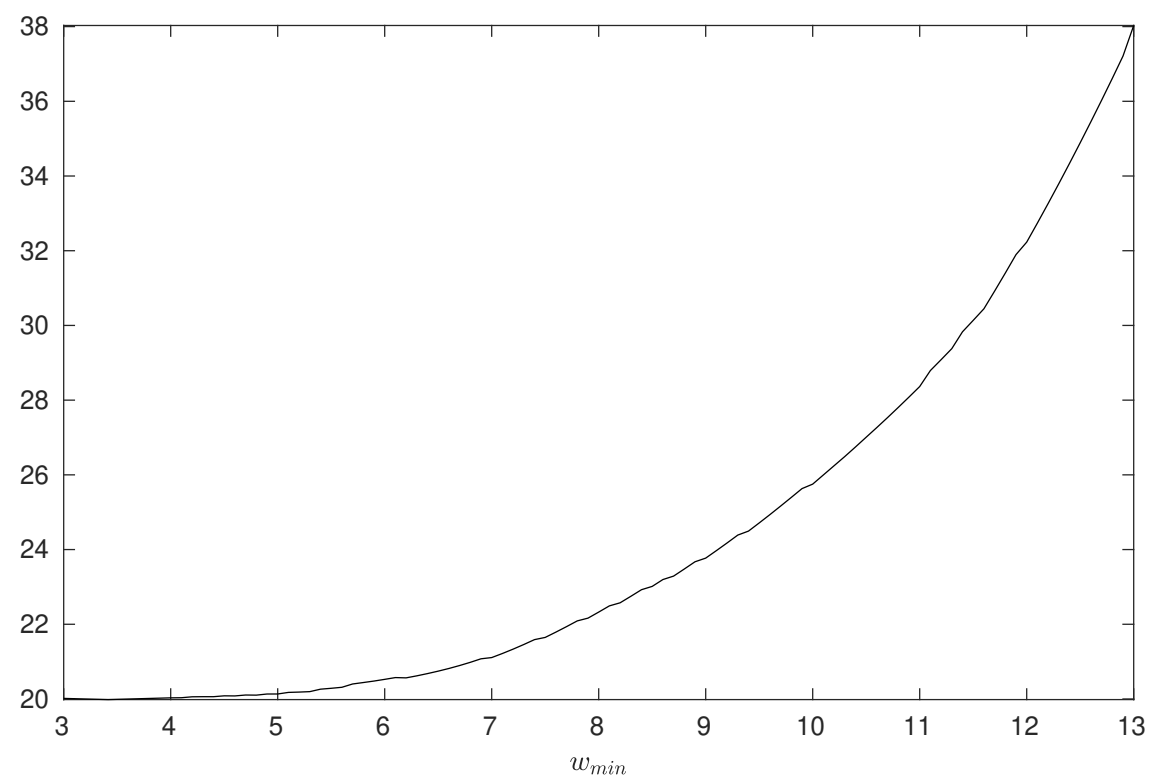

(b) Mean unemployment duration

Key: Preferred model (-); frictional component of $u(---)$;

model without change in job offer arrival rates (.............). Grey area indicates $95 \%$ confidence bands.

Figure 3: Change in Minimum Wage: Unemployment (Whole Sample) 
From there on, unemployment increases with the level of the minimum wage. The status-quo unemployment rate is again reached at 3.51 euros; this is the highest value of the minimum wage that does not lead to an increase in unemployment in relation to the status quo. For higher values, the increase in unemployment is relatively modest at first but becomes more significant above 8.00 euros. The positive effect working through higher wage offers is nearly exhausted by this point, i.e. there is little mass left in the reservation wage density. This is illustrated by the dotted line. The line shows what happens to the unemployment rate as the frictional component gains more and more in importance. Since the opportunity cost distribution $H$ is unbounded, purely frictional unemployment (corresponding to a situation in which all unemployed individuals are in Group (1)) is reached only asymptotically. However, at a minimum wage level of 8.00 euros the dotted line is already very close to its limit as $w_{\text {min }}$ approaches infinity $\left(6.96 \%\right.$ vs. $\left.100 \times \frac{1}{1+\widehat{\kappa_{0}}}=6.8 \%\right)$. For higher values of the minimum wage, the increase in unemployment resulting from the reduction in job offer arrival rates is therefore the (almost) exclusive driver of the changes in $u$. In Figure 3 , this is reflected by the near convergence of the solid line and the dotted line at about 8.00 euros.

The actual minimum wage introduced in January 2015 was 8.50 euros per hour. Adjusted to 2010 prices, this corresponds to a level of around 8.00 euros, which according to our model estimated for the whole sample would have increased the unemployment rate by 1.52 percentage points. In relative terms, this amounts to an increase of about $14 \%$ compared to the old steady-state value observed on 1 January 2007.

The mean unemployment duration (panel (b) of Figure 3) is given by

$$
\int_{\underline{w}}^{\bar{w}} \frac{A_{u}(b)}{\lambda_{0} \bar{F}(b)} \mathrm{d} b .
$$

The three effects mentioned above in the context of the unemployment rate are again at play here. In fact, each item in the expression depends on the minimum wage level. The effect on the numerator $A_{u}$ is ambiguous a priori and, given that $A$ changes little, probably fairly small. The main change is likely to take place in the denominator, where $\lambda_{0}$ decreases in the minimum wage while $\bar{F}$ increases, again giving an ambiguous effect. The influence of the change in the integral limits $\underline{w}$ and $\bar{w}$ is also an empirical question. Our simulations show that the mean unemployment duration stays fairly constant at 20 weeks until a minimum wage level of about 5.00 euros, and then grows at an increasing rate.

Heterogeneity between Labour Markets The simulation results discussed so far have been for the whole sample, i.e. they are based on an estimation in which observations from all twelve labour markets have been pooled (first row of Table 1). Figure 4 shows the effect of different minimum wage levels on the unemployment rate for the twelve labour markets defined by region and job classification. The simulated changes in unemployment for minimum wages of 7.00 euros, 8.00 euros (around 8.50 euros in 2015 prices), and 9.00 euros are reported in Table 7 in the Appendix. The simulations are based on separate estimations for each labour market (cf. Table 1). We find that the same minimum wage level can have 


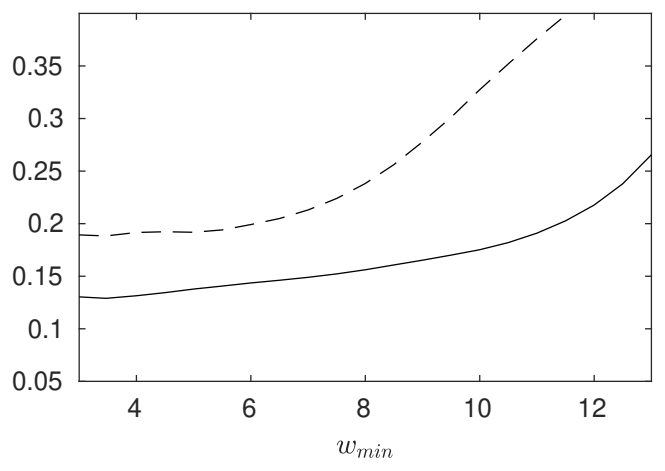

(a) Agriculture

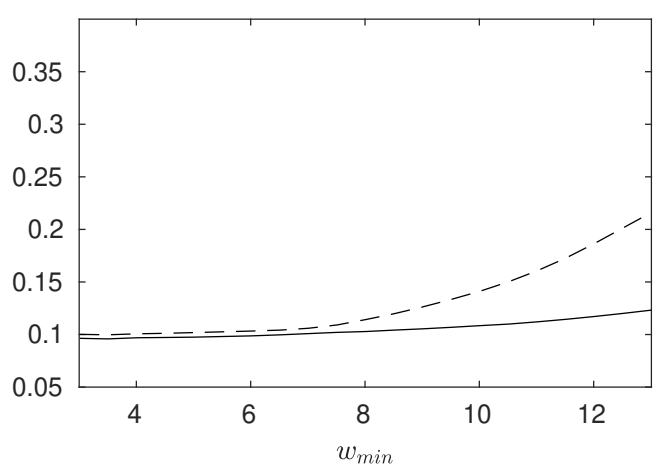

(c) White-collar

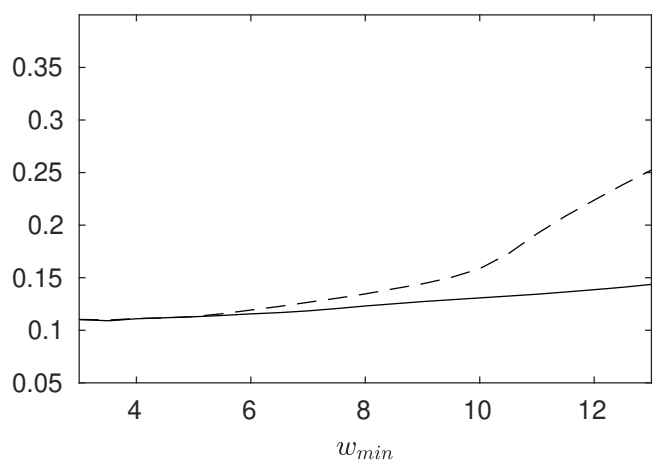

(e) Office

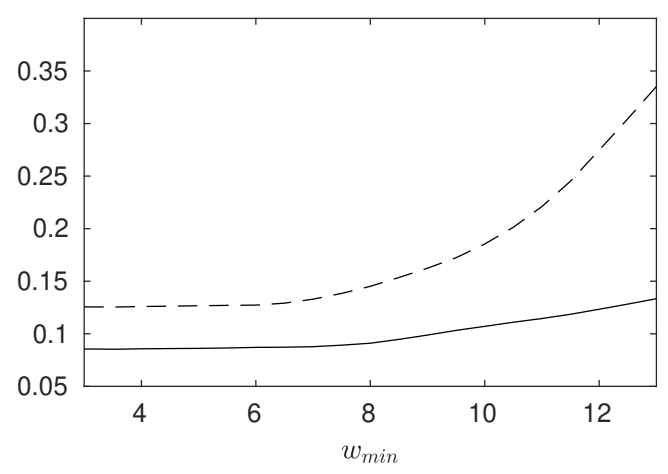

(b) Production, Craft

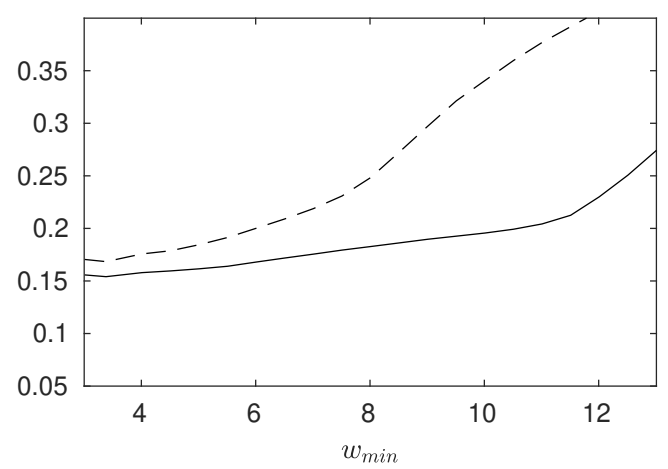

(d) Sales

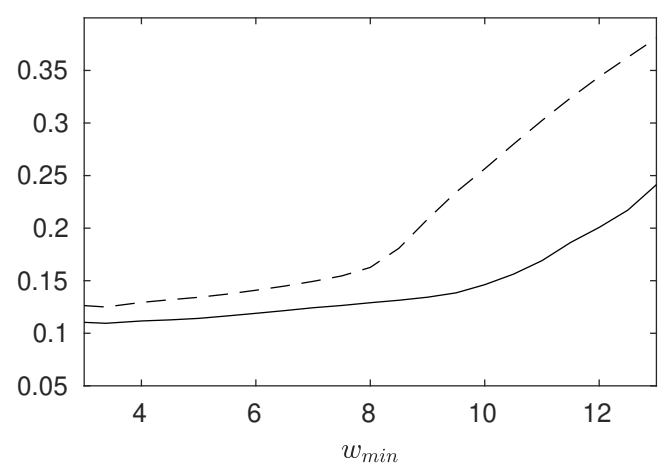

(f) Service

Key: West (—); East (----).

Figure 4: Unemployment Rate $u$ by Job Classification and Region 
very different effects on unemployment depending on the labour market segment.

Focusing on West Germany first, we find that even low minimum wage levels lead to an increase in unemployment in the agricultural and sales occupations, as well as for service workers, while for workers in production and craft, for office workers and especially for white-collar employees the negative effects set in at much higher levels only. A minimum wage of 8.00 euros would have the largest impact on unemployment for agricultural and sales jobs (an increase of around 2.6 percentage points in both labour markets) as well as for service jobs (increase of 1.9 percentage points). Notably, the biggest labour market segment in West Germany, production/craft, is relatively unaffected by intermediate minimum wage levels (the unemployment rate increases by 0.2 percentage points for a 7.00 euro minimum wage or 0.5 percentage points for a 8.00 euro minimum wage). While the unemployment effect of a 9.00 euro minimum wage is still small for production/craft workers (increase of 1.3 percentage points), it can be seen that the impact of minimum wages evolves non-linearly. Similarly, the unemployment rate increases are small for white-collar workers in West Germany - below one percentage point even for minimum wages up to 9.00 euros.

Importantly, there are strong differences between East and West Germany even for the same type of jobs. For agricultural workers, white-collar employees, and production/craft occupations, the minimum wage effects in East Germany tend to be similar to the West at first (albeit at a considerably higher level of unemployment). At minimum wage levels between 6.00 and 8.00 euros per hour, however, the two graphs clearly diverge. For sales occupations, for service workers, and for office workers, the divergence begins at even lower levels. For the big Eastern German labour market segments production/craft and white-collar workers, a minimum wage of 7.00 euros leads to a mild increase in the unemployment rate by around 0.6 percentage points. In particular, production and craft occupations in East Germany see a much stronger impact on the unemployment rate for higher minimum wage levels $(+2.0$ percentage points for a 8.00 euro minimum wage +3.7 percentage points for a 9.00 euro minimum wages) than in West Germany.

Service occupations in East Germany experience similar non-linearities especially at minimum wages around 8.00 euros. While a 7.00 euro minimum wage raises unemployment by 2.3 percentage points (3.6 percentage points for a 8.00 euro minimum wage), a minimum wage of 9.00 euro would increase the unemployment rate by more than 8 percentage points.

Our simulations indicate that the critical level at which the negative unemployment effects of the minimum wage set in differ strongly by region and by job classification. If the minimum wage were to be increased above its actual level in real terms (8.50 euros in 2015, i.e. 8.00 euros in 2010 prices), the East-West difference in the unemployment effect would likely become much larger. The simulations for the different labour markets can be aggregated in order to derive the overall unemployment rate as a function of the minimum wage level (Figure 25). The aggregated rate is very similar to the rate from Figure 3, where we simulated the effect on overall unemployment based on an estimation and a simulation for the sample as a whole. Figure 26 shows the share of the different labour market segments in the overall unemployment rate. A minimum wage of 8.00 euro increases the aggregate 
unemployment rate by 1.43 percentage points, very similar to our simulations using the pooled sample ( +1.52 percentage points). As discussed above, the size of the effect is mainly driven by large labour markets in West Germany, such as production/craft, white-collar jobs and office occupations, where a 8.00 euro minimum wage has only a small impact. Especially East German labour markets are highly affected by a minimum wage of 8.00 euro but at the same time account for a smaller fraction of the increase in aggregate unemployment.

To explore to what extent the different unemployment effects across labour market segments are driven by differences in the productivity distributions and by differences in search frictions or the opportunity cost of employment, we ran two types of counterfactual simulations. In the first one, we combine the estimated productivity distribution for each segment with the parameters estimated for the sample as a whole. ${ }^{12}$ As Figure 27 shows, the unemployment rate as a function of the minimum wage level is clearly different across labour market segments even if the estimated parameters are assumed to be identical.

In a second counterfactual experiment, we combined the productivity distribution of the whole sample with the parameters that we estimated for the different labour market segments (Figure 28). For office and service workers, and for agriculture (in West Germany), the parameters are close to those for the whole sample (Table 1), and the graph for the unemployment rate is therefore also similar to the simulation for the whole sample (Figure 3 and reproduced in each panel of Figure 28). For production/craft workers and white-collar employees, the counterfactual graphs are below the graph for the specification for the whole sample. These labour market segments stand out both for a high rate of job arrivals over job destructions (and therefore relatively low frictional unemployment) and for a high mean and variance of the reservation wage distribution (Table 1). Our second counterfactual experiment shows that if the entire labour market were characterised by these parameters, the unemployment rate would be lower, so the effect of the lower frictional unemployment dominates the effect of the higher reservation wages. For agriculture in East Germany and for sales we see the inverse picture in which the counterfactual graph for the unemployment rate based on the parameters for these labour market segments is above the graph based on the parameters that were actually estimated for the whole sample.

Overall, these counterfactual experiments indicate that the variation in the employment effects across labour market segments is mainly driven by cross-segment differences in the firm productivity distribution, rather than by differences in search frictions or the opportunity cost of employment.

\footnotetext{
${ }^{12}$ The productivity distribution of each labour market segment is implied by the non-parametric estimation of the wage distribution in combination with the estimated model parameters (cf. Equation 13) for each segment. In the counterfactual combinations, we combine these segment-specific productivity distributions with the parameters that we estimated for the whole sample. In other words, while productivity is allowed to differ, search frictions and the opportunity cost of employment are constrained to be the same in each labour market segment.
} 


\subsection{Brief Comparison to Existing Reduced-form Studies}

Our analysis includes the first assessment of the new German minimum wage based on a structural model allowing for search frictions. Previous ex ante studies have relied on the assumption of perfect competition (Ragnitz and Thum, 2008; Bauer et al., 2009; Knabe and Schöb, 2009), i.e. on a model that by construction does not allow for positive employment effects of a minimum wage. There have also been a small number of quasi-experimental studies on the actual introduction of the minimum wage. Using the IAB Establishment Panel, Bossler and Gerner (2016) compare firms with employees affected by the minimum wage with a control group of firms that are not directly affected. They estimate losses of about 60,000 jobs because of the 2015 minimum wage introduction. In line with our simulations, they find that this employment effect is mainly driven by plants in East Germany. The other two studies use variation in the regional bite of the minimum wage. While Garloff (2016) uses data from the Federal Employment Agency and a sample of prime age workers of age 30 to 54, Caliendo et al. (2017) use the Structure of Earnings Survey (SES) 2014 combined with the SOEP. Both studies find either small or no negative effects of the minimum wage on full-time employment, and a significantly negative effect on marginal employment (a decrease of 180,000 jobs in the study by Caliendo et al.). However, these studies report no effect heterogeneity across regions or labour markets. In our simulations, a minimum wage equivalent in real terms to the one actually introduced in 2015 raises the aggregate unemployment rate by 1.4 percentage points, an increase of $13 \%$ compared to the old steady-state value. The size of this effect is mainly driven by large labour markets in West Germany where a 8.00 euro minimum wage (which corresponds to 8.50 in 2015 prices) has only a small impact, such as production/craft $(+0.5$ percentage points), white-collar jobs $(+0.6$ points $)$ and office occupations ( +1.3 points). However, especially East German labour markets are highly affected by a minimum wage of 8.00 euro (unemployment increases by 1.4 to up to 8 percentage points in some segments) but account for a smaller fraction in the increase of aggregate unemployment. For the overall sample, this corresponds to a decrease of around 180.000 jobs due to the minimum wage.

Comparing the predictions of the present study with the quasi-experimental evidence is difficult for a number of reasons, some of which were already discussed in earlier sections. First, we do not consider high-skilled individuals, i.e. the group of individuals who are least likely to be affected by the minimum wage. Second, our analysis is based on the time period 2007-2010. Since then, the German labour market has been booming (Bundesagentur für Arbeit, 2017). Increasing employment levels and growing real wages are expected to influence our estimation results and minimum wage simulations in the sense that a lower bite of the minimum wage could come along with lower unemployment effects. At the same time, the German labour market has witnessed a major inflow of unskilled migrants, which led to high economic activity in certain sectors but which will also affect the skill composition of the workforce in the upcoming years. Notice also that our results refer to equilibrium changes whereas reduced-form studies typically capture short-term adjustments and may be sensitive to anticipation effects. Finally, our model assumes that prices and the productivity of firms 
are unaffected by the minimum wage, and we do not consider non-compliance. Based on the extent to which firms can react to the minimum wage along these margins, the unemployment effects of the minimum wage will be dampened.

\section{Concluding Remarks}

By estimating a structural model, our paper contributes to highlighting the transmission mechanisms underlying the employment effects of a uniform minimum wage. We document heterogeneity in search frictions and in reservation wages across labour markets differentiated by region and/or type of occupation. Given that the minimum wage is motivated by a desire to offset firms' monopsony power, this suggests that a uniform minimum wage is perhaps too blunt a tool. In future research, it will be interesting to study correlates of regional and sectoral differences in search frictions and hence firms' market power. For instance, they may be related to differences in workers' characteristics across labour market segments, to firm characteristics, market structure and union coverage.

Our analysis faces some additional limitations which bear potential for future research. First, our dataset does not contain information on working hours, and we have therefore excluded part-time workers from the analysis. These workers tend to have relatively low hourly wages on average, which means that they are potentially strongly affected by a minimum wage.

Second, the observation window in our data set includes the "Great Recession" in the wake of the 2008 financial crisis. However, the recession was actually mild and short-lived in Germany compared to other countries, and our parameter estimates fall well within the range estimated for years before the recession in Germany (Holzner and Launov, 2010; Nanos and Schluter, 2014) and for France in the 1990s (Bontemps et al., 1999). 


\section{References}

Aretz, B., B. Arntz, H. Bonin, S. Butschek, A. Dörr, B. Fitzenberger, T. Gregory, N. Guertzgen, H. Stichnoth, and T. Walter (2013). Vorbereitende Forschung für die zweite Evaluationsrunde Mindestlöhne: Verbesserung und Erweiterung der Evaluationsmethoden. Report for the German Federal Ministry of Labour, ZEW, Mannheim.

Autor, D. H., A. Manning, and C. L. Smith (2016). The contribution of the minimum wage to us wage inequality over three decades: A reassessment. American Economic Journal: Applied Economics 8(1), 58-99.

Bachmann, R. and H. Frings (2017). Monopsonistic competition, low-wage labour markets, and minimum wages - an empirical analysis. Applied Economics 49(51), 5268-5286.

Bauer, T. K., J. Kluve, S. Schaffner, and C. M. Schmidt (2009). Fiscal Effects of Minimum Wages: An Analysis for Germany. German Economic Review 10(2), 224-242.

Bontemps, C., J.-M. Robin, and G. J. Van den Berg (1999). An Empirical Equilibrium Job Search Model With Search on the Job and Heterogeneous Workers and Firms. International Economic Review 40(4), 1039-1074.

Bontemps, C., J.-M. Robin, and G. J. van den Berg (2000). Equilibrium Search with Continuous Productivity Dispersion: Theory and Nonparametric Estimation. International Economic Review 41(2), 305-358.

Boockmann, B., R. Krumm, M. Neumann, and P. Rattenhuber (2013). Turning the Switch: An Evaluation of the Minimum Wage in the German Electrical Trade Using Repeated Natural Experiments. German Economic Review 14(3), 316-348.

Bossler, M. and H.-D. Gerner (2016). Employment Effects of the New German Minimum Wage. Discussion Paper 10/2016, IAB, Nuremberg.

Breda, T., L. Haywood, and H. Wang (2016). Labor market responses to taxes and minimum wage policies. Unpublished work, Paris School of Economics and DIW Berlin.

Bundesagentur für Arbeit (2017). Arbeitsmarkt 2016. Amtliche Nachrichten der Bundesagentur für Arbeit 64. Jahrgang, Sondernummer 2, Bundesagentur für Arbeit.

Caliendo, M., A. Fedorets, M. Preuss, C. Schröder, and L. Wittbrodt (2017). The Short-Run Employment Effects of the German Minimum Wage Reform. Discussion Paper 11190, IZA, Bonn.

Engbom, N. and C. Moser (2017). Earnings inequality and the minimum wage: Evidence from Brazil. CESifo Working Paper 6393, ifo, Munich.

Fitzenberger, B., A. Osikominu, and R. Völter (2006). Imputation Rules to Improve the Education Variable in the IAB Employment Subsample. Schmollers Jahrbuch 126(3), 405-436. 
Flinn, C. J. (2006). Minimum Wage Effects on Labor Market Outcomes under Search, Matching, and Endogenous Contact Rates. Econometrica 74(4), 1013-1062.

Frings, H. (2013). The Employment Effect of Industry-Specific, Collectively Bargained Minimum Wages. German Economic Review 14(3), 258-281.

Garloff, A. (2016). Side Effects of the New German Minimum Wage on (Un)Employment: First Evidence from Regional Data. Discussion Paper 31/2016, IAB, Nuremberg.

Gartner, H. (2005). The imputation of wages above the contribution limit with the German IAB employment sample. FDZ Methodenreport 2/2005, Bundesagentur für Arbeit.

Gregory, T. (2014). When the minimum wage bites back: Quantile treatment effects of a sectoral minimum wage in germany. Discussion Paper 14133, ZEW.

Holzner, C. and A. Launov (2010). Search equilibrium and social and private returns to education. European Economic Review 54(1), 39-59.

Knabe, A. and R. Schöb (2009). Minimum Wage Incidence: The Case for Germany. FinanzArchiv: Public Finance Analysis 65 (4), 403-441.

König, M. and J. Möller (2009). Impacts of minimum wages: a microdata analysis for the German construction sector. International Journal of Manpower 30(7), 716-741.

Lancaster, T. (1990). The Econometric Analysis of Transition Data. Cambridge; New York: Cambridge University Press.

Lee, S. and R. A. Wilke (2009). Reform of unemployment compensation in Germany: A nonparametric bounds analysis using register data. Journal of Business 85 Economic Statistics 27(2), 193-205.

Manning, A. (2003). Monopsony in Motion: Imperfect Competition in Labour Markets. Princeton University Press.

Nanos, P. and C. Schluter (2014). The composition of wage differentials between migrants and natives. European Economic Review 65, 23-44.

Ragnitz, J. and M. Thum (2008). Beschäftigungswirkungen von Mindestlöhnen - eine Erläuterung zu den Berechnungen des ifo Instituts. Ifo Schnelldienst 61(01), 16-20.

Shephard, A. (2017). Equilibrium search and tax credit reform. International Economic Review 58(4), 1047-1088.

van den Berg, G. J. (2003, November). Multiple equilibria and minimum wages in labor markets with informational frictions and heterogeneous production technologies. International Economic Review 44(4), 1337-1357.

van den Berg, G. J. and G. Ridder (1998). An empirical equilibrium search model of the labor market. Econometrica 66(5), 1183-1221. 
vom Berge, P., A. Burghardt, and S. Trenkle (2013). Stichprobe der integrierten Erwerbsbiografien. FDZ Datenreport 09/2013, Bundesagentur für Arbeit.

Weber, E. (2016). Effekte der Flüchtlingsversorgung auf den Arbeitskräftebedarf in einzelnen Berufen. Aktuelle Berichte 9/2016, IAB. 


\section{A. Appendix}

\section{A.1. Data Preparation - Data Cleaning and Imputation}

Imputation of Missing Information To maximise the available information, we fill in missing values using the full dataset, i.e. prior to imposing our sample selection criteria. When imputing missing information for the variable nationality, we first use information from parallel spells for the same individual, then information from previous spells and, if there are still missing values, with information from later spells. In a similar manner, we fill in missing information on region, sector, job title, position and employment status with information of previous and following spells but only if individuals stay at the same workplace.

Educational Status Missing and inconsistent data on education are corrected according to the imputation procedure IP1 described in Fitzenberger et al. (2006). This procedure relies, roughly speaking, on the assumption that individuals cannot lose their educational degrees. Information on educational status will be aggregated in three values:

- Low-skilled: High school diploma or no qualifications.

- Medium-skilled: Completed vocational training.

- High-skilled: Technical college degree or university degree.

The final sample used in the analysis consists only of low- and medium-skilled individuals.

\section{A.2. Definition of Labour Market States}

Employment Employment spells include continuous periods of employment (allowing gaps of up to four weeks) subject to social security contributions and (after 1998) marginal employment. For parallel spells of employment and unemployment (e.g. for those individuals who in addition to their earnings receive supplementary benefits), we treat employment as the dominant labour market state. Employment spells during which individuals receive welfare benefits on top of their wage (Aufstocker) are disregarded. It is possible that individuals have multiple employment spells at the same time. In this case, only the predominant employment spell is kept. The predominant spell is determined as follows: full-time spells outrank part-time spells. When choosing between two full-time or two part-time spells, the spell with the longest duration is kept. To break any remaining ties, the spell with the highest wage wins.

Unemployment Unemployment spells include periods of registered job searching as well as periods of receiving benefits. Prior to 2005, the latter include benefits such as unemployment insurance and means-tested unemployment assistance benefits. Those (employable) individuals who were not entitled to unemployment insurance or assistance benefits could claim means-tested social assistance benefits. However, prior to 2005, spells of receiving social assistance can only be observed in the data if the job seekers' history records social assistance recipients as searching for a job. After 2004, means-tested unemployment and social assistance benefits were merged into one unified benefit, known as 'unemployment benefit II' (ALG II). Unemployment spells during which individuals receive ALG II are recorded in the data from 2007 onwards, meaning that the data only provide a consistent definition of unemployment for the period 2007-2010. We therefore restrict our estimation sample to this period. 
Distinction between Un- and Non-Employment Extending the procedure proposed by Lee and Wilke (2009), involuntary unemployment is defined as comprising all continuous periods of registered job searching and/or receipt of benefits. Gaps between such unemployment periods or gaps between receiving benefits or job searching and a new employment spell may not exceed four weeks, otherwise these periods are considered as non-employment spells (involving voluntary unemployment or leaving the social security labour force). Similarly, gaps between periods of employment and receiving benefits or job searching are treated as involuntary unemployment as long as the gap does not exceed six weeks, otherwise the gap is treated as non-employment.

\section{A.3. Data Preparation - Weekly Hours of Work}

While we observe whether an individual works full-time or part-time (defined as working less than 30 hours per week), the data lack explicit information on the number of hours worked. We only look at full-time employees and assign hours of work in the following way:

Main Specification: Imputation We complement the administrative data using the German Microcensus. To calculate hourly wages for full-time employment spells, we impute hours of work based on information from the German Microcensus. The imputation is done separately by region, sex, sector, job classification, and educational degree.

Alternative Specification: 40 Hours for Everyone In a variant, we assume 40 hours of work per week for all individuals in full-time employment.

\section{A.4. Data preparation - Assignment of Wages}

In our data, continuous employment spells may consist of a sequence of different spells with time-varying information of daily wages. To address this issue, we adopt two different variants to assign wages to one continuous employment spell. We also assign part- and full-time status consistent with these rules.

Main Specification: Average over one year We assign the duration-weighted average wage confined to the last observed year for employment spell before and without a transition. For subsequent employment spells, the wage information used is an average daily wage in the first year after the transition. An individual is considered mainly full-time employed, if the weighted average duration of full-time spells over one year exceeds $50 \%$.

Alternative Specification: Last and first observations For employment spells before a transition and employment spells without a transition, the last observed wage is assigned. For subsequent employment spells, the first observed wage is assigned. The last part-/fulltime status is assigned to the previous employment spell, whereas the first part-/full-time status is assigned to any subsequent employment spell.

\section{A.5. Data Preparation - SSC threshold}

Gross daily wages are right-censored at the upper limit for social security contributions.

Main Specification: Exclusion of Censored Observations We do not include observations with censored wages. 
Alternative specification: Imputation To analyse this problem, we construct cells based on gender, year, region (East and West Germany), and educational degree. For each cell, a Tobit regression is estimated with log daily wages as the dependent variable and age, age squared, nationality, experience, experience squared, tenure in the current employment, tenure in the current employment squared, two skill dummies, occupational, sectoral as well as regional (Federal State) dummies and dummies for part-time and full-time employment as explanatory variables. As described in Gartner (2005), right-censored observations are replaced by wages randomly drawn from a truncated normal distribution whose moments are constructed by the predicted values from the Tobit regressions and whose (lower) truncation point is given by the contribution limit to the social security system. After this imputation procedure, nominal wages are deflated by the Consumer Price Index of the Federal Statistical Office Germany, normalised to 1 in 2010.

\section{A.6. Definition of Sub-Samples}

\section{Region}

- East Germany: Former GDR, excluding Berlin

- West Germany, including Berlin

The labour market region of an employed individual is given by the location of the workplace. For the unemployed, we use the region where an individual searches for a job. Where this information is missing, we assign the region of the previous workplace.

\section{Job Classifications}

- Agriculture (Landwirtschaftsberufe)

- Production, Craft (Produktions-/Facharbeiter, Handwerker)

- White-collar (Höhere Angestellte)

- Sales (Vertriebs-/Verkaufstätigkeiten)

- Office (Bürotätigkeiten)

- Service (Dienstleister) 
Table 2: Employment-to-Employment Transitions across Labour Market, Percent

\begin{tabular}{|c|c|c|c|c|c|c|c|c|c|c|c|c|}
\hline \multirow[b]{3}{*}{ Before transition } & \multicolumn{12}{|c|}{ After transition } \\
\hline & $\begin{array}{c}\stackrel{0}{D_{0}^{0}} \\
\stackrel{4}{4} \\
:\end{array}$ & $\begin{array}{r}\dot{0} \\
0 \\
0 \\
0 \\
:\end{array}$ & 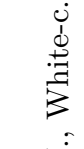 & $\begin{array}{l}\frac{0}{\pi} \\
\text { [N } \\
:\end{array}$ & $\underset{:}{\stackrel{\mathscr{E}}{0}}$ & 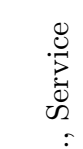 & 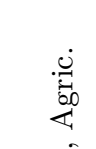 & $\begin{array}{c}\dot{0} \\
0 \\
0\end{array}$ & $\begin{array}{l}\dot{d} \\
\stackrel{d}{d} \\
\stackrel{3}{Z} \\
3\end{array}$ & $\begin{array}{l}\frac{0}{\sigma} \\
\tilde{N} \\
\tilde{N}\end{array}$ & $\stackrel{\mathscr{U}}{\mathscr{G}}$ & 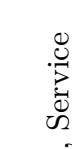 \\
\hline & $B$ & $B$ & $B$ & 3 & $B$ & $B$ & $\overline{\dot{i}}$ & {$[\hat{j}$} & $\hat{\dot{j}}$ & $\overline{\dot{j}}$ & $\overline{\mathrm{j}}$ & Ix \\
\hline W., Agric. & 70.8 & 12.3 & 1.8 & 2.6 & 2.1 & 9.5 & 0.5 & 0.3 & 0.0 & 0.0 & 0.0 & 0.3 \\
\hline W., Prod. & 0.3 & 83.9 & 3.6 & 0.9 & 2.6 & 6.3 & 0.0 & 1.9 & 0.1 & 0.0 & 0.1 & 0.2 \\
\hline W., White-c. & 0.2 & 6.8 & 72.4 & 2.1 & 11.4 & 5.5 & 0.0 & 0.3 & 0.9 & 0.1 & 0.3 & 0.1 \\
\hline W., Sale & 0.3 & 3.6 & 3.3 & 70.5 & 15.1 & 5.4 & 0.0 & 0.1 & 0.1 & 1.2 & 0.4 & 0.0 \\
\hline W., Office & 0.1 & 1.6 & 4.7 & 3.4 & 85.6 & 2.8 & 0.0 & 0.1 & 0.1 & 0.1 & 1.5 & 0.1 \\
\hline W., Service & 0.4 & 8.0 & 2.9 & 1.3 & 4.7 & 80.1 & 0.0 & 0.3 & 0.1 & 0.0 & 0.1 & 2.0 \\
\hline E., Agric. & 7.2 & 1.8 & 0.0 & 0.9 & 0.0 & 0.9 & 67.6 & 10.8 & 1.8 & 0.9 & 0.9 & 7.2 \\
\hline E., Prod. & 0.1 & 11.5 & 0.8 & 0.1 & 0.3 & 1.5 & 0.7 & 75.5 & 3.1 & 0.6 & 1.9 & 3.8 \\
\hline E., White-c. & 0.0 & 2.7 & 9.8 & 0.2 & 2.2 & 1.3 & 0.2 & 5.8 & 65.4 & 1.5 & 7.5 & 3.5 \\
\hline E., Sale & 0.0 & 0.9 & 0.9 & 15.4 & 3.0 & 0.9 & 0.3 & 4.8 & 2.1 & 58.9 & 7.3 & 5.4 \\
\hline E., Office & 0.0 & 0.5 & 1.4 & 0.9 & 12.4 & 0.8 & 0.2 & 2.5 & 2.5 & 1.8 & 73.4 & 3.6 \\
\hline E., Service & 0.1 & 0.8 & 0.4 & 0.1 & 0.9 & 16.0 & 0.5 & 6.7 & 1.6 & 1.3 & 2.5 & 69.1 \\
\hline
\end{tabular}

Note: Of a total of 43,396 employment-to-employment transitions, $95.9 \%$ remain in the same region, $83.4 \%$ remain in the same job classification, and $80.1 \%$ remain in the same region and job classification (labour market).

Table 3: Unemployment-to-Employment Transitions across Labour Market, Percent

\begin{tabular}{|c|c|c|c|c|c|c|c|c|c|c|c|c|}
\hline \multirow{3}{*}{ Before transition } & \multicolumn{12}{|c|}{ After transition } \\
\hline & 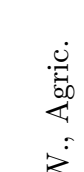 & 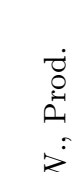 & 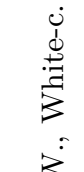 & $\begin{array}{l}\frac{0}{\pi} \\
\tilde{n} \\
\vdots \\
\vdots\end{array}$ & \begin{tabular}{c}
$\stackrel{\mathscr{U}}{\mathscr{E}}$ \\
0 \\
$\vdots$ \\
\hdashline
\end{tabular} & 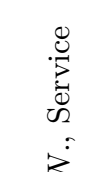 & $\stackrel{\dot{3}}{0}$ & $\begin{array}{l}\text { Dं } \\
\text { D. } \\
.\end{array}$ & $\begin{array}{l}\dot{0} \\
\stackrel{d}{d} \\
\stackrel{.}{Z} \\
\dot{3}\end{array}$ & $\frac{0}{\tilde{\pi}}$ & 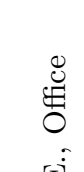 & 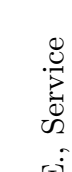 \\
\hline & $s$ & $s$ & 5 & 5 & 5 & 5 & પ્વ & [디 & [디 & [પ工 & 되 & 되 \\
\hline W., Agric. & 78.1 & 11.4 & 0.7 & 1.3 & 2.0 & 5.2 & 1.0 & 0.3 & 0.0 & 0.0 & 0.0 & 0.0 \\
\hline W., Prod. & 0.9 & 82.2 & 2.2 & 1.0 & 2.1 & 8.9 & 0.0 & 2.2 & 0.0 & 0.0 & 0.2 & 0.3 \\
\hline W., White-c. & 0.7 & 15.2 & 43.5 & 3.2 & 20.8 & 13.8 & 0.0 & 0.7 & 1.1 & 0.0 & 0.4 & 0.7 \\
\hline W., Sale & 0.6 & 17.7 & 3.4 & 43.4 & 15.6 & 15.6 & 0.3 & 0.6 & 0.3 & 0.9 & 0.6 & 0.9 \\
\hline W., Office & 0.6 & 9.5 & 6.0 & 5.0 & 66.8 & 10.0 & 0.0 & 0.4 & 0.0 & 0.1 & 1.7 & 0.0 \\
\hline W., Service & 1.1 & 19.7 & 2.7 & 1.7 & 6.7 & 65.1 & 0.0 & 0.8 & 0.1 & 0.1 & 0.2 & 1.9 \\
\hline E., Agric. & 0.5 & 2.1 & 0.0 & 0.0 & 0.5 & 0.5 & 80.0 & 12.1 & 1.1 & 0.0 & 0.5 & 2.6 \\
\hline E., Prod. & 0.0 & 7.5 & 0.1 & 0.3 & 0.3 & 1.6 & 2.1 & 76.5 & 1.8 & 0.7 & 1.6 & 7.6 \\
\hline E., White-c. & 1.0 & 2.9 & 5.8 & 0.0 & 2.9 & 3.9 & 1.0 & 16.5 & 34.0 & 1.0 & 19.4 & 11.7 \\
\hline E., Sale & 1.1 & 3.4 & 1.1 & 14.8 & 5.7 & 4.5 & 1.1 & 18.2 & 1.1 & 34.1 & 5.7 & 9.1 \\
\hline E., Office & 0.0 & 3.6 & 1.8 & 0.6 & 9.6 & 1.8 & 1.2 & 10.8 & 5.4 & 3.6 & 53.9 & 7.8 \\
\hline E., Service & 0.0 & 3.0 & 1.6 & 0.0 & 0.8 & 6.3 & 0.8 & 19.1 & 3.3 & 1.1 & 6.0 & 57.9 \\
\hline
\end{tabular}

Note: Of a total of 8,012 unemployment-to-employment transitions, $95.3 \%$ remain in the same region, $73.7 \%$ remain in the same job classification, and $70.7 \%$ remain in the same region and job classification (labour market). 


\section{A.7. Descriptives}

Table 4: Number of Observations

\begin{tabular}{|c|c|c|c|c|c|c|c|c|c|c|}
\hline \multirow[b]{2}{*}{ Sample } & \multirow[b]{2}{*}{ Total } & \multicolumn{4}{|c|}{ Unemployment Spells } & \multicolumn{5}{|c|}{ Employment Spells } \\
\hline & & Total & $\mathrm{u} \rightarrow \mathrm{e}$ & $\mathrm{rc}$ & lc & Total & $\mathrm{e} \rightarrow \mathrm{e}$ & $\mathrm{e} \rightarrow \mathrm{u}$ & $\mathrm{rc}$ & lc \\
\hline Whole sample & 235,706 & 17,973 & 8,012 & 9,961 & 3,962 & 217,733 & 43,396 & 27,357 & 146,980 & 2,807 \\
\hline \multicolumn{11}{|l|}{ West Germany } \\
\hline Agriculture & 2,685 & 456 & 306 & 150 & 58 & 2,229 & 390 & 382 & 1,457 & 9 \\
\hline Production, Craft & 76,723 & 5,575 & 2,932 & 2,643 & 1,054 & 71,148 & 12,852 & 9,329 & 48,967 & 471 \\
\hline White-collar & 16,943 & 728 & 283 & 445 & 144 & 16,215 & 3,277 & 1,362 & 11,576 & 109 \\
\hline Sales & 10,080 & 1,086 & 327 & 759 & 276 & 8,994 & 2,239 & 1,376 & 5,379 & 42 \\
\hline Office & 46,978 & 2,234 & 906 & 1,328 & 376 & 44,744 & 9,907 & 4,164 & 30,673 & 444 \\
\hline Service & 45,250 & 3,837 & 1,448 & 2,389 & 1,126 & 41,413 & 8,577 & 5,193 & 27,643 & 164 \\
\hline \multicolumn{11}{|l|}{ East Germany } \\
\hline Agriculture & 1,225 & 311 & 190 & 121 & 54 & 914 & 111 & 237 & 566 & 76 \\
\hline Production, Craft & 15,099 & 1,806 & 896 & 910 & 351 & 13,293 & 2,421 & 2,745 & 8,127 & 529 \\
\hline White-collar & 3,081 & 244 & 103 & 141 & 54 & 2,837 & 549 & 330 & 1,958 & 141 \\
\hline Sales & 1,932 & 273 & 88 & 185 & 81 & 1,659 & 331 & 297 & 1,031 & 29 \\
\hline Office & 6,655 & 439 & 167 & 272 & 97 & 6,216 & 1,157 & 717 & 4,342 & 367 \\
\hline Service & 9,055 & 984 & 366 & 618 & 291 & 8,071 & 1,585 & 1,225 & 5,261 & 426 \\
\hline
\end{tabular}

Note: Arrows $(\rightarrow)$ indicate that spells end in transitions to another employment spell (e) or to unemployment (u). Spells without an observed transition are right-censored (rc). Additionally, spells might be left-censored (lc). 
Table 5: Percentage of Spell Types

\begin{tabular}{|c|c|c|c|c|c|c|c|c|c|c|}
\hline \multirow[b]{2}{*}{ Sample } & \multirow[b]{2}{*}{ Total } & \multicolumn{4}{|c|}{ Unemployment Spells } & \multicolumn{5}{|c|}{ Employment Spells } \\
\hline & & Total & $\mathrm{u} \rightarrow \mathrm{e}$ & $\mathrm{rc}$ & lc & Total & $\mathrm{e} \rightarrow \mathrm{e}$ & $\mathrm{e} \rightarrow \mathrm{u}$ & $\mathrm{rc}$ & lc \\
\hline Whole sample & $100.0 \%$ & $7.6 \%$ & $44.6 \%$ & $55.4 \%$ & $22.0 \%$ & $92.4 \%$ & $19.9 \%$ & $12.6 \%$ & $67.5 \%$ & $1.3 \%$ \\
\hline \multicolumn{11}{|l|}{ West Germany } \\
\hline Agriculture & $100.0 \%$ & $17.0 \%$ & $67.1 \%$ & $32.9 \%$ & $12.7 \%$ & $83.0 \%$ & $17.5 \%$ & $17.1 \%$ & $65.4 \%$ & $0.4 \%$ \\
\hline Production, Craft & $100.0 \%$ & $7.3 \%$ & $52.6 \%$ & $47.4 \%$ & $18.9 \%$ & $92.7 \%$ & $18.1 \%$ & $13.1 \%$ & $68.8 \%$ & $0.7 \%$ \\
\hline White-collar & $100.0 \%$ & $4.3 \%$ & $38.9 \%$ & $61.1 \%$ & $19.8 \%$ & $95.7 \%$ & $20.2 \%$ & $8.4 \%$ & $71.4 \%$ & $0.7 \%$ \\
\hline Sales & $100.0 \%$ & $10.8 \%$ & $30.1 \%$ & $69.9 \%$ & $25.4 \%$ & $89.2 \%$ & $24.9 \%$ & $15.3 \%$ & $59.8 \%$ & $0.5 \%$ \\
\hline Office & $100.0 \%$ & $4.8 \%$ & $40.6 \%$ & $59.4 \%$ & $16.8 \%$ & $95.2 \%$ & $22.1 \%$ & $9.3 \%$ & $68.6 \%$ & $1.0 \%$ \\
\hline Service & $100.0 \%$ & $8.5 \%$ & $37.7 \%$ & $62.3 \%$ & $29.3 \%$ & $91.5 \%$ & $20.7 \%$ & $12.5 \%$ & $66.7 \%$ & $0.4 \%$ \\
\hline \multicolumn{11}{|l|}{ East Germany } \\
\hline Agriculture & $100.0 \%$ & $25.4 \%$ & $61.1 \%$ & $38.9 \%$ & $17.4 \%$ & $74.6 \%$ & $12.1 \%$ & $25.9 \%$ & $61.9 \%$ & $8.3 \%$ \\
\hline Production, Craft & $100.0 \%$ & $12.0 \%$ & $49.6 \%$ & $50.4 \%$ & $19.4 \%$ & $88.0 \%$ & $18.2 \%$ & $20.6 \%$ & $61.1 \%$ & $4.0 \%$ \\
\hline White-collar & $100.0 \%$ & $7.9 \%$ & $42.2 \%$ & $57.8 \%$ & $22.1 \%$ & $92.1 \%$ & $19.4 \%$ & $11.6 \%$ & $69.0 \%$ & $5.0 \%$ \\
\hline Sales & $100.0 \%$ & $14.1 \%$ & $32.2 \%$ & $67.8 \%$ & $29.7 \%$ & $85.9 \%$ & $20.0 \%$ & $17.9 \%$ & $62.1 \%$ & $1.7 \%$ \\
\hline Office & $100.0 \%$ & $6.6 \%$ & $38.0 \%$ & $62.0 \%$ & $22.1 \%$ & $93.4 \%$ & $18.6 \%$ & $11.5 \%$ & $69.9 \%$ & $5.9 \%$ \\
\hline Service & $100.0 \%$ & $10.9 \%$ & $37.2 \%$ & $62.8 \%$ & $29.6 \%$ & $89.1 \%$ & $19.6 \%$ & $15.2 \%$ & $65.2 \%$ & $5.3 \%$ \\
\hline
\end{tabular}

Note: Arrows $(\rightarrow)$ indicate that spells end in transitions to another employment spell (e) or to unemployment (u). Spells without an observed transition are right-censored (rc). Additionally, spells might be left-censored (lc). Columns Total Unemployment Spells and Total Employment Spells refer to column Total as 100\%. Columns u $\rightarrow$ e, rc and lc refer to Column Total Unemployment Spells as 100\%. Columns e $\rightarrow$ e, e $\rightarrow$ u , rc and lc refer to Column Total Employment Spells as $100 \%$. 


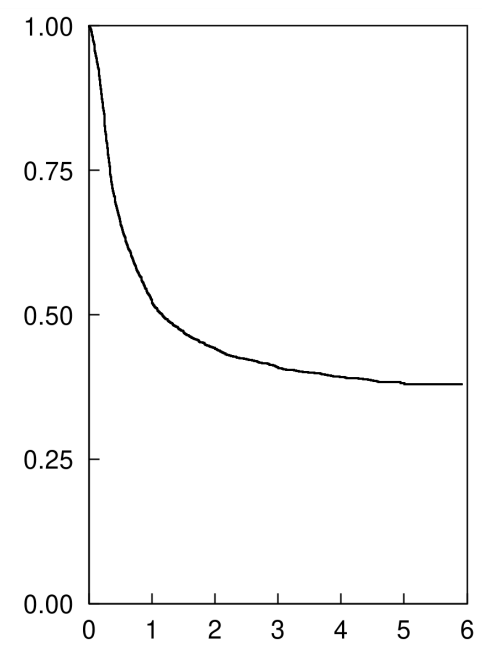

(a) $\mathrm{u} \rightarrow \mathrm{e}$

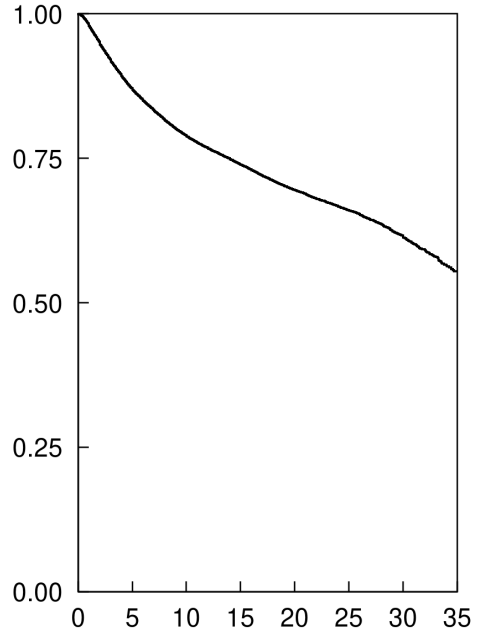

(b) $\mathrm{e} \rightarrow \mathrm{e}$

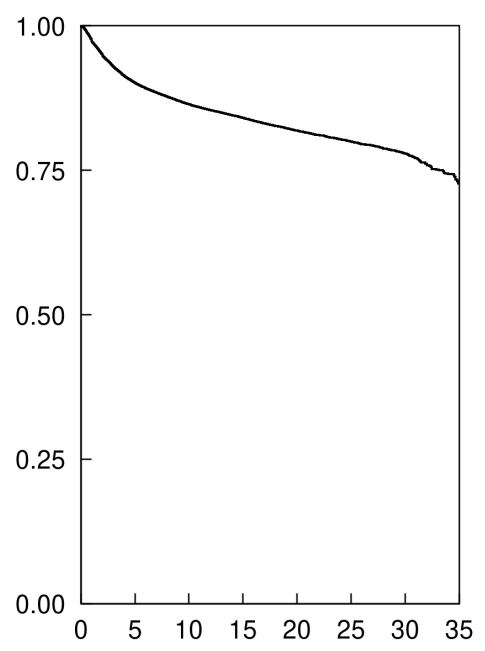

(c) $\mathrm{e} \rightarrow \mathrm{u}$

Note: Plots show Kaplan-Meier survival estimate for durations in years. Arrows $(\rightarrow)$ indicate that spells end in another employment spell (e) or unemployment (u).

Figure 5: Survival Probabilities (Whole Sample) 


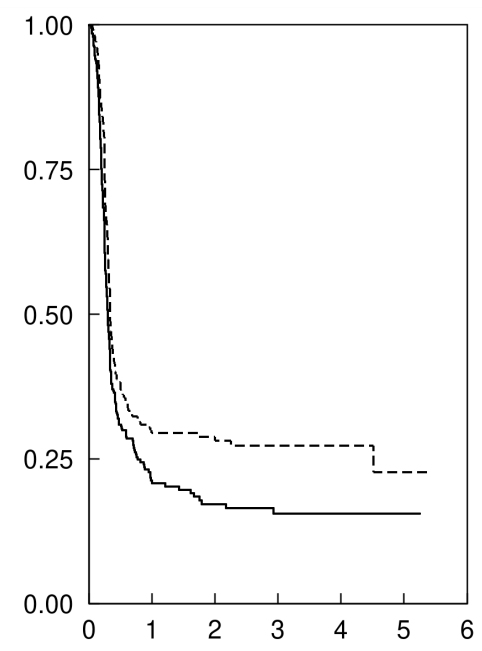

(a) $\mathrm{u} \rightarrow \mathrm{e}$

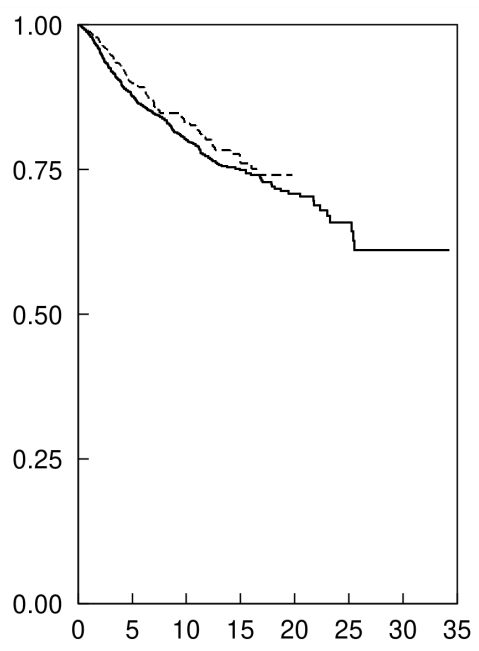

(b) $\mathrm{e} \rightarrow \mathrm{e}$

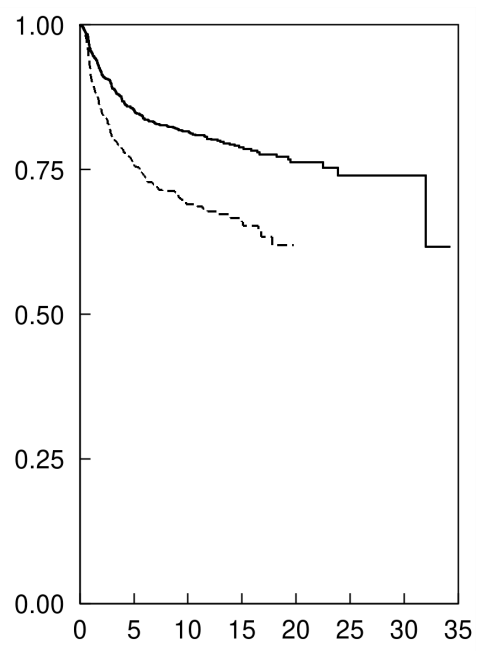

(c) $\mathrm{e} \rightarrow \mathrm{u}$

Key: West (-); East (----). Note: Plots show Kaplan-Meier survival estimate for durations in years. Arrows $(\rightarrow)$ indicate that spells end in another employment spell (e) or unemployment $(u)$.

Figure 6: Survival Probabilities by Region - Agriculture

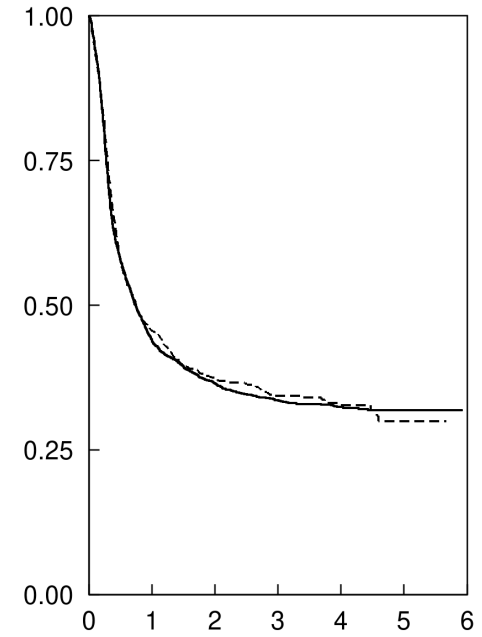

(a) $\mathrm{u} \rightarrow \mathrm{e}$

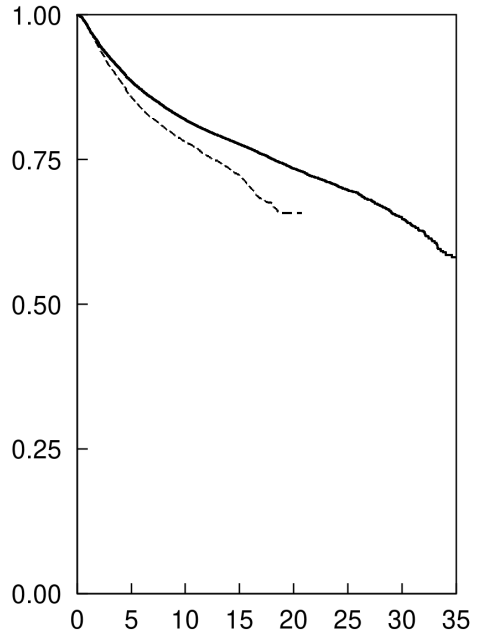

(b) $\mathrm{e} \rightarrow \mathrm{e}$

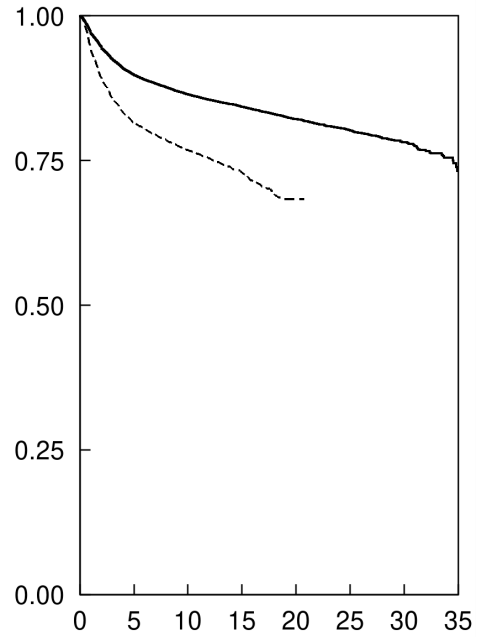

(c) $\mathrm{e} \rightarrow \mathrm{u}$

Key: West (-); East (----). Note: Plots show Kaplan-Meier survival estimate for durations in years. Arrows $(\rightarrow)$ indicate that spells end in another employment spell (e) or unemployment $(\mathrm{u})$.

Figure 7: Survival Probabilities by Region - Production, Craft 


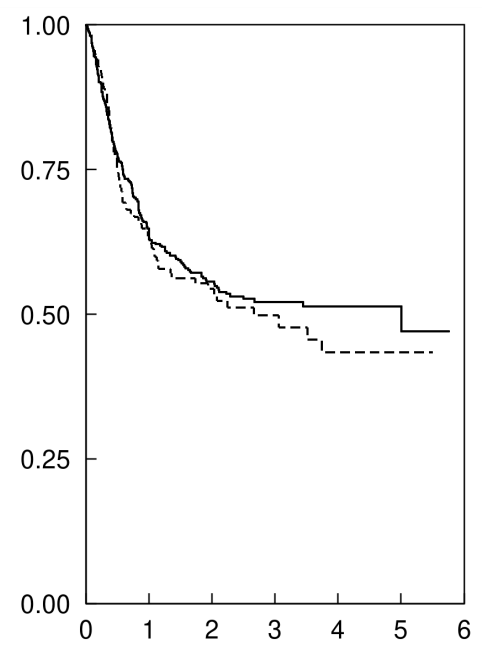

(a) $\mathrm{u} \rightarrow \mathrm{e}$

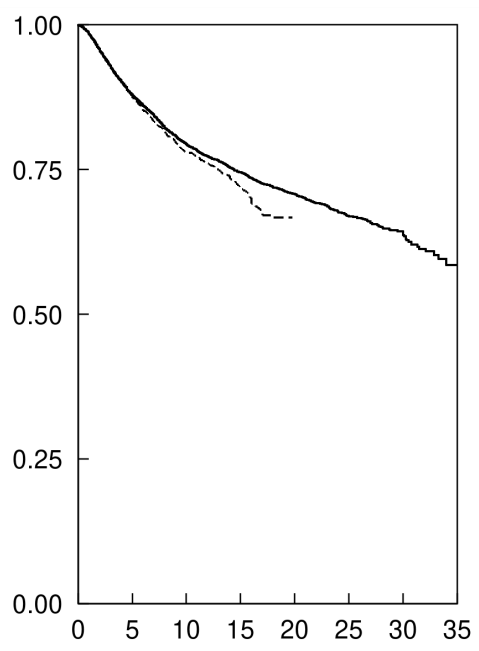

(b) $\mathrm{e} \rightarrow \mathrm{e}$

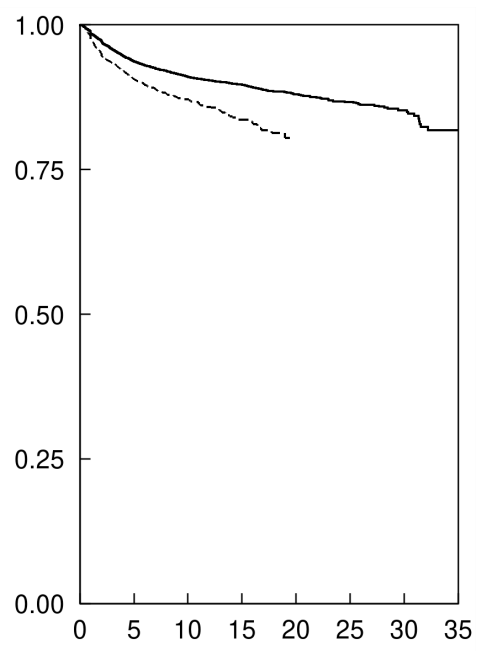

(c) $\mathrm{e} \rightarrow \mathrm{u}$

Key: West (-); East (----). Note: Plots show Kaplan-Meier survival estimate for durations in years. Arrows $(\rightarrow)$ indicate that spells end in another employment spell (e) or unemployment $(u)$.

Figure 8: Survival Probabilities by Region - White-collar

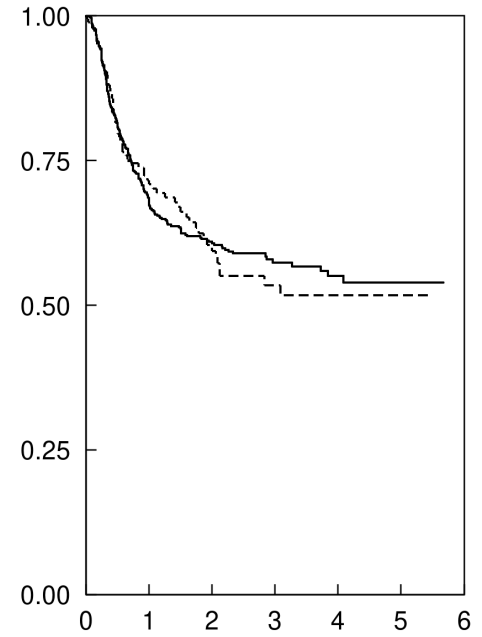

(a) $\mathrm{u} \rightarrow \mathrm{e}$

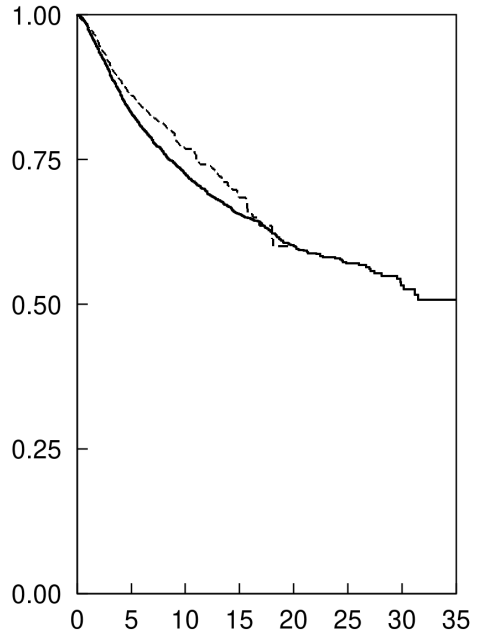

(b) $\mathrm{e} \rightarrow \mathrm{e}$

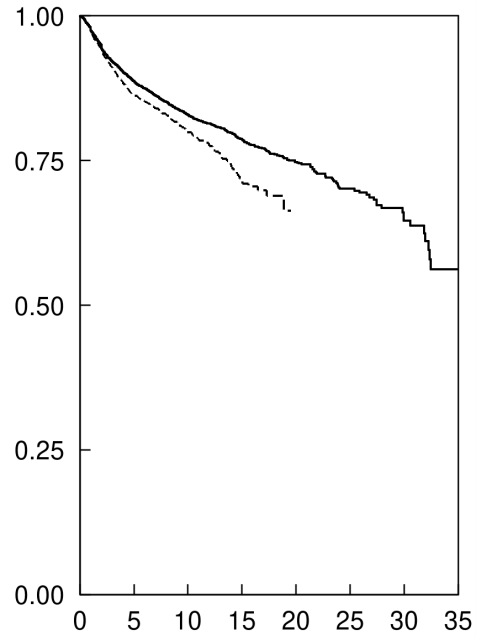

(c) $\mathrm{e} \rightarrow \mathrm{u}$

Key: West (-); East (----). Note: Plots show Kaplan-Meier survival estimate for durations in years. Arrows $(\rightarrow)$ indicate that spells end in another employment spell (e) or unemployment $(\mathrm{u})$.

Figure 9: Survival Probabilities by Region - Sales 


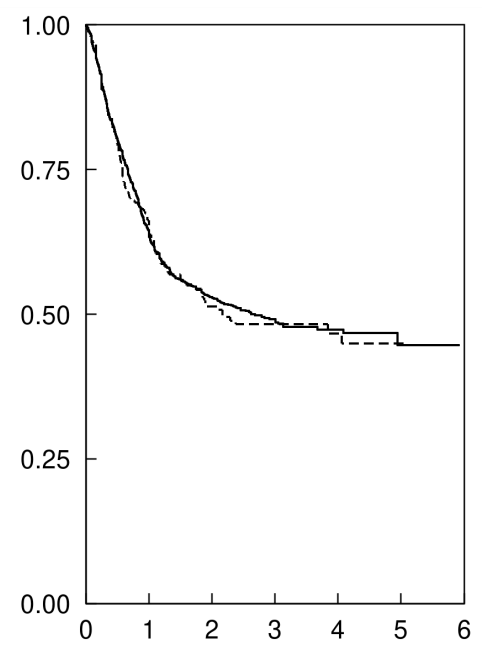

(a) $\mathrm{u} \rightarrow \mathrm{e}$

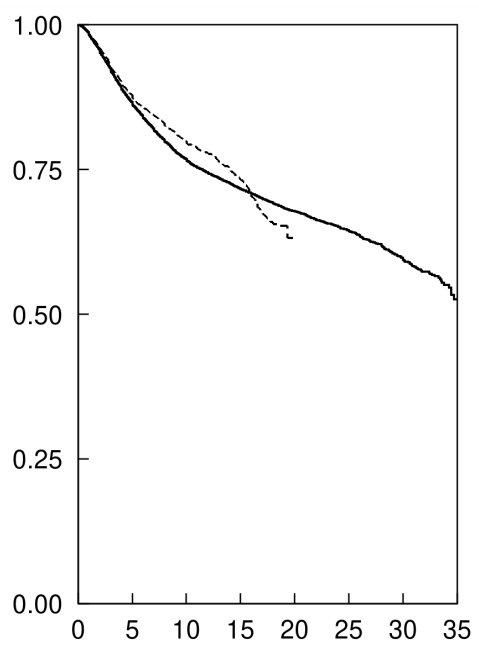

(b) $\mathrm{e} \rightarrow \mathrm{e}$

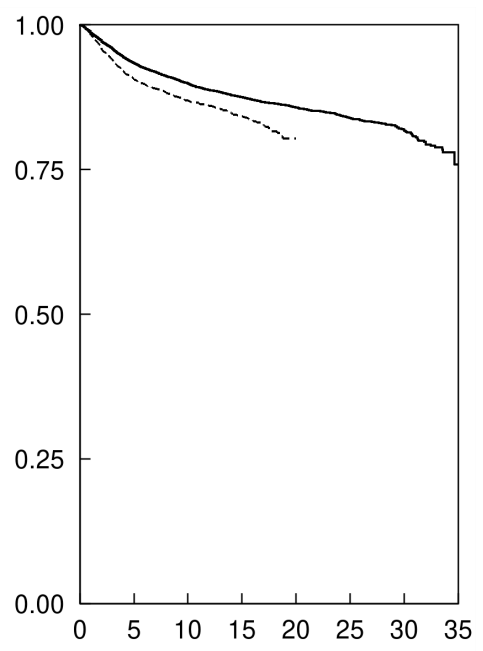

(c) $\mathrm{e} \rightarrow \mathrm{u}$

Key: West (-); East (----). Note: Plots show Kaplan-Meier survival estimate for durations in years. Arrows $(\rightarrow)$ indicate that spells end in another employment spell (e) or unemployment $(\mathrm{u})$.

Figure 10: Survival Probabilities by Region - Office

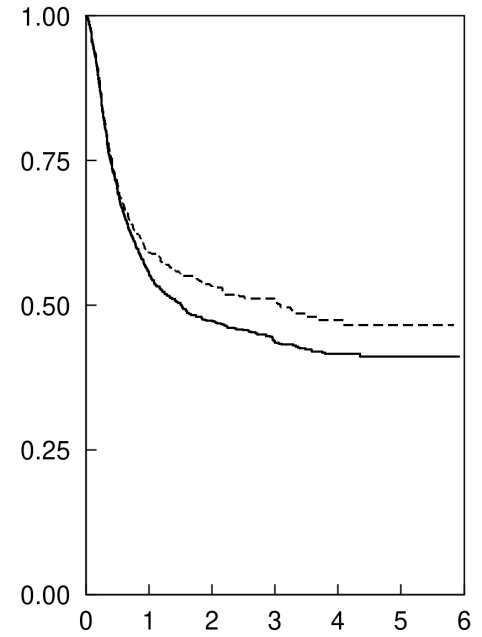

(a) $\mathrm{u} \rightarrow \mathrm{e}$

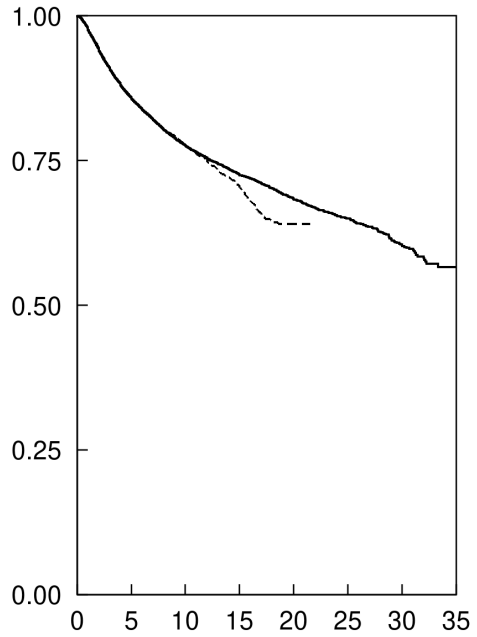

(b) $\mathrm{e} \rightarrow \mathrm{e}$

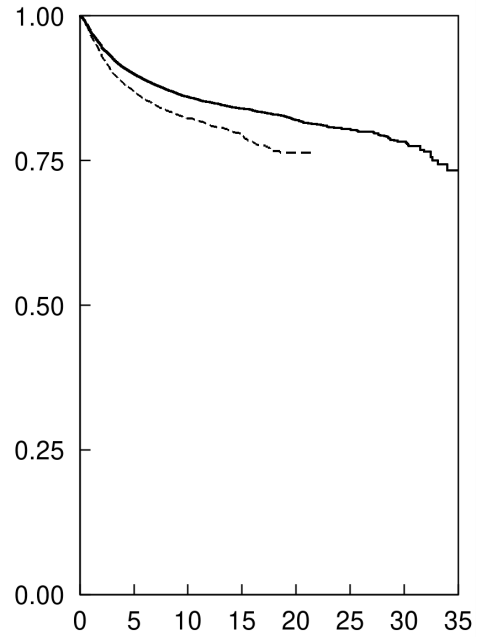

(c) $\mathrm{e} \rightarrow \mathrm{u}$

Key: West (-); East (----). Note: Plots show Kaplan-Meier survival estimate for durations in years. Arrows $(\rightarrow)$ indicate that spells end in another employment spell (e) or unemployment (u).

Figure 11: Survival Probabilities by Region - Service 


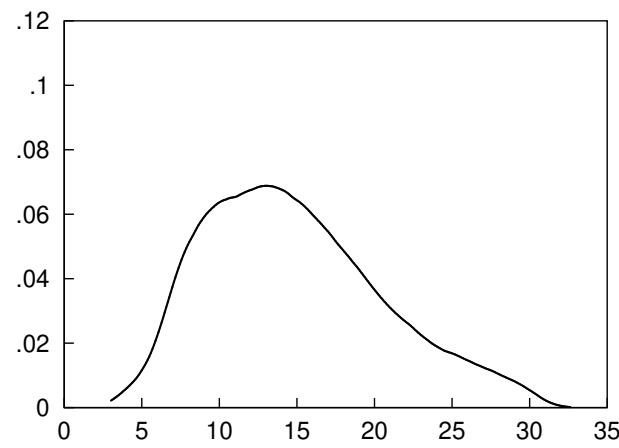

(a) $\mathrm{e} \rightarrow \mathrm{e}$

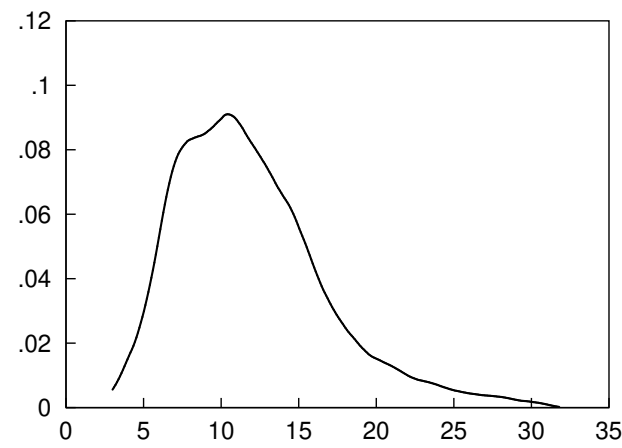

(b) $\mathrm{e} \rightarrow \mathrm{u}$

Panel A - Before Transition

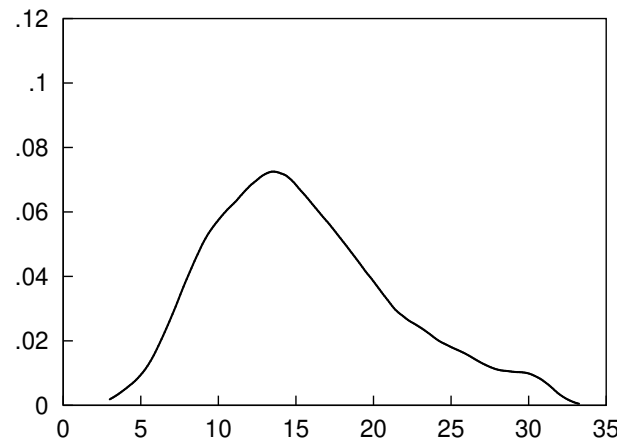

(c) $\mathrm{e} \rightarrow \mathrm{e}$

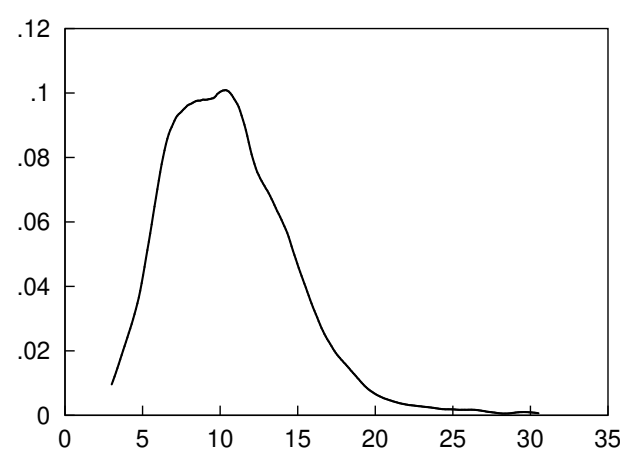

(d) $\mathrm{u} \rightarrow \mathrm{e}$

Panel B - After Transition

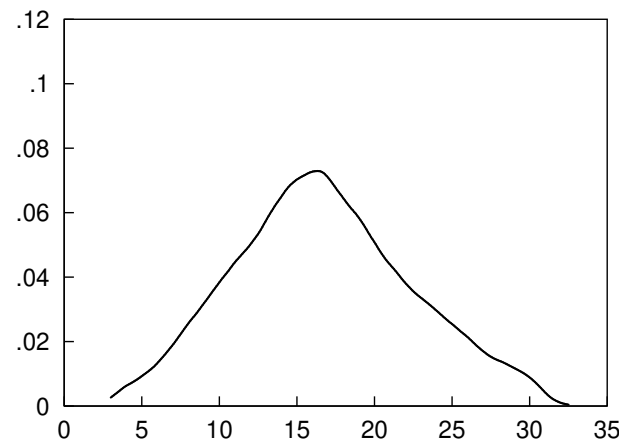

(e) right-censored

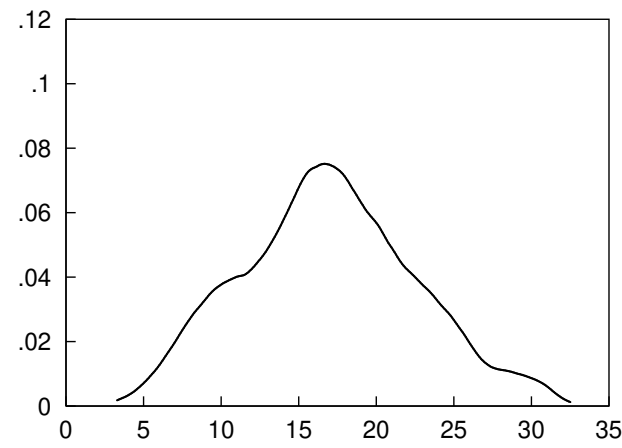

(f) left-censored

Panel C - Censored Spells

Note: Epanechnikov kernel density estimate. Arrows $(\rightarrow$ ) indicate that spells end in another employment spell (e) or unemployment $(\mathrm{u})$. Spells without an observed transition are right-censored. Additionally, spells might be leftcensored.

Figure 12: Density of Hourly Wages (Whole Sample) 


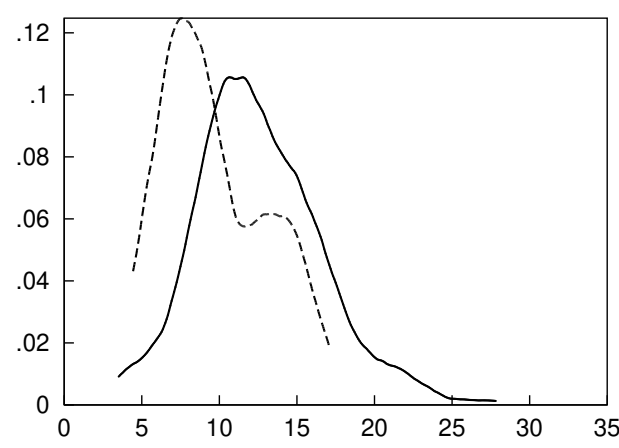

(a) $\mathrm{e} \rightarrow \mathrm{e}$

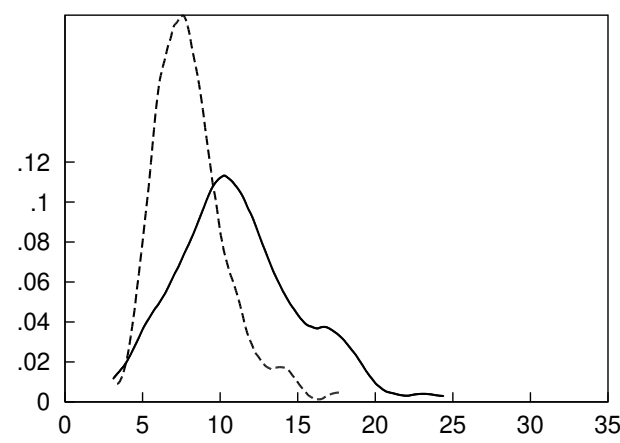

(b) $\mathrm{e} \rightarrow \mathrm{u}$

Panel A - Before Transition

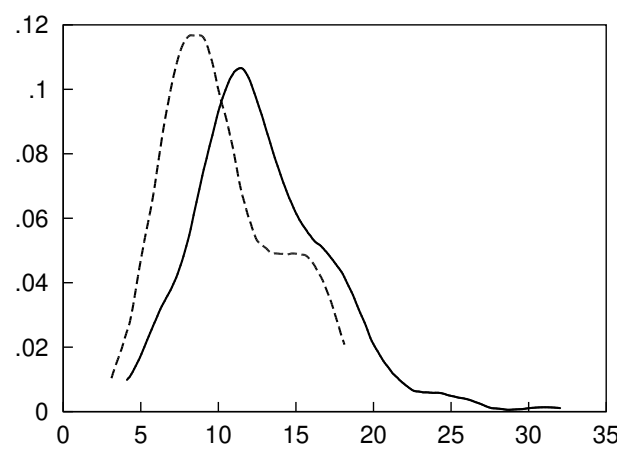

(c) $\mathrm{e} \rightarrow \mathrm{e}$

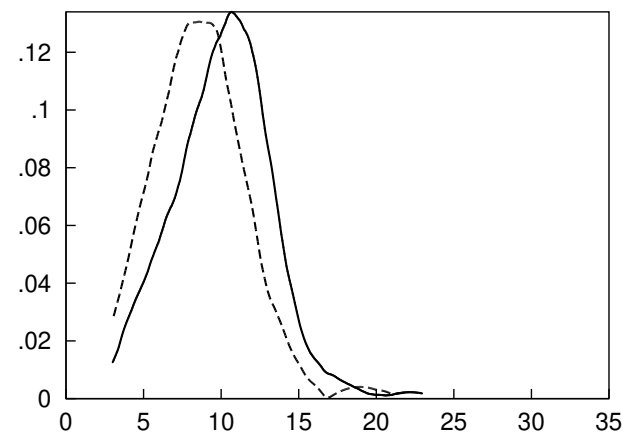

(d) $u \rightarrow e$

Panel B - After Transition

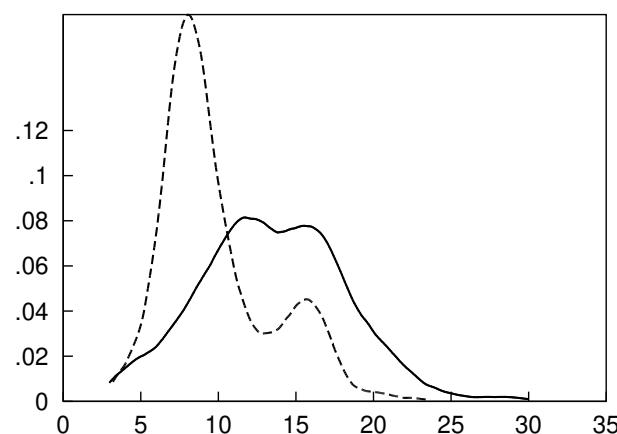

(e) right-censored

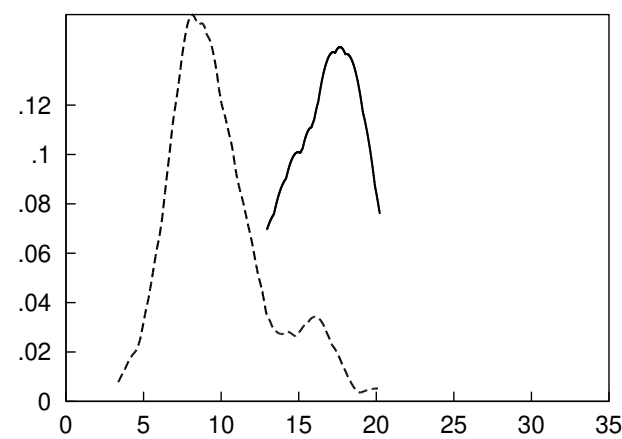

(f) left-censored

\section{Panel C - Censored Spells}

Key: West (-); East (----). Note: Epanechnikov kernel density estimate. Arrows $(\rightarrow)$ indicate that spells end in another employment spell (e) or unemployment (u). Spells without an observed transition are right-censored. Additionally, spells might be left-censored.

Figure 13: Density of Hourly Wages by Region - Agriculture 


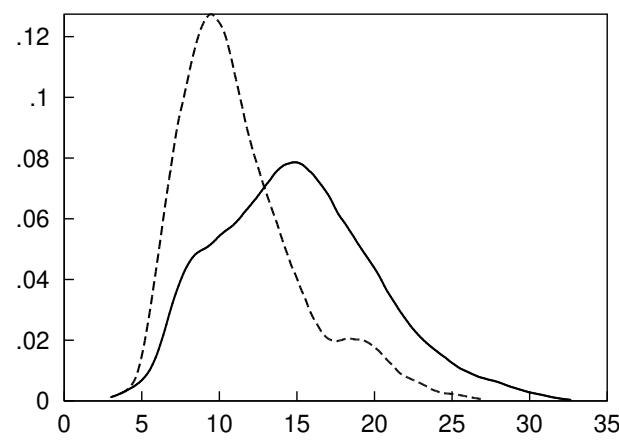

(a) $\mathrm{e} \rightarrow \mathrm{e}$

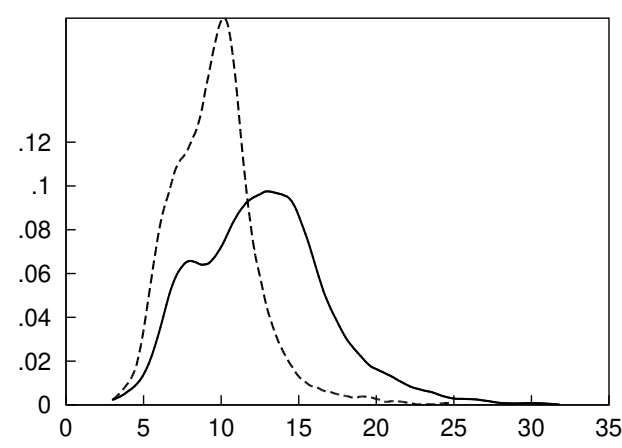

(b) $\mathrm{e} \rightarrow \mathrm{u}$

Panel A - Before Transition

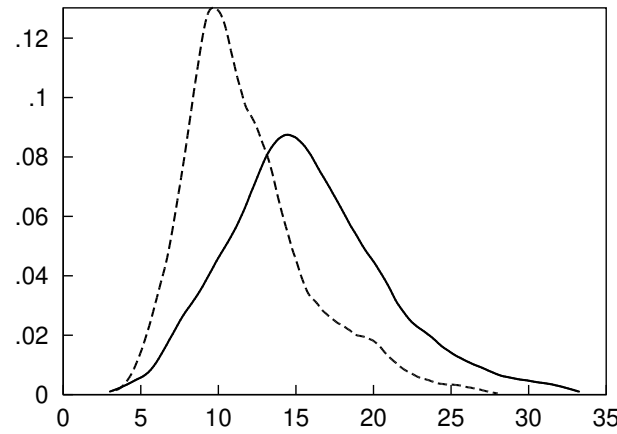

(c) $\mathrm{e} \rightarrow \mathrm{e}$

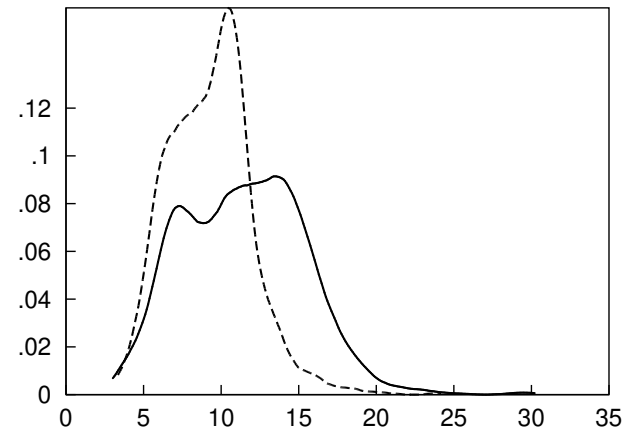

(d) $u \rightarrow e$

Panel B - After Transition

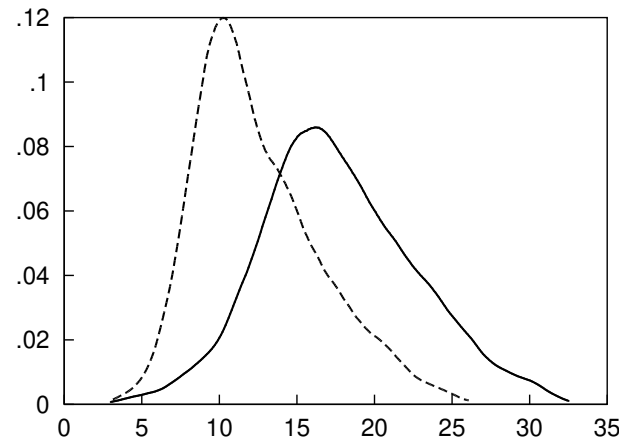

(e) right-censored

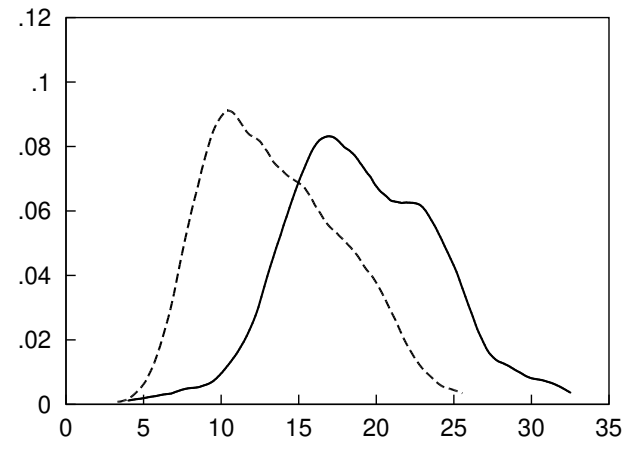

(f) left-censored

Panel C - Censored Spells

Key: West (-); East (----). Note: Epanechnikov kernel density estimate. Arrows $(\rightarrow)$ indicate that spells end in another employment spell (e) or unemployment (u). Spells without an observed transition are right-censored. Additionally, spells might be left-censored.

Figure 14: Density of Hourly Wages by Region - Production, Craft 


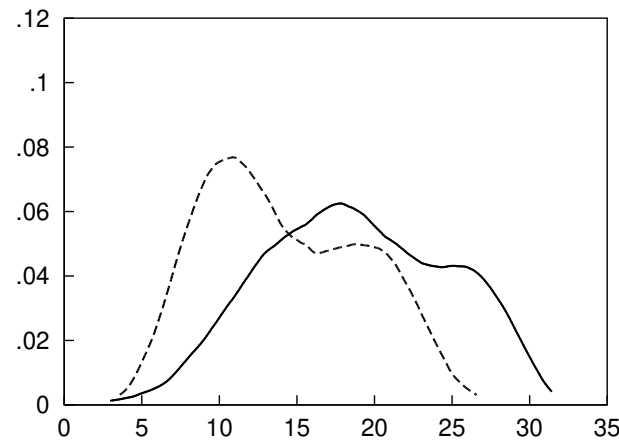

(a) $\mathrm{e} \rightarrow \mathrm{e}$

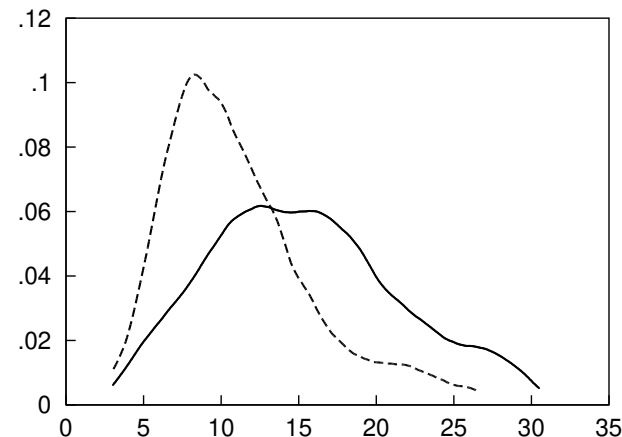

(b) e $\rightarrow \mathrm{u}$

Panel A - Before Transition

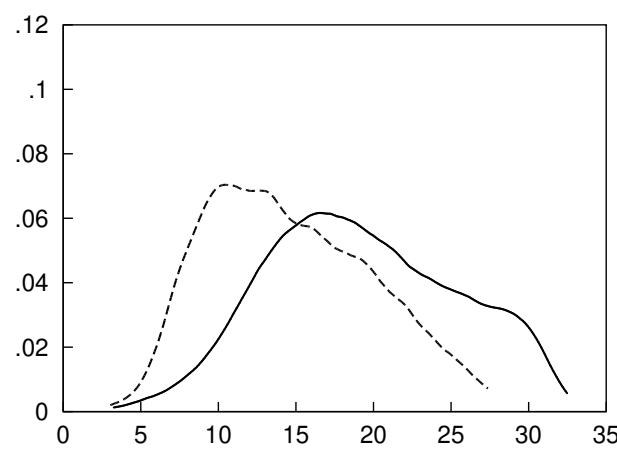

(c) $\mathrm{e} \rightarrow \mathrm{e}$

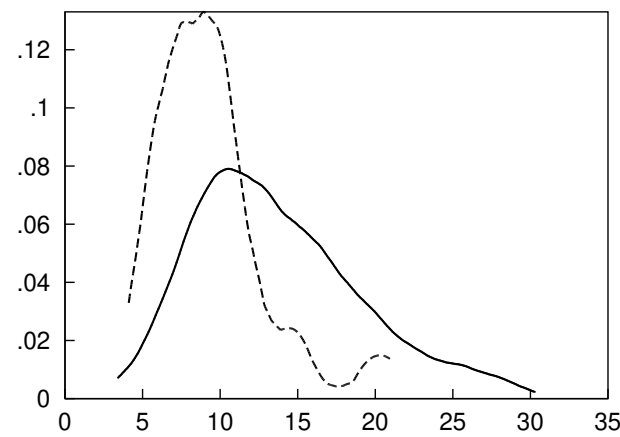

(d) $\mathrm{u} \rightarrow \mathrm{e}$

Panel B - After Transition

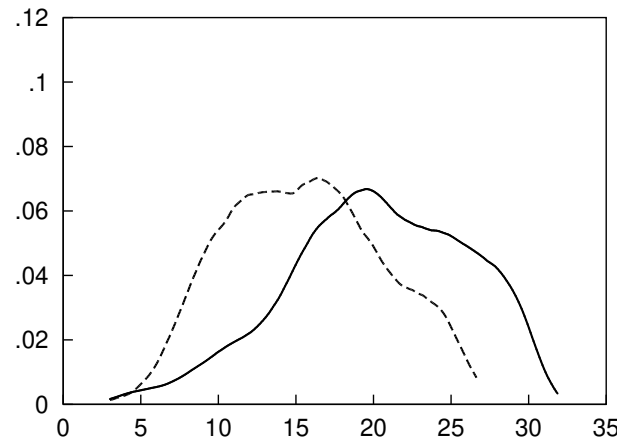

(e) right-censored

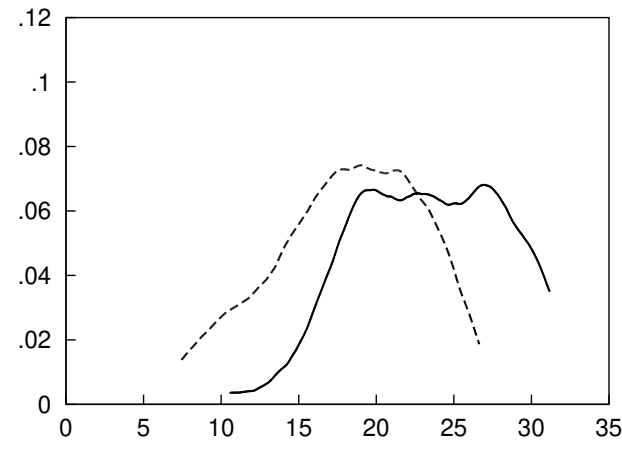

(f) left-censored

Panel C - Censored Spells

Key: West (-); East (----). Note: Epanechnikov kernel density estimate. Arrows $(\rightarrow)$ indicate that spells end in another employment spell (e) or unemployment (u). Spells without an observed transition are right-censored. Additionally, spells might be left-censored.

Figure 15: Density of Hourly Wages by Region - White-collar 


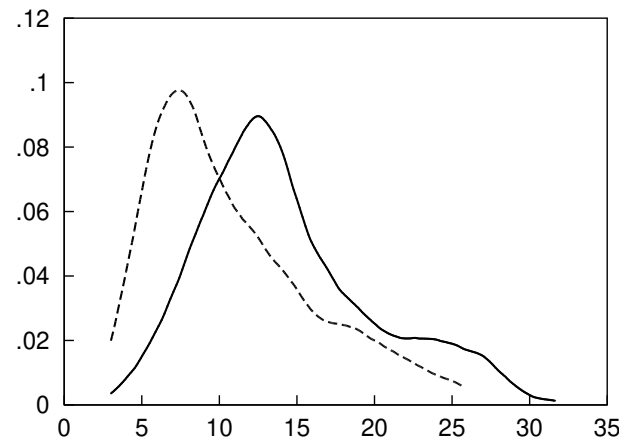

(a) $\mathrm{e} \rightarrow \mathrm{e}$

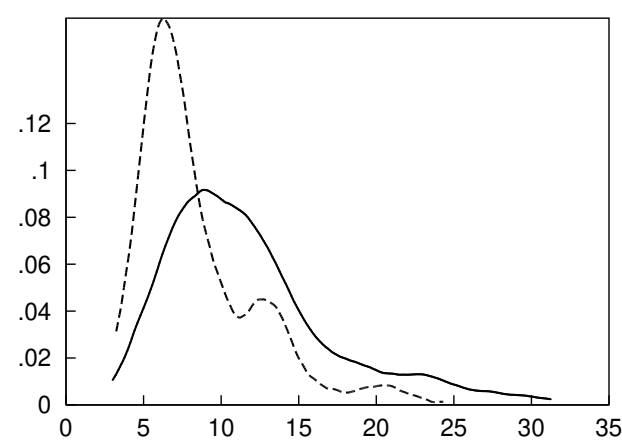

(b) $\mathrm{e} \rightarrow \mathrm{u}$

Panel A - Before Transition

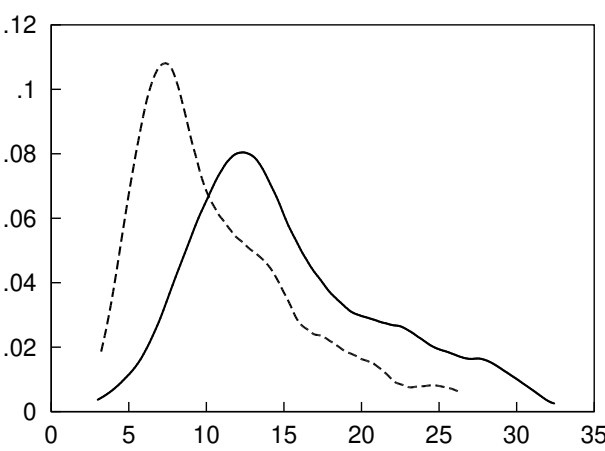

(c) $\mathrm{e} \rightarrow \mathrm{e}$

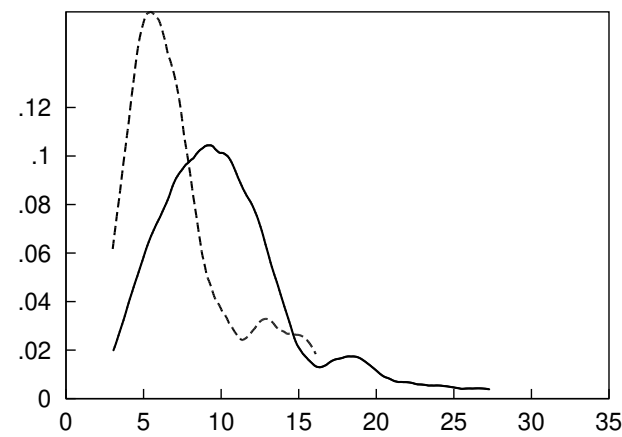

(d) $\mathrm{u} \rightarrow \mathrm{e}$

Panel B - After Transition

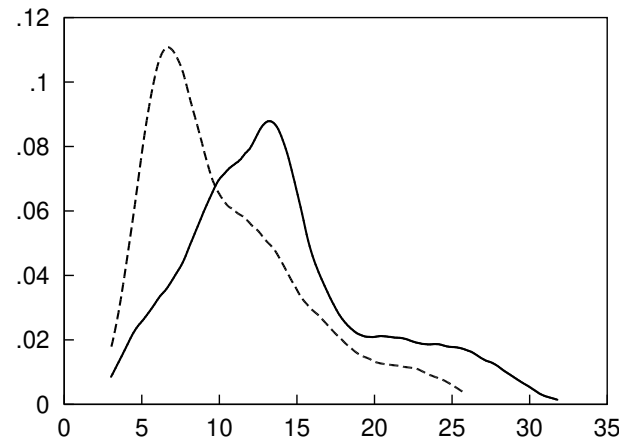

(e) right-censored

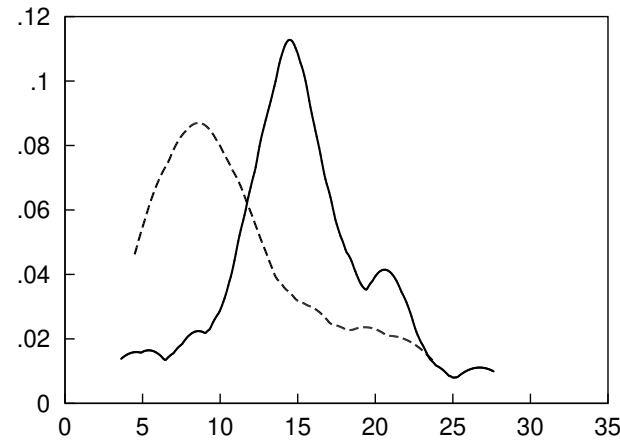

(f) left-censored

Panel C - Censored Spells

Key: West (-); East (----). Note: Epanechnikov kernel density estimate. Arrows $(\rightarrow)$ indicate that spells end in another employment spell (e) or unemployment (u). Spells without an observed transition are right-censored. Additionally, spells might be left-censored.

Figure 16: Density of Hourly Wages by Region - Sales 


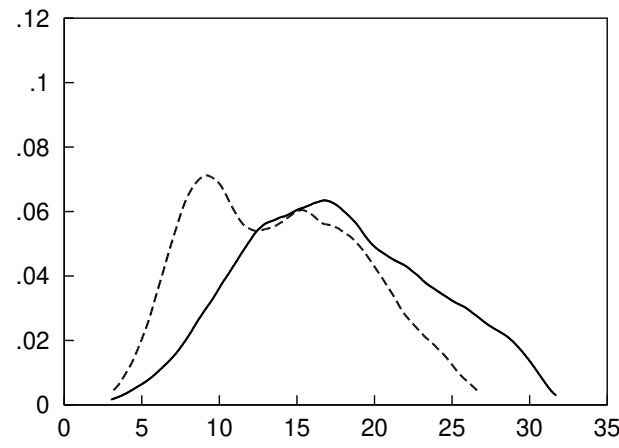

(a) $\mathrm{e} \rightarrow \mathrm{e}$

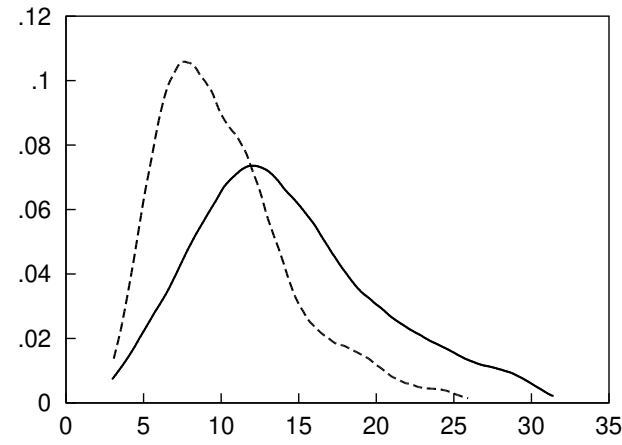

(b) $\mathrm{e} \rightarrow \mathrm{u}$

Panel A - Before Transition

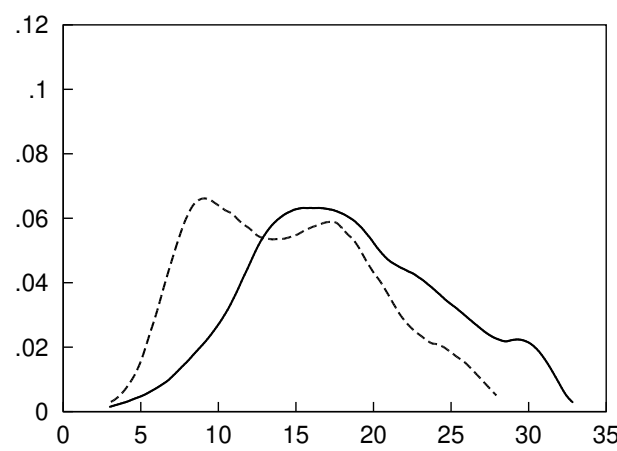

(c) $\mathrm{e} \rightarrow \mathrm{e}$

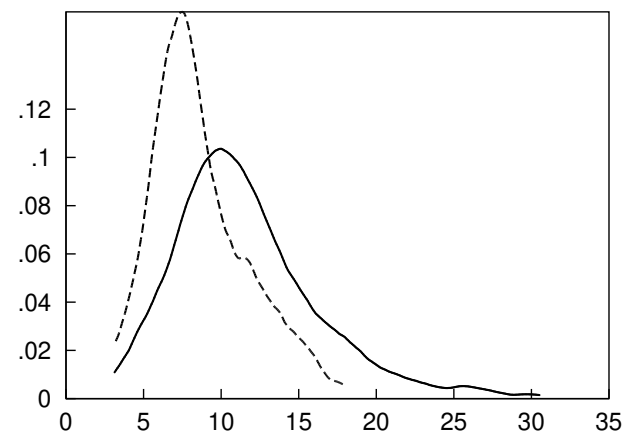

(d) $\mathrm{u} \rightarrow \mathrm{e}$

Panel B - After Transition

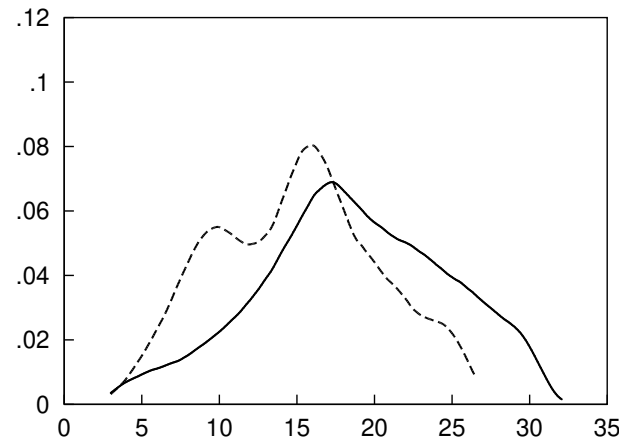

(e) right-censored

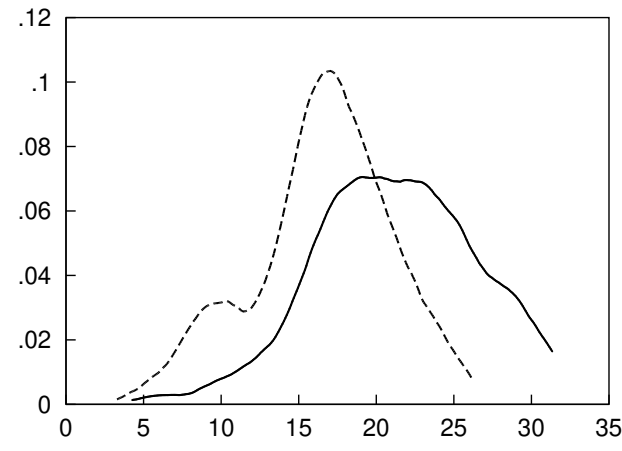

(f) left-censored

Panel C - Censored Spells

Key: West (-); East (----). Note: Epanechnikov kernel density estimate. Arrows $(\rightarrow)$ indicate that spells end in another employment spell (e) or unemployment (u). Spells without an observed transition are right-censored. Additionally, spells might be left-censored.

Figure 17: Density of Hourly Wages by Region - Office 


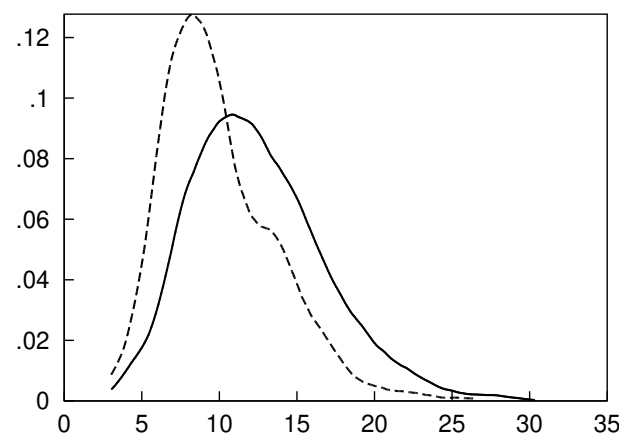

(a) $\mathrm{e} \rightarrow \mathrm{e}$

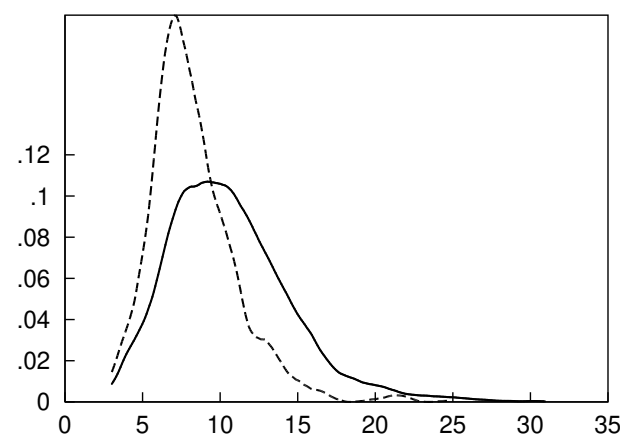

(b) $\mathrm{e} \rightarrow \mathrm{u}$

Panel A - Before Transition

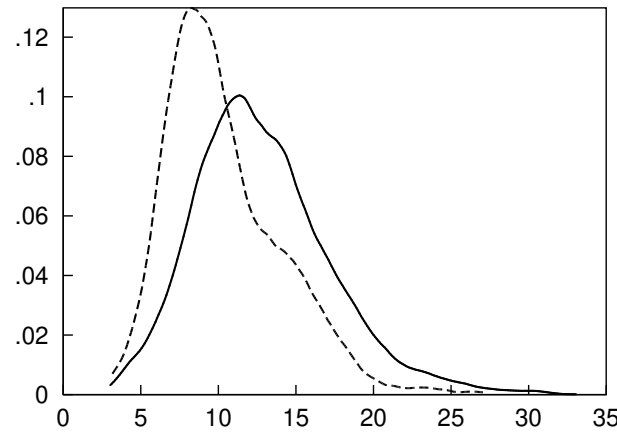

(c) $\mathrm{e} \rightarrow \mathrm{e}$

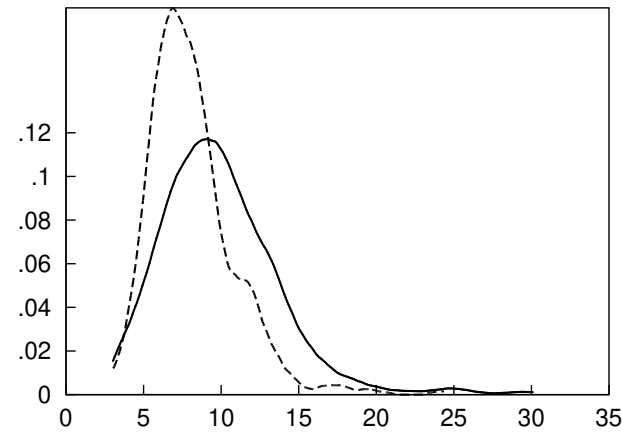

(d) $\mathrm{u} \rightarrow \mathrm{e}$

Panel B - After Transition

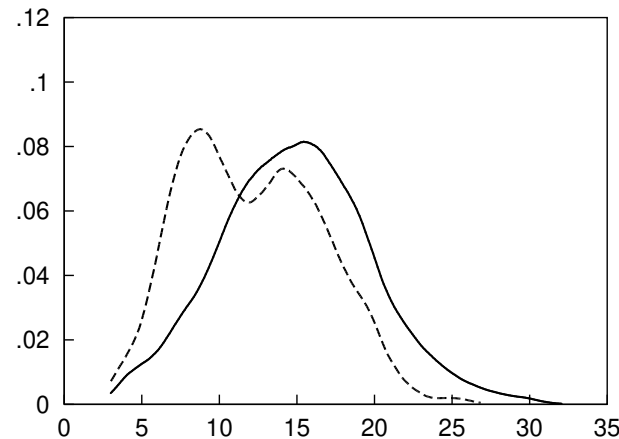

(e) right-censored

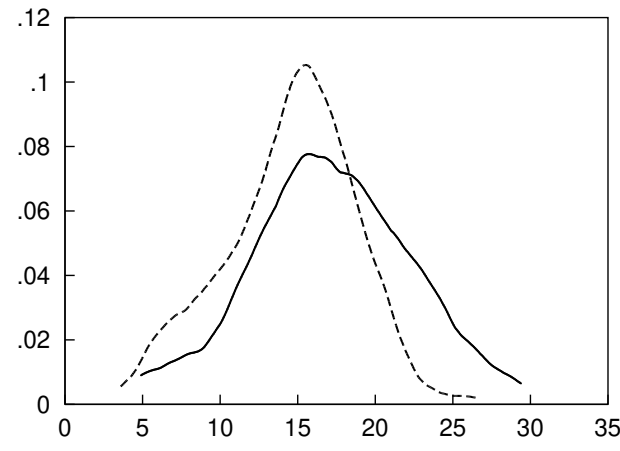

(f) left-censored

\section{Panel C - Censored Spells}

Key: West (-); East (----). Note: Epanechnikov kernel density estimate. Arrows $(\rightarrow)$ indicate that spells end in another employment spell (e) or unemployment (u). Spells without an observed transition are right-censored. Additionally, spells might be left-censored.

Figure 18: Density of Hourly Wages by Region - Service 


\section{A.8. Estimation Results}

Bootstrapping We report bootstrapped standard errors. In very rare cases we exclude bootstrap runs with extreme outliers according to the following criteria: a) If the likelihood does not converge: occurs in 1 of 101 bootstrap runs in Whole sample, in 1 of 101 bootstrap runs in W. Agric., in 12 of 112 bootstrap runs in E. Agric., in 5 of 105 bootstrap runs in E. Sale, in 1 of 101 bootstrap runs in E. Office, in 1 of 101 bootstrap runs in the robustness check with truncation of wages at the 99th percentile, in 1 of 101 bootstrap runs in the robustness check with $\rho=0.002$, in 3 of 103 bootstrap runs in the robustness check with $\rho=0.006$. b) If the estimated job offer arrival rate $\lambda_{1}$ is 100 times higher than the job destruction rate $\delta$ : occurs in 1 of 101 bootstrap runs in E. Serv. 


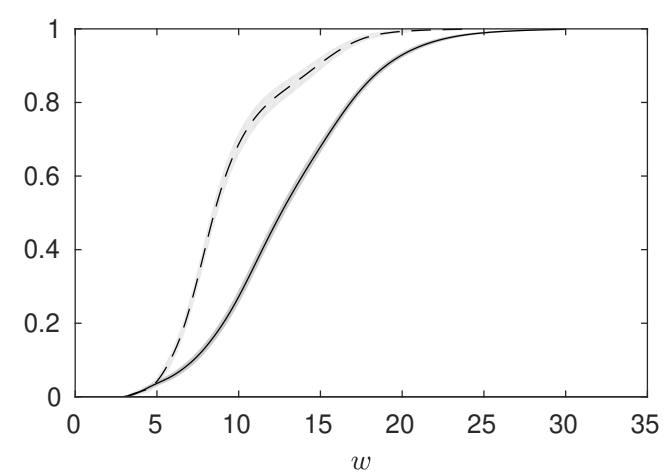

(a) Wage distribution $G(w)$

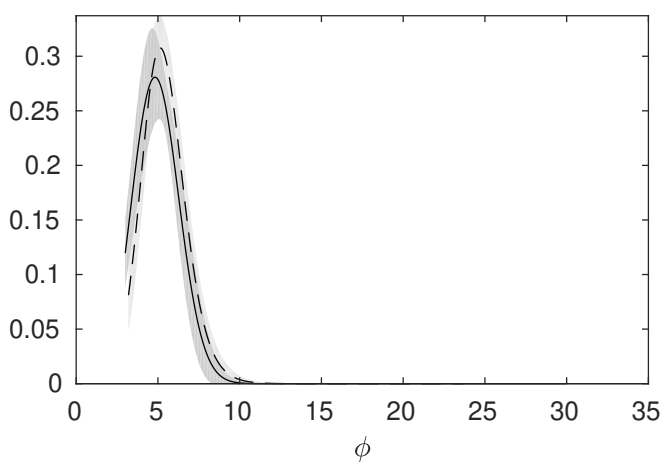

(c) Reservation wage density $A(w)$

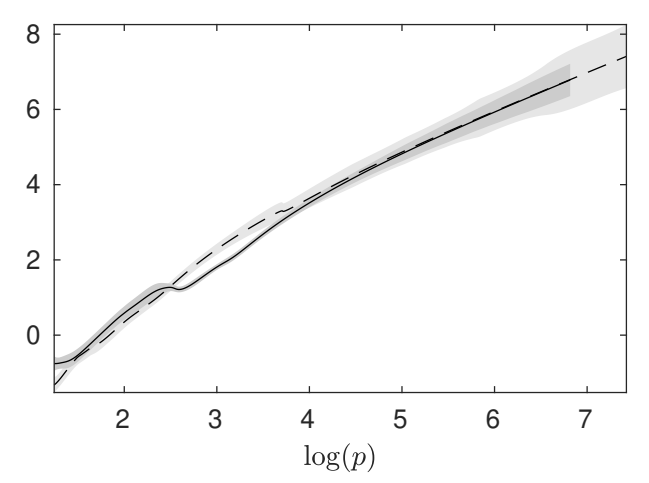

(e) Log absolute markup

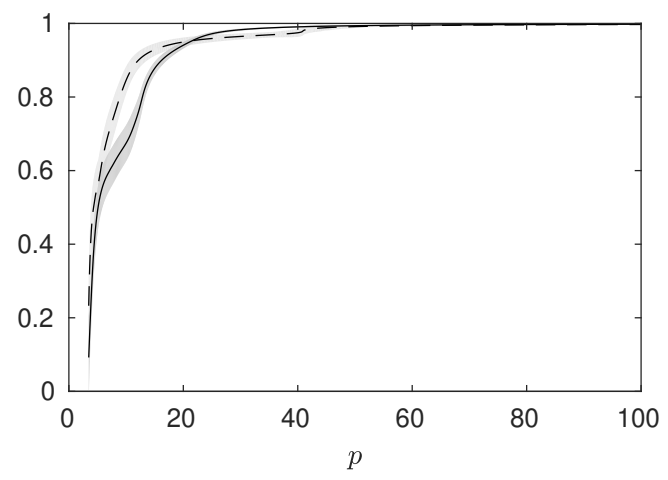

(g) Productivity distribution $\Gamma(p)$

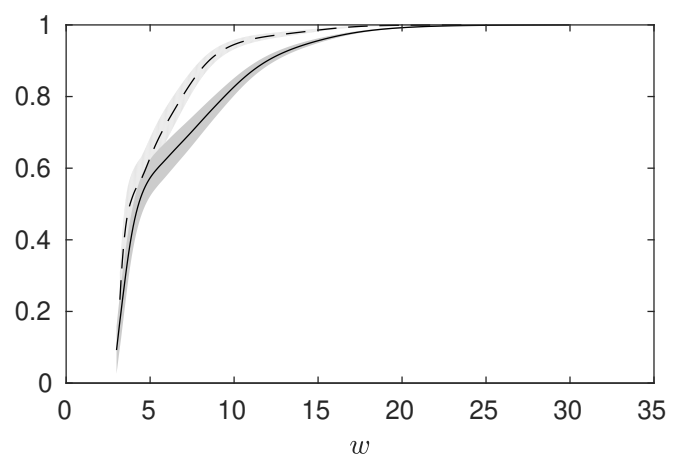

(b) Wage offer distribution $F(w)$

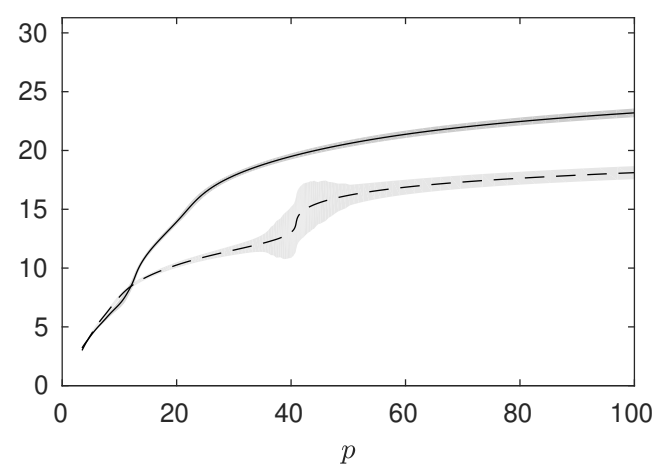

(d) Wage function $K(p)$

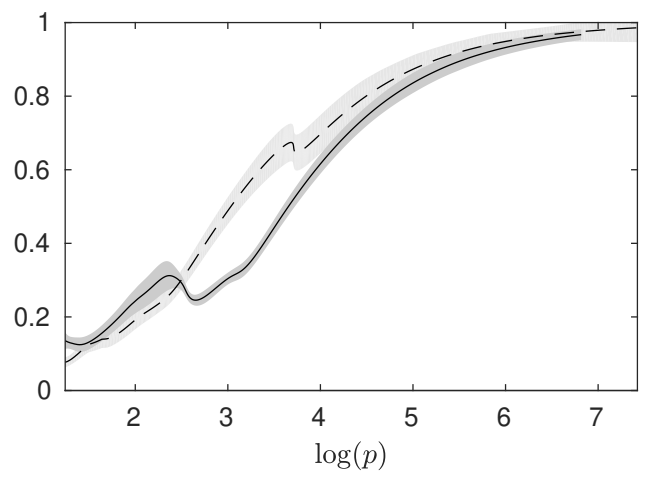

(f) Monopsony power $[p-K(p)] / p$

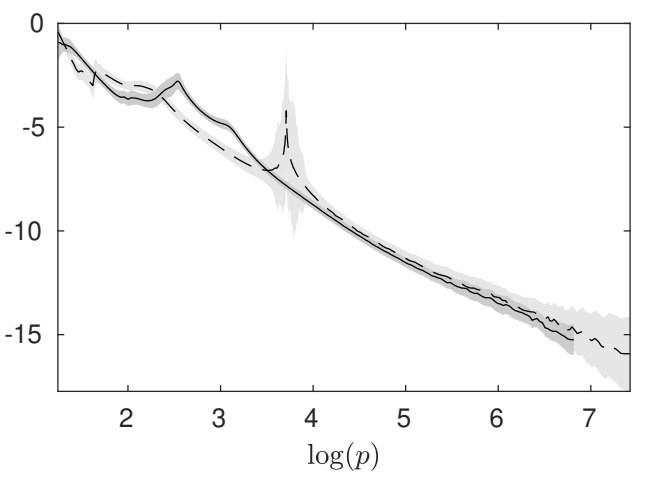

(h) Productivity log density $\log (\gamma(p))$

Key: West (-); East (----). Grey areas indicate 95\% confidence bands.

Figure 19: Main Equilibrium Functions by Region - Agriculture 


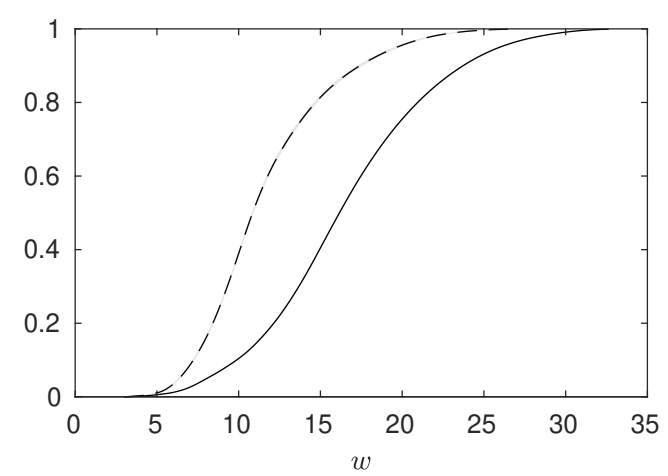

(a) Wage distribution $G(w)$

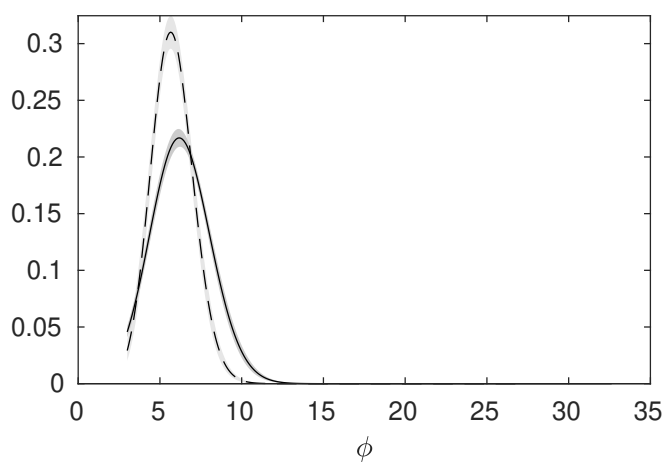

(c) Reservation wage density $A(w)$

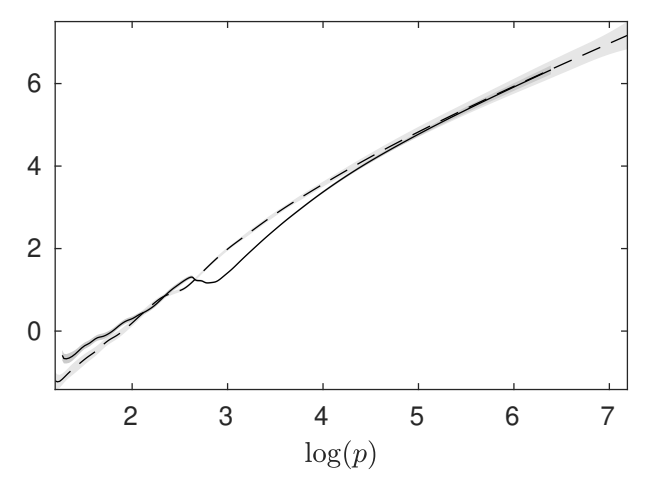

(e) Log absolute markup

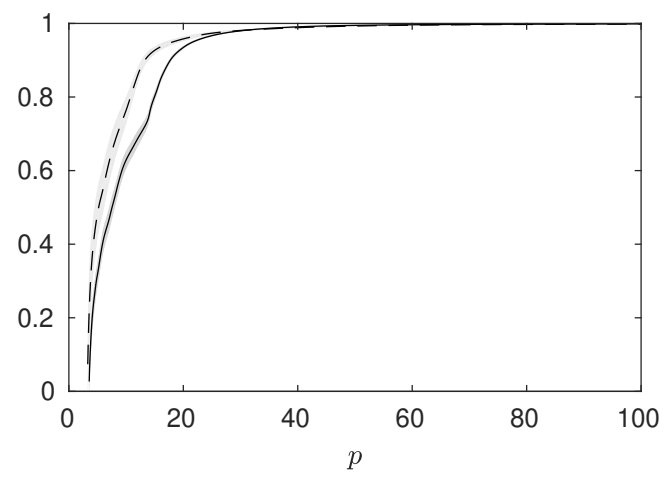

(g) Productivity distribution $\Gamma(p)$

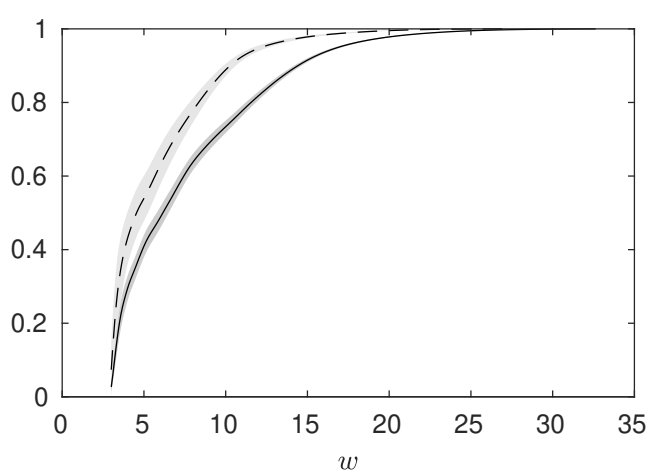

(b) Wage offer distribution $F(w)$

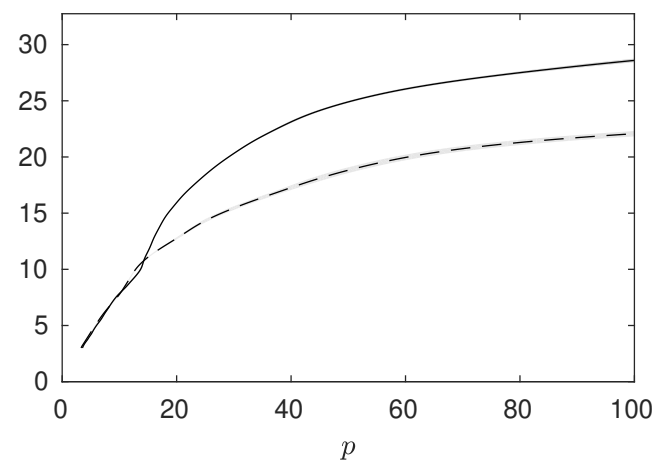

(d) Wage function $K(p)$

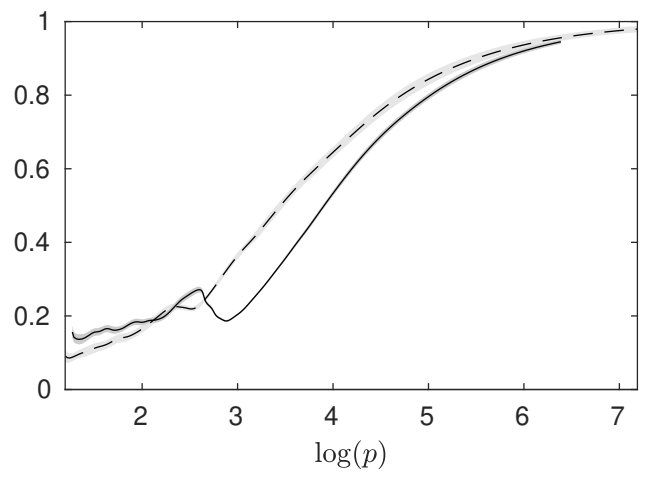

(f) Monopsony power $[p-K(p)] / p$

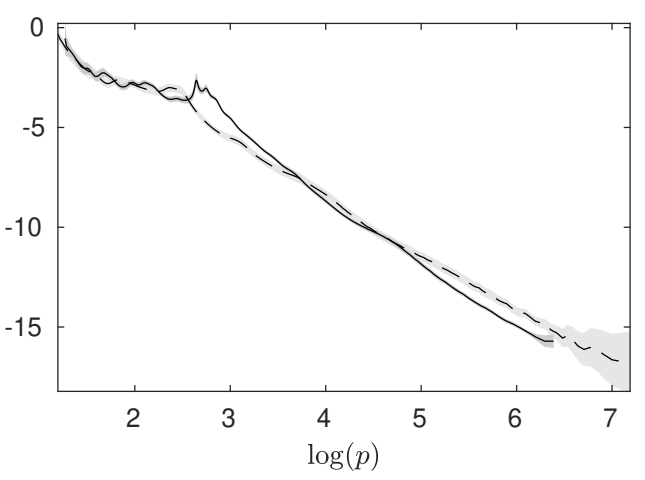

(h) Productivity log density $\log (\gamma(p))$

Key: West (-); East (----). Grey areas indicate $95 \%$ confidence bands.

Figure 20: Main Equilibrium Functions by Region - Production, Craft 


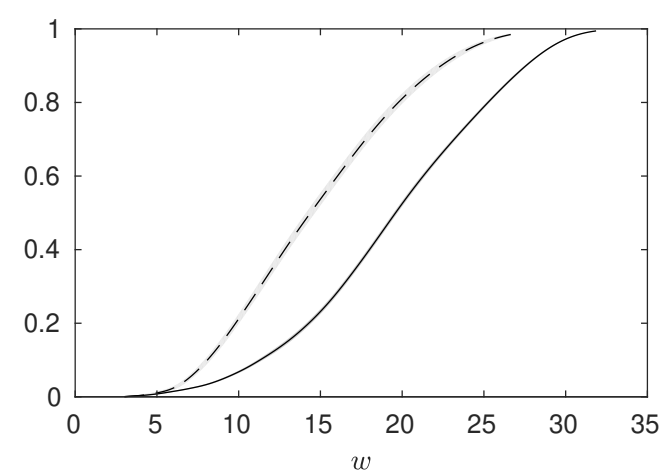

(a) Wage distribution $G(w)$

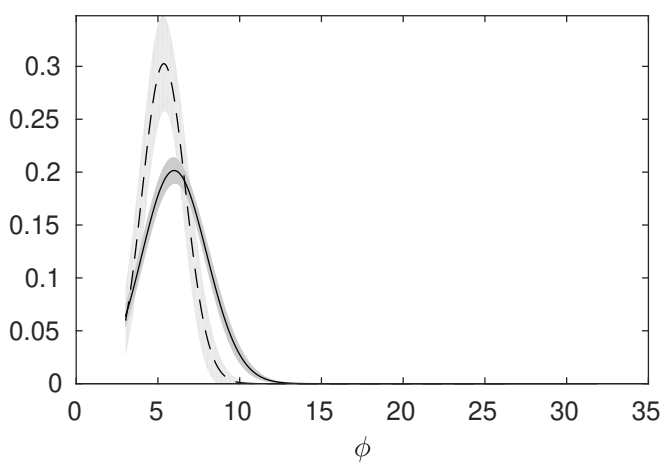

(c) Reservation wage density $A(w)$

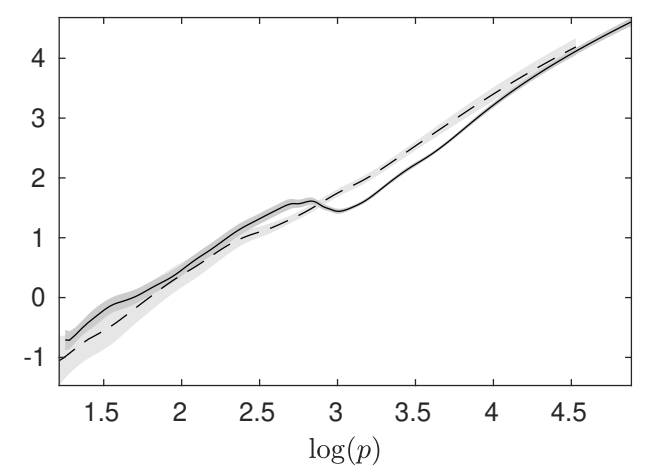

(e) Log absolute markup

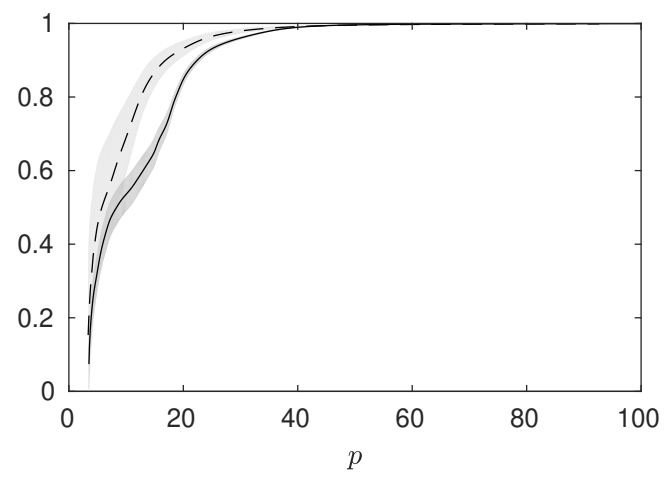

(g) Productivity distribution $\Gamma(p)$

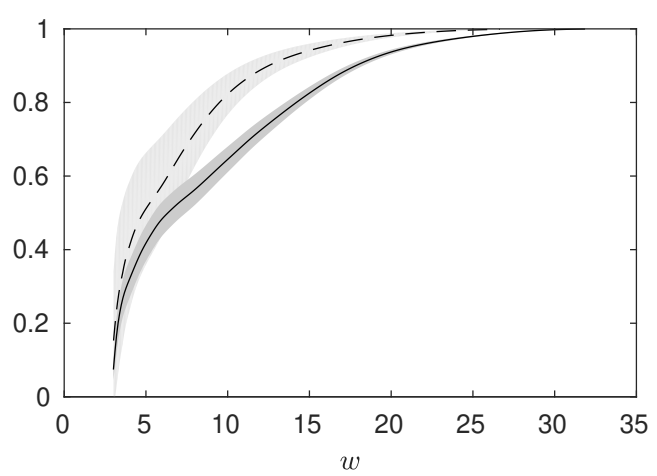

(b) Wage offer distribution $F(w)$

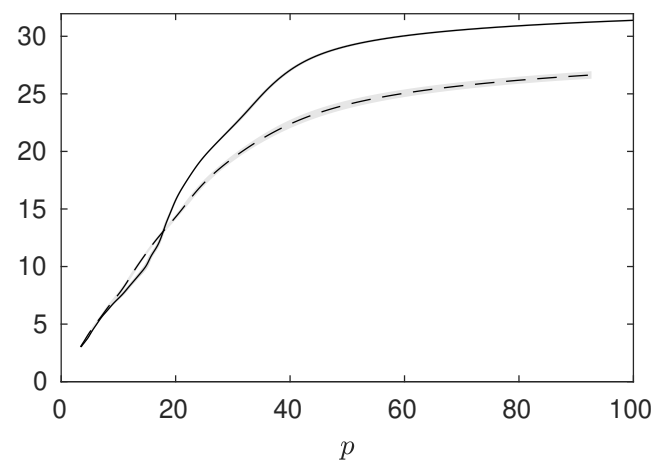

(d) Wage function $K(p)$

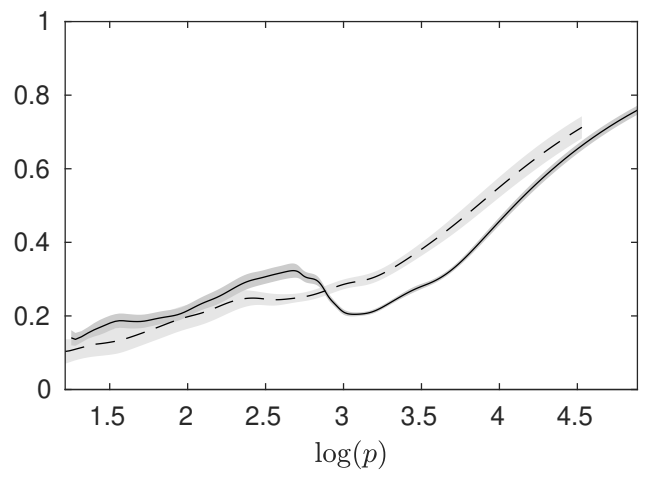

(f) Monopsony power $[p-K(p)] / p$

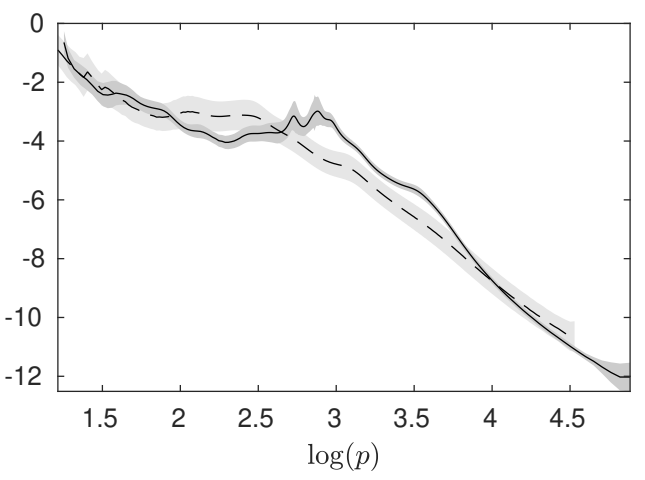

(h) Productivity log density $\log (\gamma(p))$ Key: West (-); East (----). Grey areas indicate $95 \%$ confidence bands.

Figure 21: Main Equilibrium Functions by Region - White-collar 


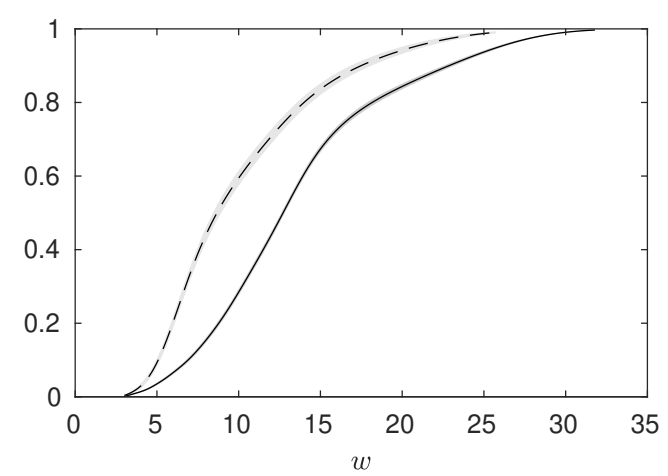

(a) Wage distribution $G(w)$

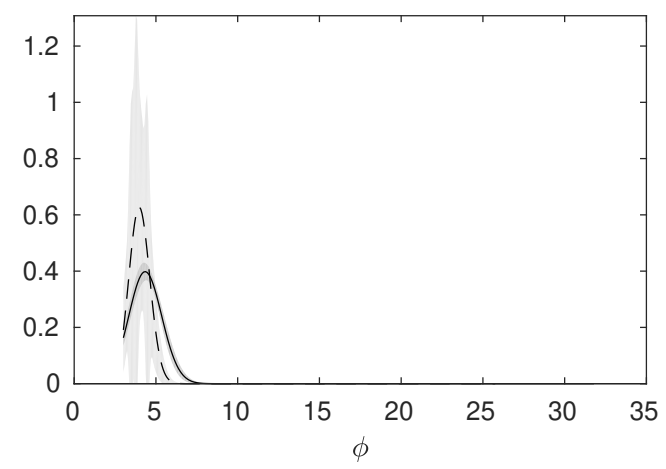

(c) Reservation wage density $A(w)$

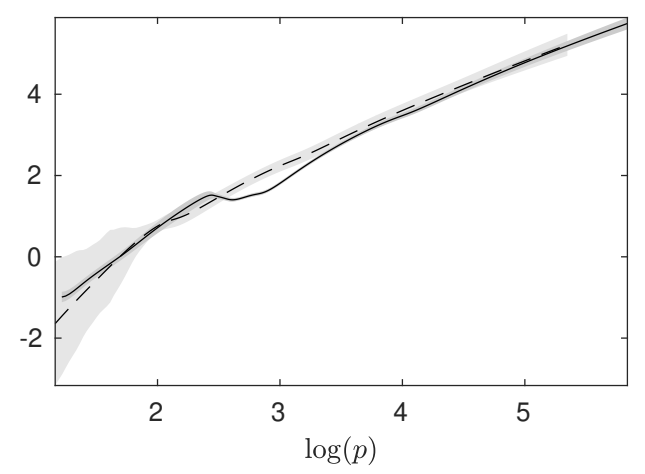

(e) Log absolute markup

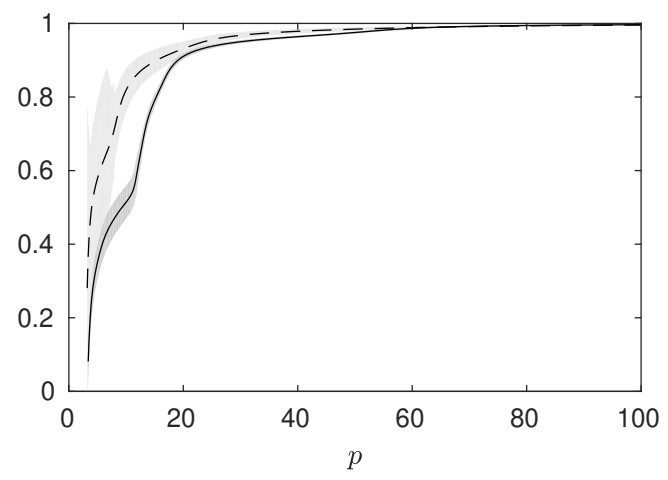

(g) Productivity distribution $\Gamma(p)$

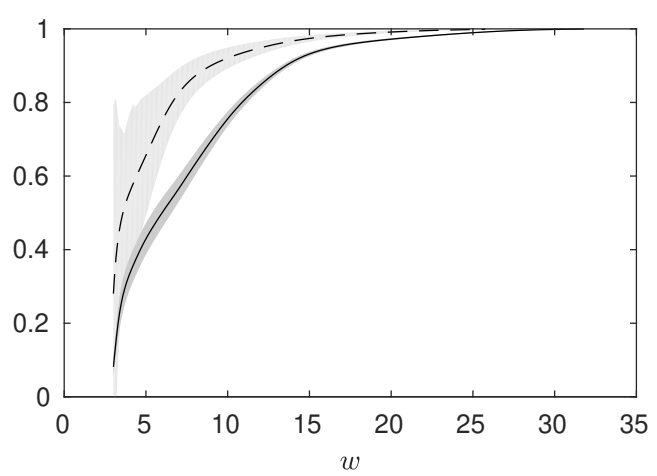

(b) Wage offer distribution $F(w)$

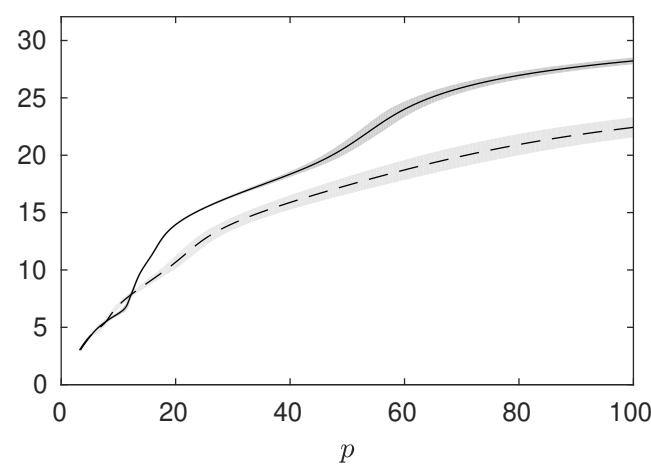

(d) Wage function $K(p)$

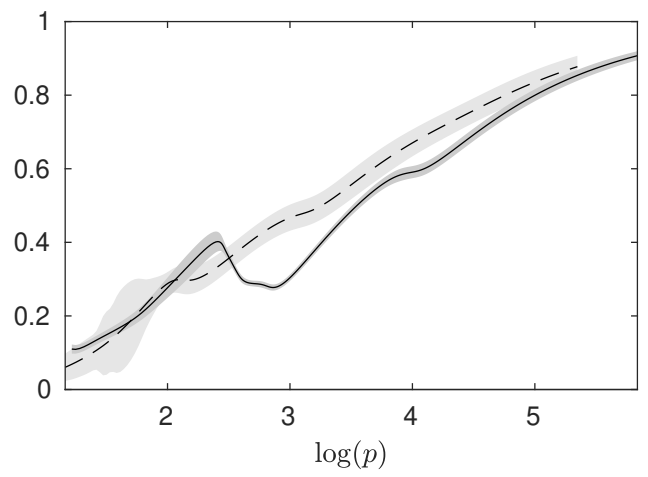

(f) Monopsony power $[p-K(p)] / p$

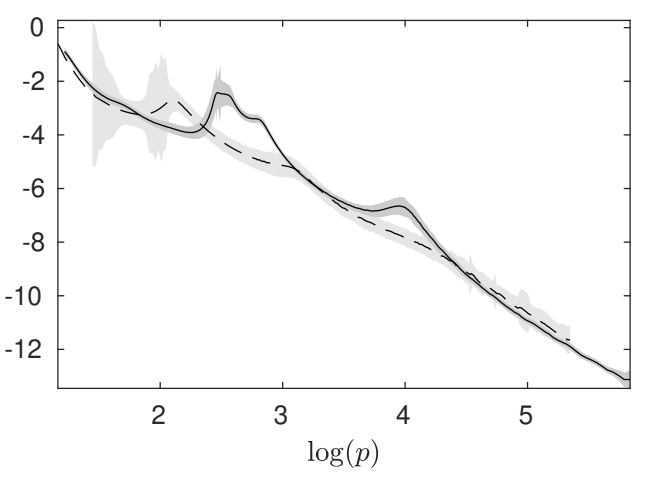

(h) Productivity log density $\log (\gamma(p))$

Key: West (-); East (----). Grey areas indicate $95 \%$ confidence bands.

Figure 22: Main Equilibrium Functions by Region - Sales 


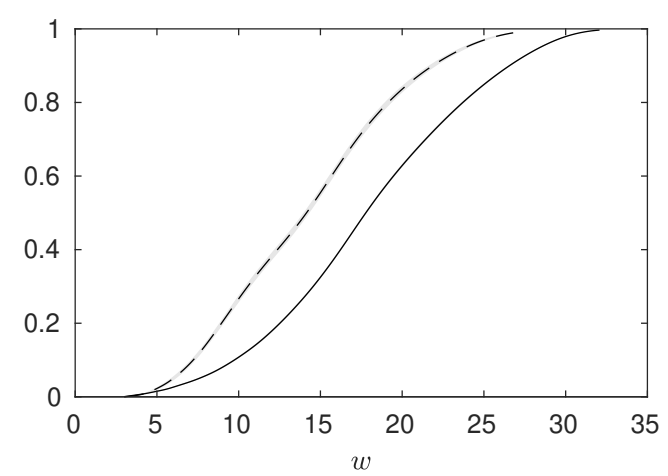

(a) Wage distribution $G(w)$

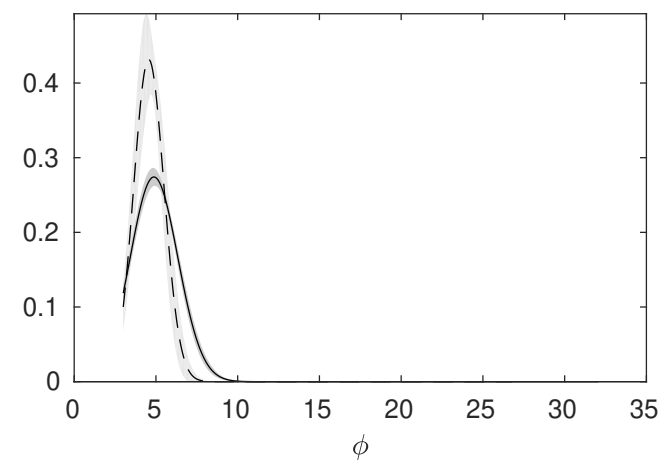

(c) Reservation wage density $A(w)$

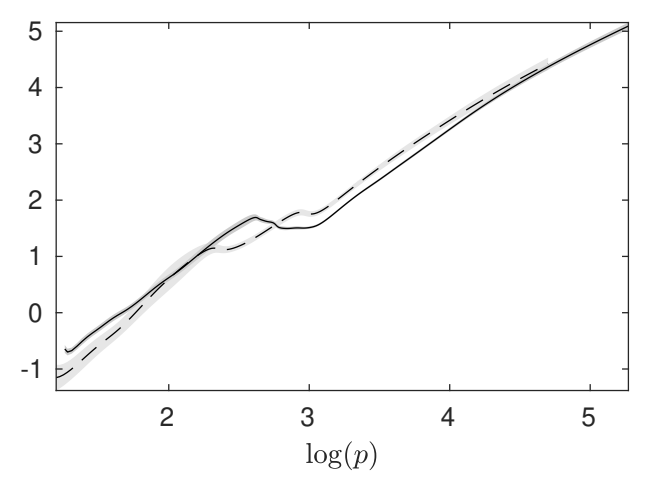

(e) Log absolute markup

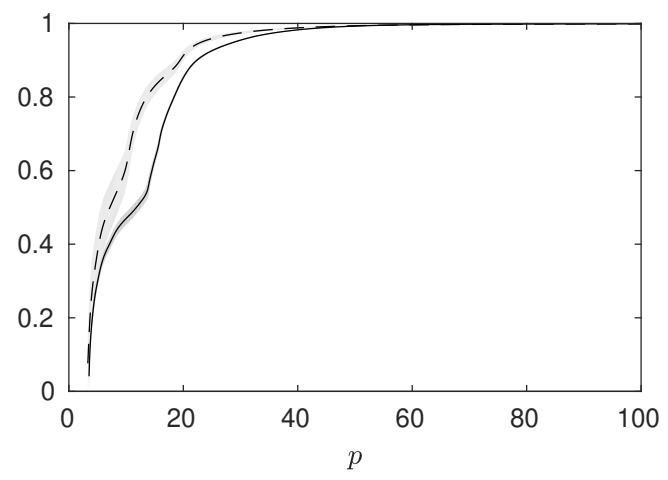

(g) Productivity distribution $\Gamma(p)$

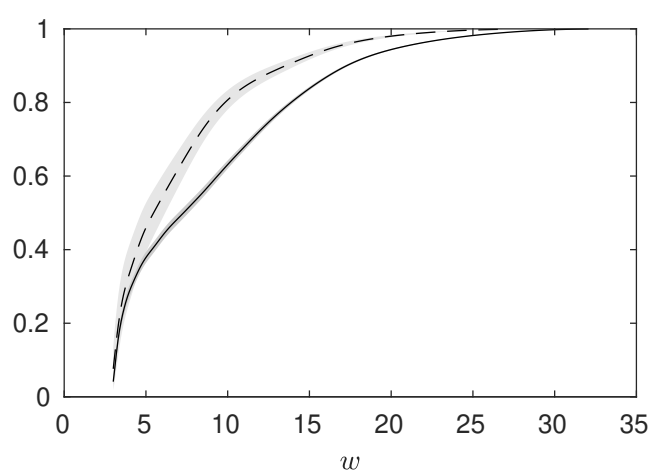

(b) Wage offer distribution $F(w)$

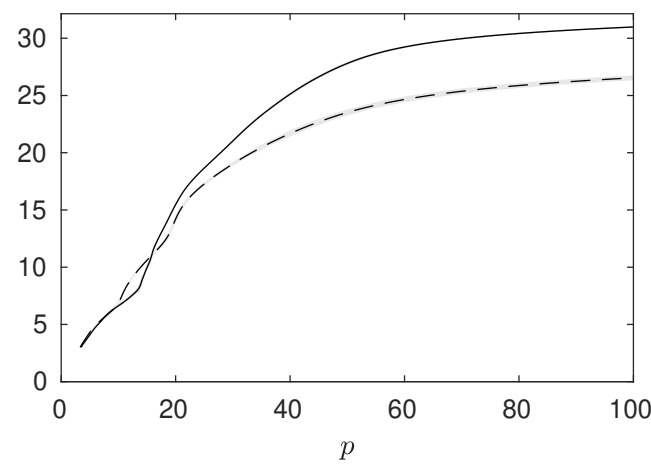

(d) Wage function $K(p)$

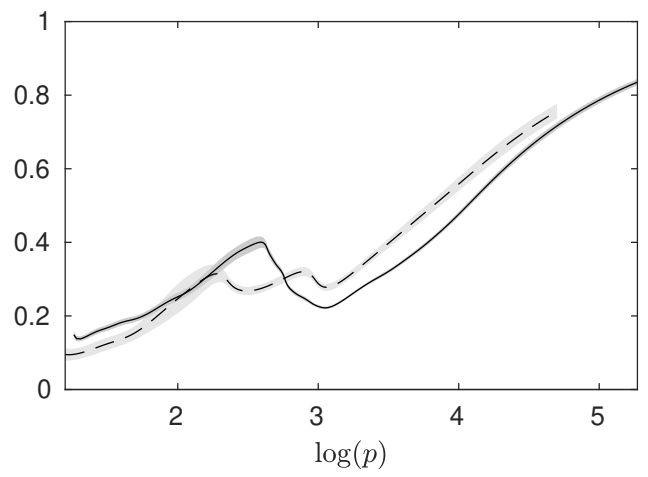

(f) Monopsony power $[p-K(p)] / p$

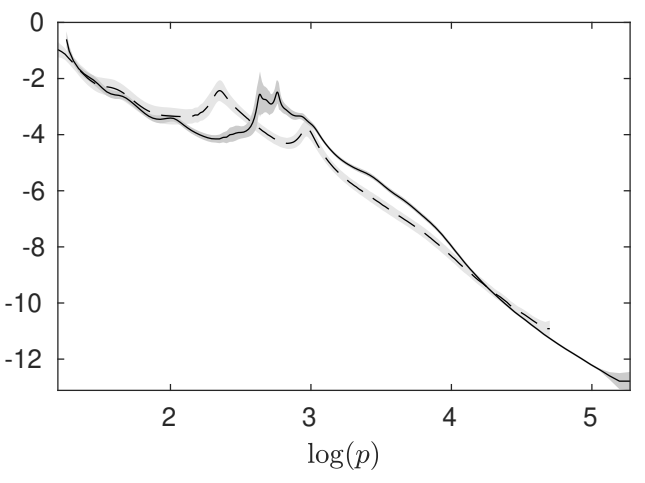

(h) Productivity log density $\log (\gamma(p))$

Key: West (-); East (----). Grey areas indicate 95\% confidence bands.

Figure 23: Main Equilibrium Functions by Region - Office 


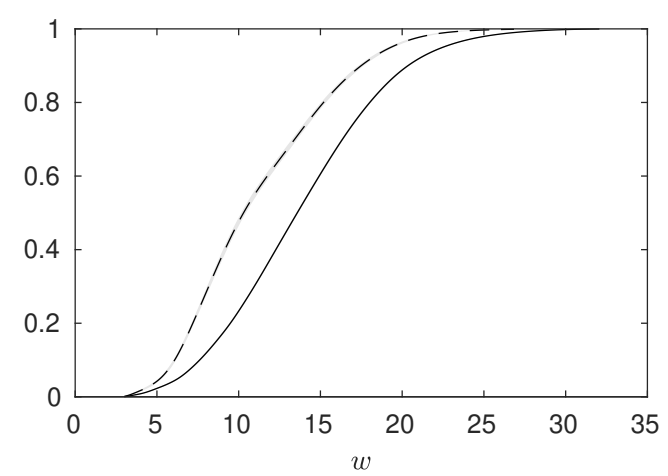

(a) Wage distribution $G(w)$

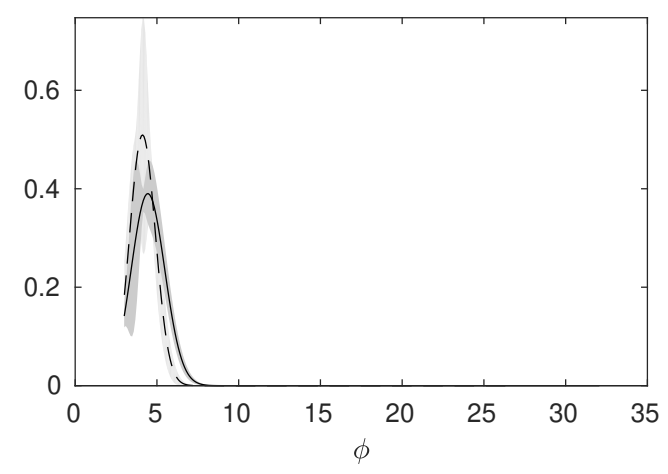

(c) Reservation wage density $A(w)$

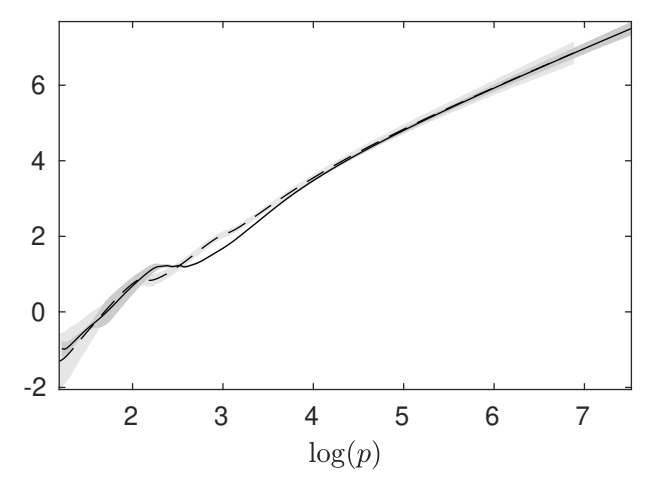

(e) Log absolute markup

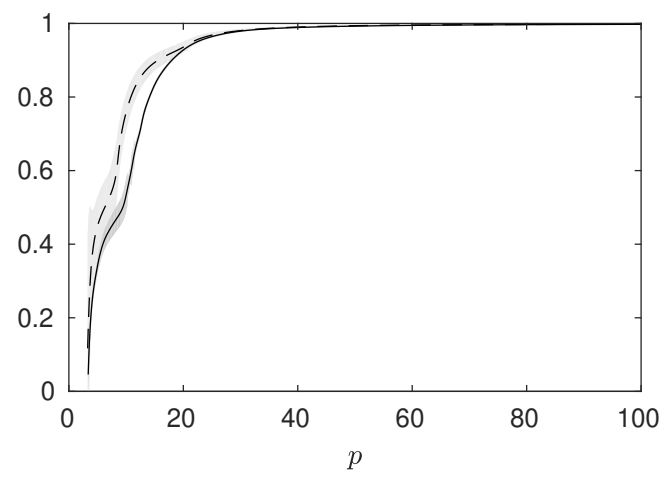

(g) Productivity distribution $\Gamma(p)$

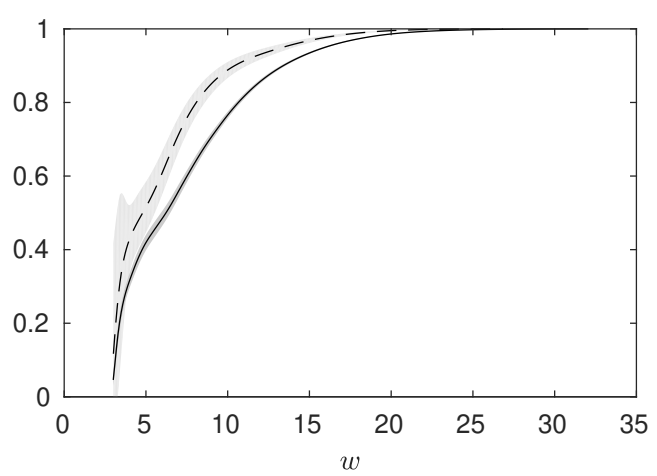

(b) Wage offer distribution $F(w)$

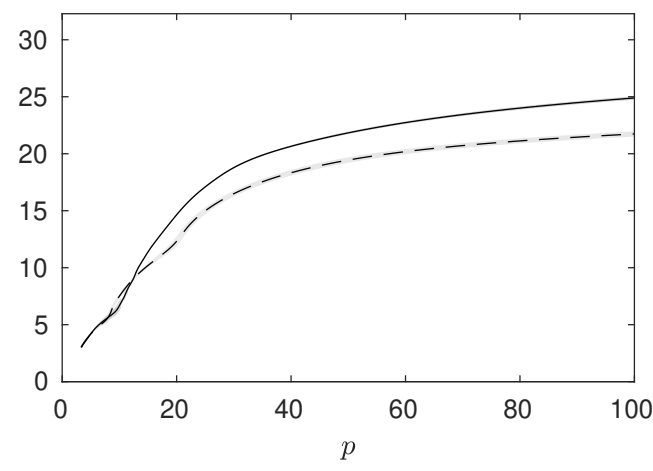

(d) Wage function $K(p)$

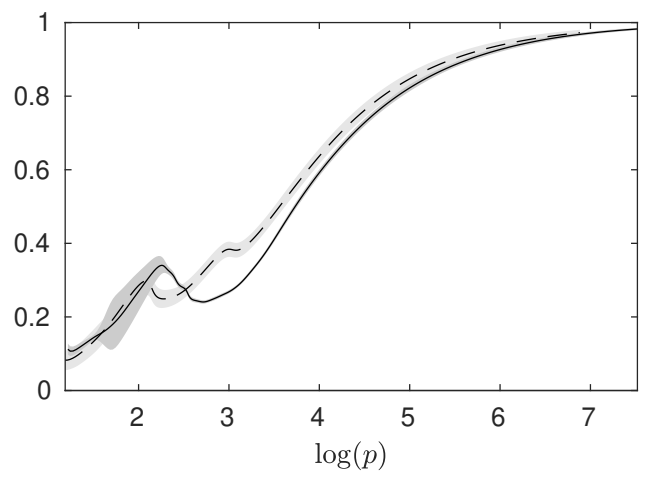

(f) Monopsony power $[p-K(p)] / p$

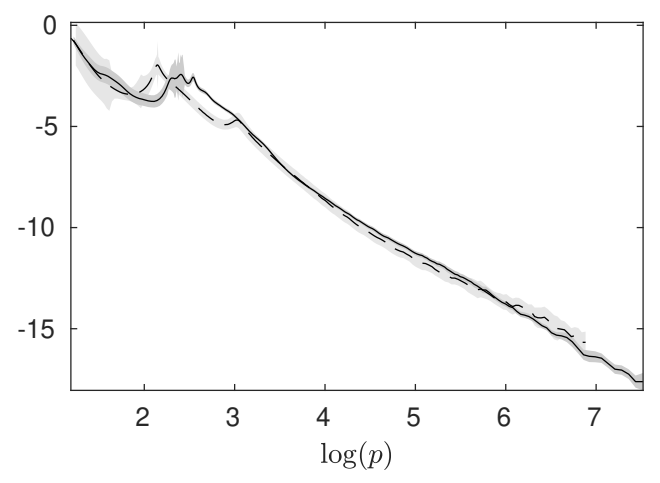

(h) Productivity log density $\log (\gamma(p))$

Key: West (-); East (----). Grey areas indicate $95 \%$ confidence bands.

Figure 24: Main Equilibrium Functions by Region - Service 


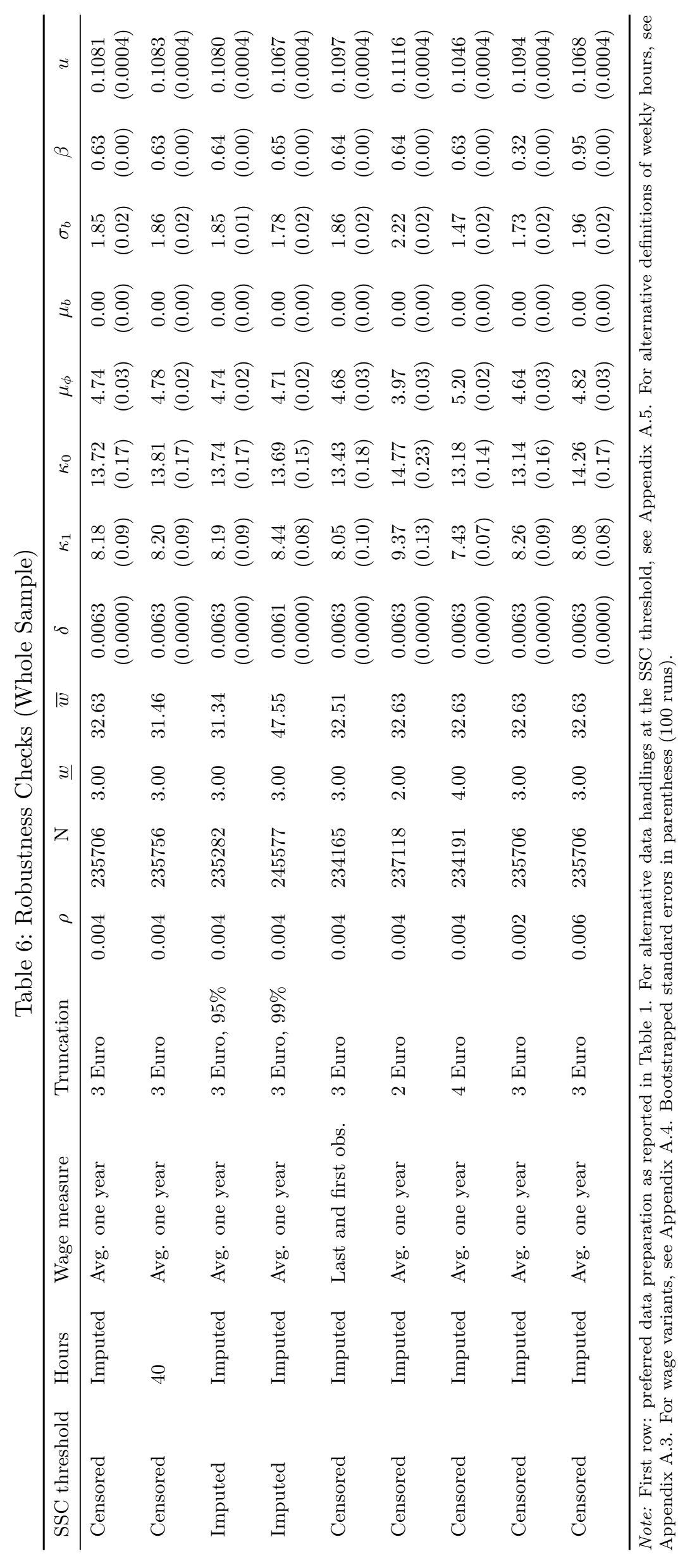




\section{A.9. Minimum Wage Simulations}

Table 7: Unemployment Rate $u$ by Region and Job Classification

\begin{tabular}{lccccc}
\hline & Level & & \multicolumn{3}{c}{ Change compared to no MW } \\
\cline { 2 - 2 } \cline { 5 - 6 } Minimum wage & No MW & & 7.00 euro & 8.00 euro & 9.00 euro \\
\hline Whole Sample & 0.108 & & 0.009 & 0.015 & 0.022 \\
\hline West Germany & & & & \\
Agriculture & 0.130 & & 0.019 & 0.026 & 0.035 \\
Production, Craft & 0.086 & & 0.002 & 0.005 & 0.013 \\
White-collar & 0.096 & & 0.004 & 0.006 & 0.009 \\
Sales & 0.156 & & 0.020 & 0.027 & 0.034 \\
Office & 0.110 & & 0.008 & 0.013 & 0.017 \\
Service & 0.110 & & 0.014 & 0.019 & 0.024 \\
East Germany & & & & \\
Agriculture & 0.189 & & 0.024 & 0.049 & 0.088 \\
Production, Craft & 0.126 & 0.007 & 0.020 & 0.037 \\
White-collar & 0.100 & & 0.006 & 0.014 & 0.026 \\
Sales & 0.170 & 0.048 & 0.078 & 0.127 \\
Office & 0.110 & 0.016 & 0.024 & 0.034 \\
Service & 0.126 & 0.023 & 0.036 & 0.082 \\
\hline Total & 0.106 & 0.009 & 0.014 & 0.023 \\
\hline
\end{tabular}

Note: The first row shows simulations based on the whole sample while the row Total aggregates the minimum wage effects by labour markets.

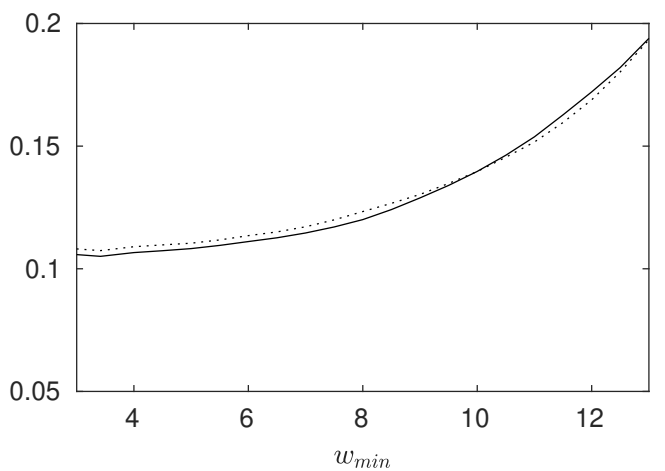

Key: Separate estimation for each labour market (- ${ }^{-}$); whole sample (..............).

Figure 25: Unemployment Rate $u$ for Different Minimum Wages 


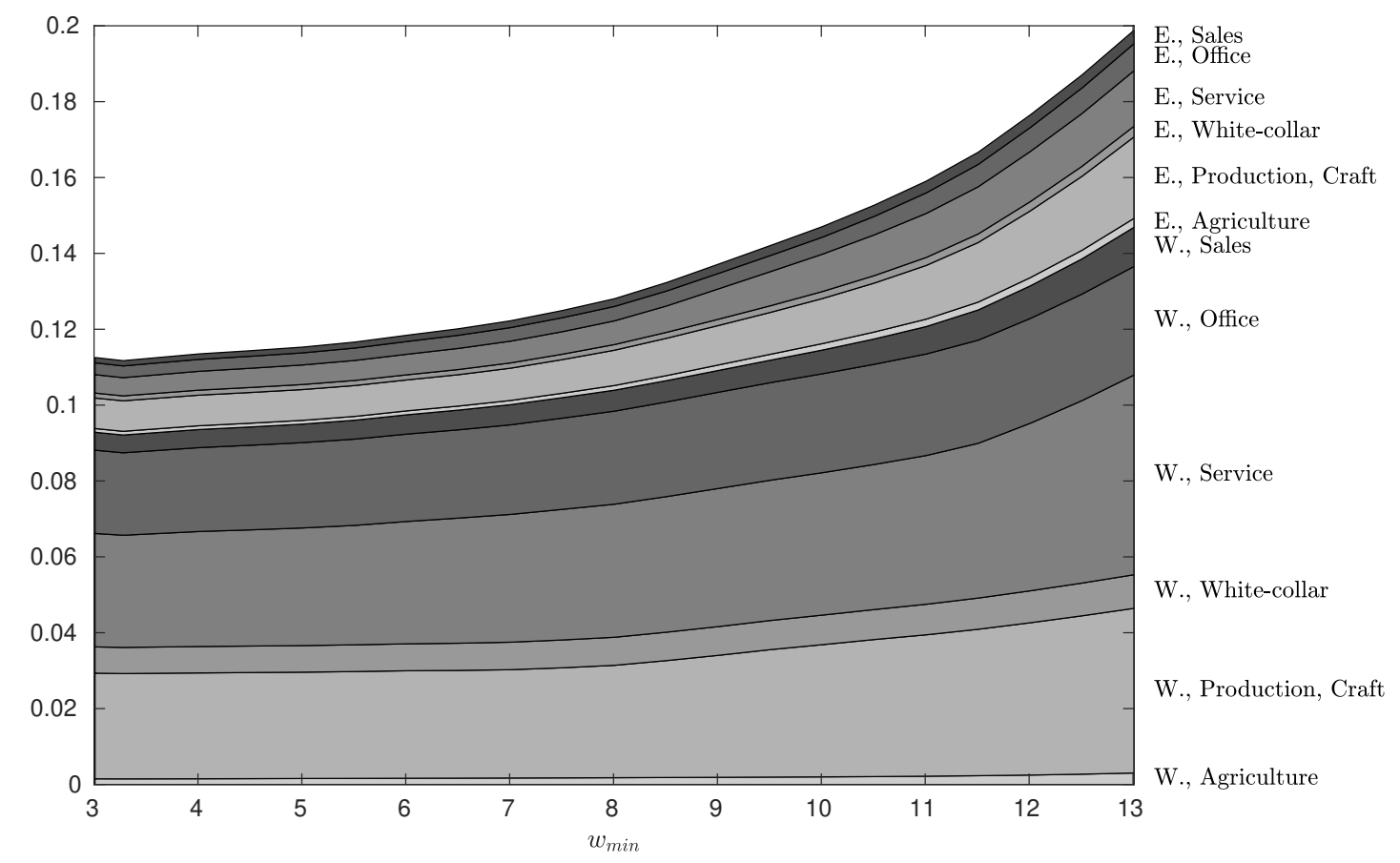

Figure 26: Composition of the Unemployment Rate $u$ for Different Minimum Wages 


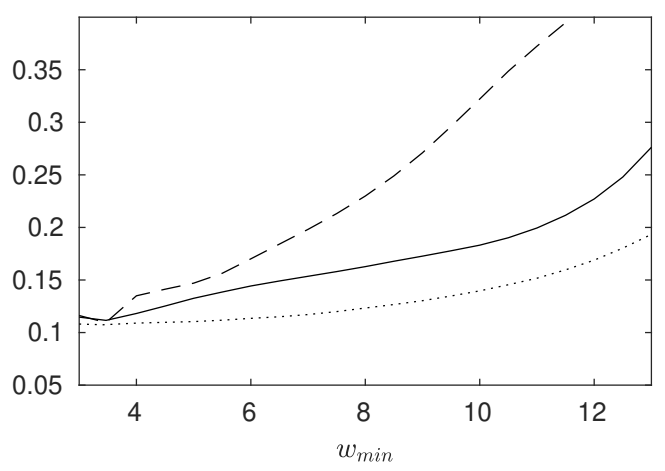

(a) Agriculture

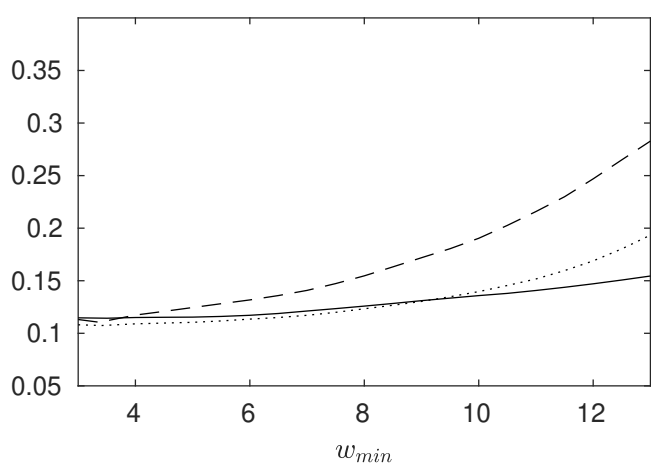

(c) White-collar

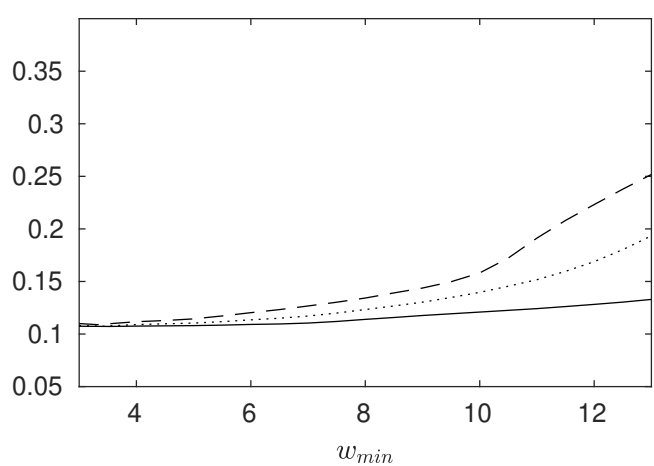

(e) Office

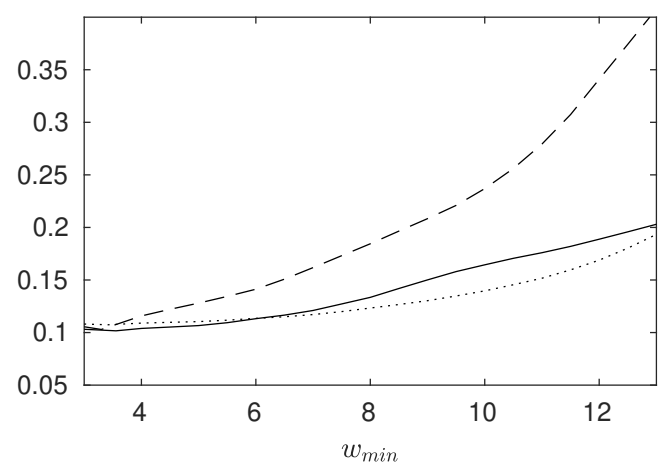

(b) Production, Craft

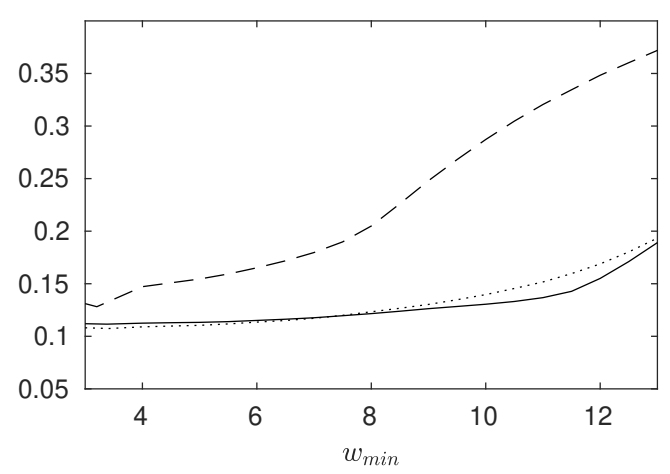

(d) Sales

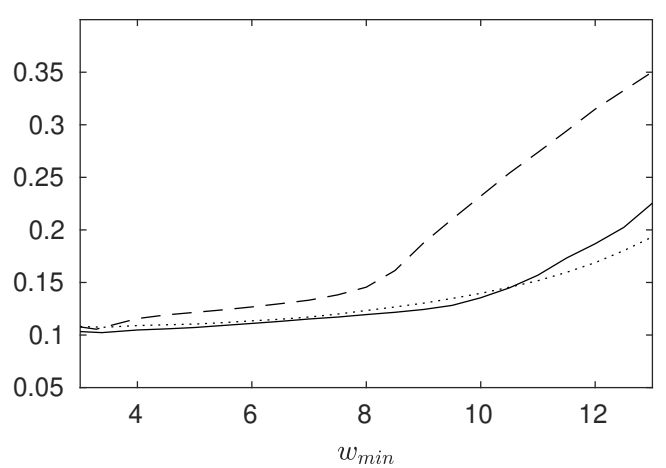

(f) Service

Key: West (labour markets and combined with estimated parameters for the whole sample.

Figure 27: Unemployment Rate $u$ for Different Productivity Distributions by Job Classification and Region. 


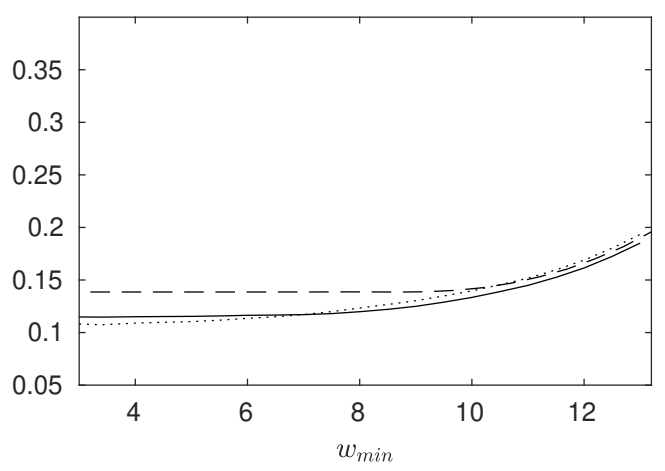

(a) Agriculture

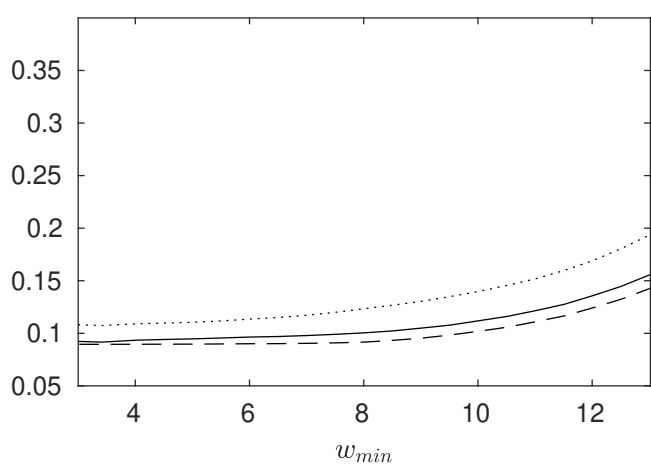

(c) White-collar

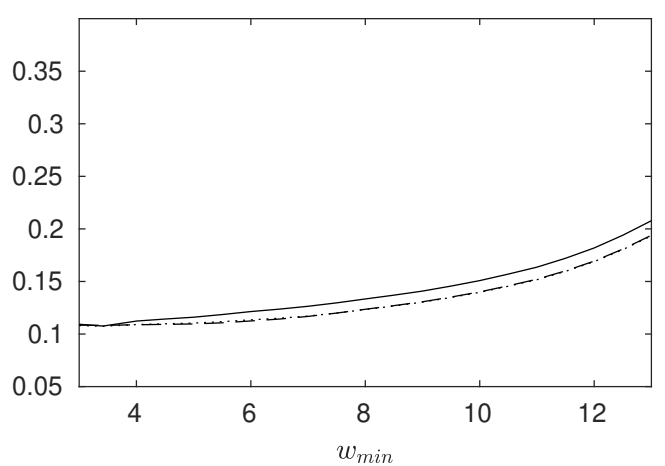

(e) Office

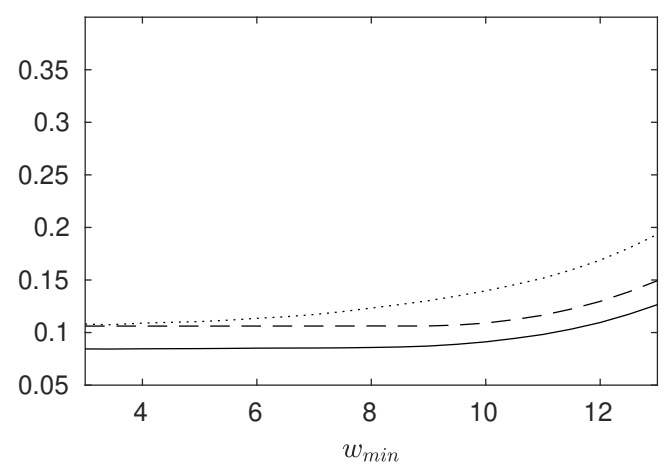

(b) Production, Craft

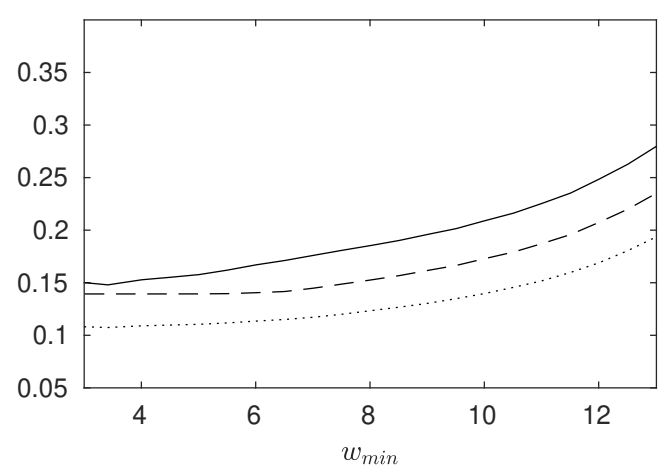

(d) Sales

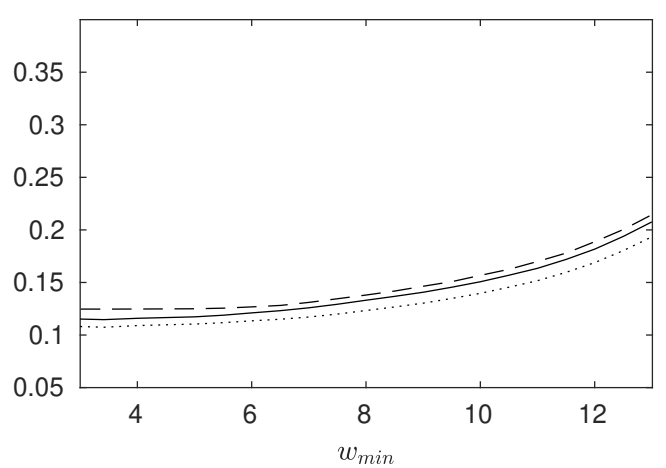

(f) Service

Key: West (-); East (----); whole sample (…….....). Note: Productivity distributions are taken from the whole sample and combined with estimated parameters for the different labour markets.

Figure 28: Unemployment Rate $u$ by Job Classification and Region given the Productivity Distribution of the Whole Sample. 